\title{
Synthesis, in vitro Cytotoxicity and Trypanocidal Evaluation of Novel 1,3,6-Substituted Non-fluoroquinolones
}

\author{
Richard M. Beteck ${ }^{\mathrm{a}, \star} \mathbb{D}^{\S}$, Michelle Isaacs ${ }^{\mathrm{c}}$, Heinrich C. Hoppe ${ }^{\mathrm{b}, \mathrm{c}}$ and Setshaba D. Khanye $\mathrm{e}^{\mathrm{a}, \mathrm{c}, \mathrm{d}, \star}(\mathbb{D})$ \\ ${ }^{a}$ Department of Chemistry, Rhodes University, Grahamstown, 6140, South Africa. \\ ${ }^{b}$ Department of Biochemistry and Microbiology, Rhodes University, Grahamstown, 6140, South Africa. \\ ${ }^{c}$ Centre for Chemico- and Biomedical Research, Rhodes University, Grahamstown, 6140, South Africa. \\ ${ }^{d}$ Faculty of Pharmacy, Rhodes University, Grahamstown, 6140, South Africa.
}

Received 7 March 2018, revised 13 November 2018, accepted 15 November 2018.

\begin{abstract}
Sleeping sickness (trypanosomiasis) is a neglected tropical disease that affects mostly the poorest communities in sub-Saharan Africa. Toxic side effects associated with the use of current anti-trypanosomal drugs, which in some cases kill faster than the disease itself, necessitate the search for new drugs with better safety margins. To this effect, a small library bearing different substituents at position $-1,-3$, and -6 of the quinolone nucleus were synthesized and evaluated in vitro against HeLa cell lines and Trypanosoma brucei brucei for cytotoxicity and trypanocidal potentials, respectively. While most of these compounds showed no cytotoxic effect, they exhibited moderate to weak anti-trypanosomal activities. The SAR studies of this series provide new information worth considering in future exploration of the quinolone scaffold in search of more potent and safe trypanocidal agents.
\end{abstract}

KEYWORDS

Sleeping sickness, trypanosomiasis, quinolones, non-fluoroquinolones.

\section{Introduction}

Human African trypanosomiasis (HAT), also referred to as sleeping sickness, ${ }^{1}$ is among the WHO's list of neglected tropical diseases (NTDs). ${ }^{2}$ It mostly affects people living in rural areas of sub-Saharan Africa, ${ }^{3}$ where medical facilities are scarce and drug purchasing power of inhabitants is very low. ${ }^{4}$ At least 2184 new cases of the disease were reported in 2016, ${ }^{5}$ and approximately 60 million people living in 36 different countries are presently at risk of contracting the disease. ${ }^{6}$

HAT takes two forms caused by two different subspecies of Trypanosoma brucei. ${ }^{7}$ T. $b$. gambiense is the pathogenic subspecies causing the form of HAT commonly found in central and western Africa, ${ }^{8,9}$ whereas T. $b$. rhodesiense is the subspecies responsible for the form of HAT prevalent in eastern and southern Africa. ${ }^{10}$ It has been noted that the two sub-pathogenic species coexist in Uganda. ${ }^{11}$ These pathogens are transmitted between humans following the bite of an infected tsetse fly. ${ }^{12}$ The disease exists in two stages: ${ }^{13,14}$ haemolymphatic stage - wherein the parasites are localized in blood and lymphatic systems, ${ }^{15}$ and an encephalitic stage - wherein the parasites have invaded the central nervous system. . $^{16,17}$

Current treatment options are limited to just four drugs..$^{18}$ In any case of HAT, the drug to be used is dictated by the form and stage of the disease. Pentamidine is the drug of choice for treating the haemolymphatic stage of HAT caused by T. b. gambiense, ${ }^{19}$ while a combination of nifurtimox and eflornithine is used to treat the encephalitic stage. ${ }^{20}$ In cases of T. $b$. rhodesiense, suramin is the recommended drug for treating the haemolymphatic stage ${ }^{21}$ while malarsoprol is used to treat the encephalitic stage. ${ }^{22}$ Besides limited treatment options, the foregoing drugs are far from ideal. They all have poor oral bioavailability (and hence are administered intravenously), and considerable toxic side

* To whom correspondence should be addressed. E-mail: r.beteck@ru.ac.za / s.khanye@ru.ac.za effects. ${ }^{23}$ For example, pentamidine causes hyper or hypoglycaemia and hypotension, ${ }^{24}$ suramin causes renal failure, eflornithine causes alopecia and seizures, ${ }^{25}$ while at least $5.9 \%$ of patients on malarsoprol die from its toxicity, ${ }^{26}$ creating a scenario wherein patients either die from an acute illness or die faster from a pill.

The overwhelming life-threatening side effects of existing drugs used to treat sleeping sickness create a dire need for new compounds with better drug properties such as high oral bioavailability, and a high safety margin. The therapeutic potentials of quinolones cannot be over emphasized. Compounds containing this scaffold are currently in use as drugs to treat bacterial and viral infections as well as other conditions such as cancers. ${ }^{27}$ Fluoroquinolones (Fig. 1a) in clinical use have been extensively screened against trypanosomes and their activity profiles established as moderate to poor. ${ }^{28,29,30}$ A hit optimization study by Hiltensperger and co-workers generated a potent library of fluoroquinolones characterized by benzylamides, (a)cyclic amines, and aliphatic chains at positions $-3,-7$, and -1 of the quinolone nucleus. However, the lead compound (Fig. 1b) in this series suffers from poor solubility, ${ }^{31}$ necessitating further work on this class of compounds. Unlike fluoroquinolones, the anti-trypanosomal potentials of non-fluorinated quinolones have not been extensively investigated, with just one study on non-fluorinated quinolones bearing substituents at position -1 and -2 , respectively, being reported ${ }^{32}$ (Fig. 1c). To further expand the SAR around the non-fluoquinolone scaffold, we conceptualized and synthesized a library of 18 non-fluorinated quinolones bearing unique concurrent substituents at position -1, -3, and -6. Target compounds were subjected to in vitro cytotoxicity and anti-trypanosomal evaluation. At $20 \mu \mathrm{M}$ concentration, most of the compounds exhibited less than $50 \%$ parasite viability while having little effect on the viability of HeLa cell lines (see Supplementary information). This suggests that the quinolone scaffold 
<smiles>O=C(O)c1cn(C2CC2)c2cc(N3CCNCC3)c(F)cc2c1=O</smiles><smiles>CCCn1cc(C(=O)NCc2ccccc2)c(=O)c2cc(F)c(N3CCOCC3)cc21</smiles><smiles>[R]c1cc(=O)c2ccccc2n1[R]</smiles>

Figure 1 Representative structures of fluoroquinolones (a and $\mathbf{b}$ ) and non-fluoroquinolones (c) investigated for anti-trypanosomal activities.

can be tailored via chemical synthesis to generate safe and potent drug substrates to treat trypanosomiasis.

\section{Results and Discussion}

We conceptualized and synthesized a set of 18 novel compounds that bear different substituents at positions $-1,-3$ and -6 of the quinolone scaffold. Conceptualized compounds were synthesized as depicted in Scheme 1. Briefly, $4^{\prime}$-nitroacetophenone was reduced to 4 '-aminoacetophenone using reduced iron powder and acetic acid. ${ }^{33} 4^{\prime}$-Aminoacetophenone and 4-chloroaniline were each treated with diethyl ethoxymethylenemalonate in refluxing acetonitrile to form condensed methylenemalonate esters, which underwent cyclization in boiling diphenylether at $245-250^{\circ} \mathrm{C}$ for $5 \mathrm{~min}$ to form compound 2. Deprotonation of 2 using $\mathrm{K}_{2} \mathrm{CO}_{3}$, followed by $\mathrm{N}$-alkylation with alkylhalides afforded target compounds $\mathbf{3} \mathbf{a}-\mathbf{h}$ in yields ranging between 40 and $70 \%$. Ester functionality in compounds $\mathbf{3 d}-\mathbf{h}$ underwent selective aminolysis in the presence of a ketone to afford target compounds $4 \mathbf{a}-\mathbf{j}$ in $30-50 \%$ yields. This transformation was realized using DBU as a base. All targeted compounds were characterized using proton and carbon NMR, HRMS and IR. The carbon NMR spectra of all compounds show a peak at $c .174 \mathrm{ppm}$, which is indicative of an oxo carbon within the quinolone nucleus (C-4) and the peak at c. $164 \mathrm{ppm}$ is assigned to ester or amide carbonyl carbon (C-3a). With the exception of compounds $3 \mathbf{a}-\mathbf{c}$, the proton NMR spectra of all compounds show a singlet signal at $\sim 2.3-2.6 \mathrm{ppm}$, which is assigned to a methyl attached to a carbonyl carbon $\left(\mathrm{CH}_{3} \mathrm{C}=\mathrm{O}\right)$. The carbonyl carbon is also evident in the respective carbon spectra at $\sim 197 \mathrm{ppm}$. The presence of a triplet peak $(J=5.9 \mathrm{~Hz})$ at c. 9.9 ppm in the proton NMR spectra of compounds $\mathbf{4 a}-\mathbf{j}$, which is absent in compounds $\mathbf{3} \mathbf{d}-\mathbf{h}$, suggests the successful conver-

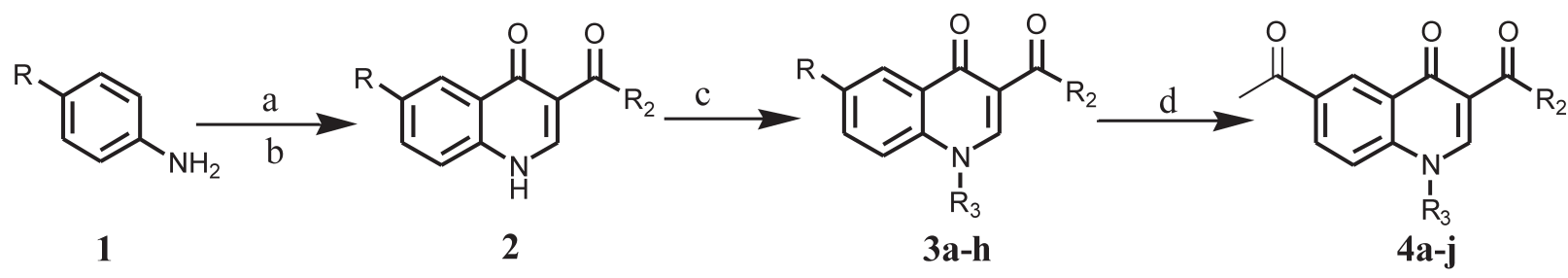

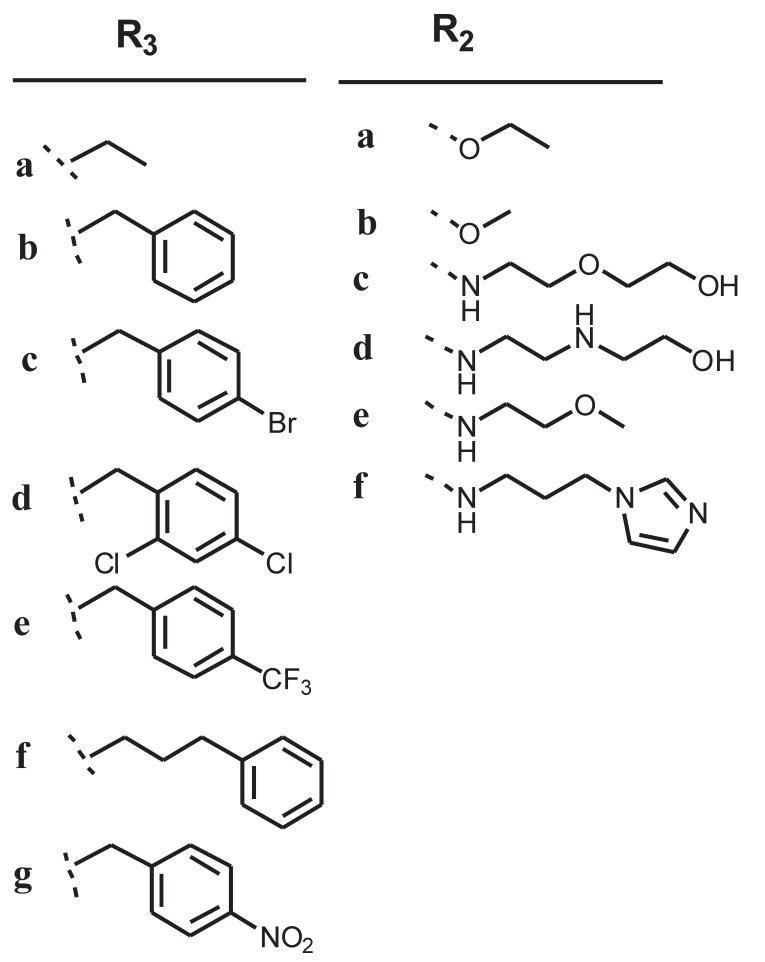

$$
\begin{aligned}
& \text { 3a } \mathrm{R}=\mathrm{Cl}, \mathrm{R}_{2}=\mathrm{a}, \mathrm{R}_{3}=\mathrm{g} \\
& \text { 3b } \mathrm{R}=\mathrm{Cl}, \mathrm{R}_{2}=\mathrm{a}, \mathrm{R}_{3}=\mathrm{c} \\
& \text { 3c } \mathrm{R}=\mathrm{Cl}, \mathrm{R}_{2}=\mathrm{a}, \mathrm{R}_{3}=\mathrm{e} \\
& \text { 3d } \mathrm{R}=\mathrm{COCH}_{3}, \mathrm{R}_{2}=\mathrm{a}, \mathrm{R}_{3}=\mathrm{a} \\
& \text { 3e } \mathrm{R}=\mathrm{COCH}_{3}, \mathrm{R}_{2}=\mathrm{a}, \mathrm{R}_{3}=\mathrm{e} \\
& \text { 3f } \mathrm{R}=\mathrm{COCH}_{3}, \mathrm{R}_{2}=\mathrm{b}, \mathrm{R}_{3}=\mathrm{b} \\
& \text { 4a } \mathrm{R}_{2}=\mathrm{e}, \mathrm{R}_{3}=\mathrm{a} \\
& \text { 3g R }=\mathrm{COCH}_{3}, \mathrm{R}_{2}=\mathrm{b}, \mathrm{R}_{3}=\mathrm{c} \\
& 4 \mathrm{~g} \mathrm{R}_{2}=\mathrm{c}, \mathrm{R}_{3}=\mathrm{c} \\
& \text { 3h R }=\mathrm{COCH}_{3}, \mathrm{R}_{2}=\mathrm{b}, \mathrm{R}_{3}=\mathrm{d} \\
& \text { 4h } \mathrm{R}_{2}=\mathrm{d}, \mathrm{R}_{3}=\mathrm{b} \\
& \text { 4i } R_{2}=e, R_{3}=d \\
& 4 j \quad R_{2}=d, R_{3}=e
\end{aligned}
$$


sion of ester to amide. It is also worth noting that the acquisition of NMR spectroscopic data was at times hindered by compounds crystallizing out of the solutions. This sometimes necessitated the use of hot solvents to encourage compounds to remain in solution long enough to obtain $1 \mathrm{H}$ and $13 \mathrm{C} \mathrm{NMR}$ spectroscopic data (see Supplementary information). The absorption band at $1654 / \mathrm{cm}$ on the IR spectrum further confirms the presence of amide.

This focused library was screened in vitro against human cervix adenocarcinoma (HeLa) cell lines to investigate potential cytotoxicity effects. The compounds were incubated at $20 \mu \mathrm{M}$ in 96-well plates containing HeLa cells for $48 \mathrm{~h}$. The numbers of cells surviving upon drug exposure were determined using resazurin reduction to resorufin by live cells and reading resorufin fluorescence in a multiwell plate reader. Compounds were tested in duplicate, and a standard deviation (S.D.) calculated. Results are expressed as \% viability based on fluorescence readings in treated wells versus untreated control wells. Emetine (which induces cell apoptosis) was used as positive control. With the exception of compound $\mathbf{4 f}$ ( $\%$ viability, $-19 \%)$, and $4 \mathbf{j}(\%$ viability, $-13 \%)$, which strongly inhibited HeLa cell lines, the rest of the series had little to no effect on HeLa cell viability. This observation suggests that this series with necessary optimization could serve as templates for the development of non-toxic anti-trypanosomal agents.

The compounds were further evaluated in vitro for antitrypanosomal activities by screening against the 427 strain of $T . b$. brucei. Compounds were added to in vitro cultures of T. $b$. brucei in 96-well plates at a $20 \mu \mathrm{M}$ concentration. After an incubation period of $48 \mathrm{~h}$, the numbers of parasites surviving drug exposure were determined by adding resazurin. As in HeLa cells, resazurin is reduced to resorufin by living parasites. Resorufin is a fluorophore $\left(\operatorname{Exc}_{560} / \mathrm{Em}_{590}\right)$ and can thus be quantified in a multiwell fluorescence plate reader. Compounds were tested in duplicate wells, and a standard deviation (S.D.) calculated. Results are expressed as \% viability - the resorufin fluorescence in compound-treated wells relative to untreated controls. Pentamidine (an existing drug for treatment of trypanosomiasis) was used as a positive control. At $20 \mu \mathrm{M}$ concentration, 11 compounds inhibited parasite growth below $50 \%$ (Table 1); however, only compounds inhibiting parasite viability below $25 \%$ with little or no effect on HeLa cell line were considered for
$\mathrm{IC}_{50}$ determination. The IC50 values for the selected compounds are summarized in Fig. 2.

Structure-activity relationship analysis across this series suggests that modifications at position $-1,-3$, and -6 of the quinolone scaffold influence anti-trypanosomal activities. For example, comparing the activity profiles of compounds $3 \mathbf{b}$ ( $\mathrm{IC}_{50}$ $19 \mu \mathrm{M})$ and $3 \mathrm{~g}\left(\mathrm{IC}_{50}, 24 \mu \mathrm{M}\right)$, all having the same substituents at position -1 and -3 and differing in substitution pattern only at position -6 suggests that a chloride substituent at this position leads to increase anti-trypanosomal activity than a ketone. Also, comparing compounds $3 \mathbf{d}\left(\mathrm{IC}_{50}, 32 \mu \mathrm{M}\right)$ bearing an alkyl chain at position -1 and $3 \mathrm{~g}\left(\mathrm{IC}_{50}, 24 \mu \mathrm{M}\right)$ bearing a substituted-benzyl moiety at position -1 , indicates that the presence of a substi-

Table 1 In vitro cytotoxicities and anti-trypanosomal activities of target compounds expressed as percentage viabilities.

\begin{tabular}{|c|c|c|}
\hline \multirow[t]{2}{*}{ Comp. } & \multicolumn{2}{|c|}{$\%$ Viability \pm S.D. } \\
\hline & T. b. brucei & HeLa cells \\
\hline $3 a$ & $21.2 \pm 4.0$ & $97.6 \pm 5.6$ \\
\hline $3 b$ & $4.0 \pm 0.7$ & $100.2 \pm 6.2$ \\
\hline $3 c$ & $97.3 \pm 3.3$ & $102.7 \pm 7.6$ \\
\hline $3 d$ & $21.0 \pm 3.7$ & $77.0 \pm 0.7$ \\
\hline $3 e$ & $43.8 \pm 3.2$ & $96.7 \pm 3.7$ \\
\hline $3 f$ & $87.3 \pm 7.0$ & $107.2 \pm 1.6$ \\
\hline $3 g$ & $5.5 \pm 5.2$ & $103.6 \pm 3.7$ \\
\hline $3 \mathrm{~h}$ & $42.3 \pm 8.4$ & $108.6 \pm 5.3$ \\
\hline $4 a$ & $95.4 \pm 10$ & $92.6 \pm 3.6$ \\
\hline $4 b$ & $4.8 \pm 0.1$ & $86.1 \pm 2.4$ \\
\hline $4 c$ & $105.8 \pm 1.6$ & $110.7 \pm 6.7$ \\
\hline $4 d$ & $31.2 \pm 12.2$ & $88.9 \pm 5.8$ \\
\hline $4 e$ & $100.0 \pm 2.7$ & $102.6 \pm 5.7$ \\
\hline $4 \mathrm{f}$ & $-1.3 \pm 0.3$ & $-19.2 \pm 0.04$ \\
\hline $4 \mathrm{~g}$ & $24.7 \pm 7.6$ & $102.1 \pm 5.8$ \\
\hline $4 i$ & $64.5 \pm 7.8$ & $91.0 \pm 4.9$ \\
\hline $4 j$ & $50.3 \pm 4.4$ & $-14.0 \pm 0.6$ \\
\hline $\begin{array}{l}\mathbf{P E}^{\mathrm{a}} \\
\text { EMT }^{\mathrm{b}}\end{array}$ & $\begin{array}{c}0.0 \\
\text { N.D }\end{array}$ & $\begin{array}{c}\text { N.D } \\
0.0\end{array}$ \\
\hline
\end{tabular}

${ }^{\mathrm{a}} \mathrm{PE}=$ pentamidine, ${ }^{\mathrm{b}} \mathrm{EMT}=$ ematine,${ }^{\mathrm{c}} \mathrm{N} \cdot \mathrm{D}=$ not determined.

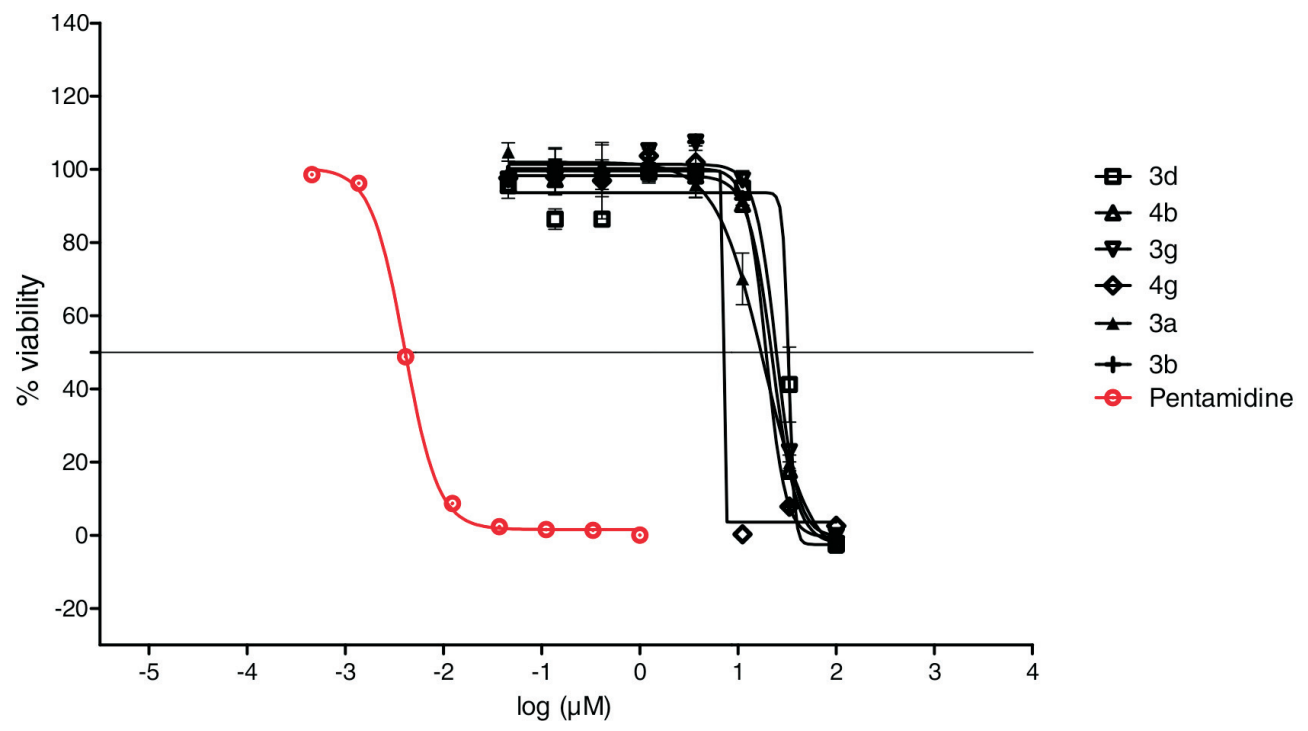

\begin{tabular}{|c|c|}
\hline Compound & $\mathrm{IC}_{50}(\mu \mathrm{M})$ \\
\hline $3 \mathrm{a}$ & 18.4 \\
\hline $3 \mathrm{~b}$ & 19.4 \\
\hline $3 \mathrm{~d}$ & 32.9 \\
\hline $3 \mathrm{~g}$ & 24.6 \\
\hline $4 \mathrm{~b}$ & 22.4 \\
\hline $4 \mathrm{~g}$ & 7.14 \\
\hline $\mathrm{PE}^{*}$ & 0.0062 \\
\hline
\end{tabular}

Figure 2 Plot of percentage viability against $\log$ concentration for compound $3 \mathbf{a}, 3 \mathbf{b}, 3 \mathbf{d}, \mathbf{3 g}, \mathbf{4 b}$ and $4 \mathrm{~g}$ as well as the standard (PE $=$ pentamidine) and their corresponding $\mathrm{IC}_{50}$ values. 
tuted-benzyl moiety at position -1 seems to promote antitrypanosomal activities over alkyl chains. We also observed that the substituent on the benzyl moiety at position -1 also influences anti-trypanosomal activities. This is evident when comparing the effects of compounds $3 \mathbf{a}, 3 \mathbf{b}$ and $3 \mathbf{c}$ on parasite viability at a concentration of $20 \mu \mathrm{M}$. Compounds $\mathbf{3 a}$ and $\mathbf{3 b}$ bearing $-\mathrm{NO}_{2}$, and $-\mathrm{Br}$, respectively, exhibited more than $75 \%$ parasite growth inhibition, while compound $3 \mathrm{c}$ having $-\mathrm{CF}_{3}$ substituent exhibited less than $5 \%$ parasite growth inhibition. These results suggest that electron-withdrawing units promote activity while electron-donating unit leads to poor activity. The substitution pattern at position -3 also seems to greatly influence activity. Comparing the activity of compounds $3 \mathrm{~g}\left(\mathrm{IC}_{50}, 24 \mu \mathrm{M}\right)$ and $4 \mathrm{~g}\left(\mathrm{IC}_{50}, 7 \mu \mathrm{M}\right)$, both of which differ only in the substituent at position -3 , suggests that an amide moiety at position -3 seems to enhance activity over ethyl ester.

\section{Conclusion}

We have synthesized a series of novel quinolones with varied substituents at position $-1,-3$ and -6 of the quinolone scaffold. While most compounds in this series showed no promising cytotoxicity potentials, compounds $4 \mathrm{~g}$ emerged as potent anti-trypanosomal hit with $\mathrm{IC}_{50}$ value of $7 \mu \mathrm{M}$. Although this series exhibited moderate to weak activities profiles, the comprehensive structure-activity relationship analyses of this series will undoubtedly serve as a resource for further optimization of the quinolone scaffold in search of new and potent anti-trypanosomal agents.

\section{Experimental}

\subsection{General Method}

All the chemicals and solvents used were purchased from various chemical suppliers and were used without further purification. Melting points were determined using a Reichert hot stage microscope and are uncorrected. The progress of the reactions was monitored by thin layer chromatography (TLC) using Merck F254 silica gel plates supported on aluminium. The crude products were purified by a silica gel column chromatography using Merck Kieselgel 60 A: 70-230 (0.068-0.2 mm) silica gel mesh. ${ }^{1} \mathrm{H}$ and ${ }^{13} \mathrm{C}$ NMR spectra were recorded on Bruker Biospin $300 \mathrm{MHz}$, or $400 \mathrm{MHz}$ spectrometers, and the chemical shifts are given in $\delta$ values referenced to solvents and are reported in parts per million (ppm). The high-resolution mass spectrometric data of final compounds was recorded on a Waters Synapt G2 quadrupole time-of-flight (QTOF) mass spectrometer operated with an electrospray ionization probe in the positive mode (University of Stellenbosch). The instrument was operated with an electrospray ionization probe in the positive mode. The starting quinolones 2 were synthesized from the synthetically accessible compounds $\mathbf{1}$ as previously described in literature..$^{34}$

\subsection{Synthesis of Compounds}

4.2.1. General Method for the Preparation of N-alkylated Compounds 3a-h

A mixture of 2 (3.86 mmol, $1 \mathrm{~g}$, 1 eq), $\mathrm{K}_{2} \mathrm{CO}_{3}(5.0 \mathrm{mmol}, 0.53 \mathrm{~g})$, alkyl halide (5 eq.) in acetone $(50 \mathrm{~mL})$ was refluxed for $15 \mathrm{~h}$. Upon reaction completion as indicated by TLC, the mixture was filtered, and the filtrate evaporated to dryness to obtain a crude $\mathrm{N}$-alkylated product which was purified through silica gel column chromatography using $\mathrm{CH}_{2} \mathrm{Cl}_{2} / \mathrm{MeOH}$ (10:1) as the mobile phase. Compounds $\mathbf{3 a}-\mathbf{h}$ were obtained in $40-70 \%$ yield following this procedure.
Methyl 6-chloro-1-(4-nitrobenzyl)-4-oxo-1,4-dihydroquinoline-3carboxylate, 3a<smiles>COC(=O)c1cn(Cc2ccc([N+](=O)[O-])cc2)c2ccc(Cl)cc2c1=O</smiles>

Brown powder, $0.515 \mathrm{~g}(48 \%), R_{f}=0.81(\mathrm{DCM} / \mathrm{MeOH} 10: 1)$ m.p. $153-155^{\circ} \mathrm{C} ;{ }^{1} \mathrm{H}$ NMR (300 MHz, DMSO) $\delta 9.00$ (s, 1H, H-2), $8.16(\mathrm{~d}, J=2.5 \mathrm{~Hz}, 1 \mathrm{H}, \mathrm{H}-5), 7.89-7.57$ (m, 3H, H-1c, H-8), 7.48 -7.05 (m, 3H, H-7, H-1d), 5.82 (s, 2H, H-1a), 4.24 (s, 3H, H-3c). ${ }^{13} \mathrm{C}$ NMR (75 MHz, DMSO) $\delta 172.2$ (C-4), 164.1 (C-3a), 151.3 (C-2), 141.1 (C-3), 138.2 (C-6), 133.2 (C-1d), 131.3 (C-1c), 130.5 (C-5), 130.1 (C-7), 127.6 (C-1b), 126.3 (C-4a), 125.9 (C-8), 120.7 (C-8a), 110.9 (C-1e), 57.3 (C-3c), 55.7 (C-1a). IR (neat, $\mathrm{cm}^{-1}$ ): 3093, 2972, 2931, 1702, 1686; ESI-HRMS $\mathrm{m} / \mathrm{z}[\mathrm{M}+\mathrm{H}]^{+}$calcd for $\mathrm{C}_{18} \mathrm{H}_{14} \mathrm{ClN}_{2} \mathrm{O}_{5}$ 373.0586, found 373.0594 .

Ethyl 1-(4-bromobenzyl)-6-chloro-4-oxo-1,4-dihydroquinoline-3carboxylate, $\mathbf{3 b}$<smiles>CCOC(=O)c1cn(Cc2ccc(Br)cc2)c2ccc(Cl)cc2c1=O</smiles>

White powder, $0.015 \mathrm{~g}(46 \%), R_{f}=0.8$ (DCM/MeOH 10:1), m.p. 196-198 ${ }^{\circ} \mathrm{C}$; ${ }^{1} \mathrm{H}$ NMR (400 MHz, DMSO) $\delta 8.94$ (s, 1H, H-2), 8.16 $(\mathrm{d}, J=2.5 \mathrm{~Hz}, 1 \mathrm{H}, \mathrm{H}-5), 7.81-7.48(\mathrm{~m}, 4 \mathrm{H}, \mathrm{H}-7, \mathrm{H}-8, \mathrm{H}-1 \mathrm{c}), 7.21$ (d, $J=8.4 \mathrm{~Hz}, 2 \mathrm{H}, \mathrm{H}-1 \mathrm{~d}), 5.68$ (s, 2H, H-1a), 4.25 (q, J = 7.1 Hz, 2H, $\mathrm{H}-3 \mathrm{c}), 1.30$ (t, $J=7.1 \mathrm{~Hz}, 3 \mathrm{H}, \mathrm{H}-3 \mathrm{~d}) .{ }^{13} \mathrm{C}$ NMR (101 MHz, DMSO) d 172.0 (C-4), 165.0 (C-3a), 151.0 (C-2), 138.5 (C-3), 135.5 (C-6), 132.9 (C-5), 132.2 (C-1d), 130.6 (C-1b), 129.9 (C-1c), 128.9 (C-4a), 125.9 (C-7), 121.8 (C-1e), 120.6 (C-8), 111.1 (C-8a), 60.3 (C-3c), 55.6 (C-1a), 14.2 (C-3d). IR (neat, $\mathrm{cm}^{-1}$ ): 3096, 2978, 2941, 1702, 1680. ESI-HRMS $m / z[\mathrm{M}+\mathrm{H}]^{+}$calcd for $\mathrm{C}_{19} \mathrm{H}_{16} \mathrm{BrClNO}_{3} 419.997$, found 419.9998.

Ethyl 6-chloro-4-oxo-1-(4-(trifluoromethyl)benzyl)-1,4-dihydroquinoline-3-carboxylate, 3c<smiles>CCOC(=O)c1cn(Cc2ccc(C(F)(F)F)cc2)c2ccc(Cl)cc2c1=O</smiles>

Brown powder, $0.5 \mathrm{~g}(70 \%), R_{f}=0.81$ (DCM/MeOH 10:1), m.p. 203-205 ${ }^{\circ} \mathrm{C}$; ${ }^{1} \mathrm{H}$ NMR (400 MHz, Pyridine) $\delta 9.19$ (s, 1H, H-2), 7.65 $(\mathrm{d}, J=8.4 \mathrm{~Hz}, 2 \mathrm{H}, \mathrm{H}-\mathrm{cc}), 7.56-7.49$ (m, 3H, H-5, H-7, H-8), 7.43 (d, $J=8.4 \mathrm{~Hz}, 2 \mathrm{H}, \mathrm{H}-1 \mathrm{~d}), 5.00$ (s, 2H, H-1a), 4.36 (q, J = 6.9 Hz, 2H, $\mathrm{H}-3 \mathrm{c}), 1.23(\mathrm{t}, J=6.9 \mathrm{~Hz}, 3 \mathrm{H}, \mathrm{H}-3 \mathrm{~d}) .{ }^{13} \mathrm{C}$ NMR (101 MHz, Pyridine) $\delta 173.0$ (C-4), 164.7 (C-3a), 150.64 (C-2), 140.6 (C-3), 140.2 (C-1b), 137.9 (C-6), 135.5 (C-1d), 132.9 (C-1c), 130.9 (C-5), 130.2 (C-7), 127.2 (C-1e), 126.4 (C-4a), 125.9 (C-8), 120.7 (C-8a), 119.5 (C-1f), 112.2 (C-1f), 60.3 (C-3c), 56.0 (C-1a), 14.2 (C-3d). IR (neat, $\mathrm{cm}^{-1}$ ): 3003, 2962, 2921, 1705, 1684, ESI-HRMS $\mathrm{m} / z[\mathrm{M}+\mathrm{H}]^{+}$calcd for $\mathrm{C}_{20} \mathrm{H}_{16} \mathrm{ClF}_{3} \mathrm{NO}_{3} 410.0765$, found 410.0766 . 
Ethyl 6-acetyl-1-ethyl-4-oxo-1,4-dihydroquinoline-3-carboxylate, 3d<smiles>CCOC(=O)c1cn(CC)c2ccc(C(C)=O)cc2c1=O</smiles>

Red powder, $0.65 \mathrm{~g}(70 \%), R_{f}=0.71$ (DCM/MeOH 10:1); m.p $143-147^{\circ} \mathrm{C} ;{ }^{1} \mathrm{H} N M R\left(300 \mathrm{MHz}, \mathrm{CDCl}_{3}\right) \delta 8.97(\mathrm{~s}, 1 \mathrm{H}, \mathrm{H}-2), 8.44(\mathrm{~d}$, $J=2.1 \mathrm{~Hz}, 1 \mathrm{H}, \mathrm{H}-5), 8.22(\mathrm{dd}, J=8.9,2.1 \mathrm{~Hz}, 1 \mathrm{H}, \mathrm{H}-7), 7.46(\mathrm{~d}, J=$ $9.0 \mathrm{~Hz}, 1 \mathrm{H}, \mathrm{H}-8), 4.39-4.31$ (m, 2H, H-1a), 4.23 (q, J = 7.2 Hz, $2 \mathrm{H}$, H-3c), 2.63 (s, 3H, H-6b), 1.50 (t, $J=7.3 \mathrm{~Hz}, 3 \mathrm{H}, \mathrm{H}-3 \mathrm{~d}), 1.37-1.20$ (m, 3H, H-1b). ${ }^{13} \mathrm{C}$ NMR (75 MHz, $\left.\mathrm{CDCl}_{3}\right) \delta 196.9$ (6a), 173.9 (4), 165.4 (3a), 149.1 (2), 141.6 (3), 133.3 (6), 131.4 (5), 129.5 (7), 128.7 (4a), 116.2 (8), 112.4 (8a), 61.1 (3c), 49.1 (1a), 26.6 (6b), 14.5 (1b), 14.4 (3d). IR (neat, $\mathrm{cm}^{-1}$ ): 3053, 2982, 2921, 1712, 1685, ESI-HRMS m/z $[\mathrm{M}+\mathrm{H}]^{+}$calcd for $\mathrm{C}_{16} \mathrm{H}_{18} \mathrm{NO}_{4} 288.1230$, found 288.1234.

Methyl 6-acetyl-4-oxo-1-(4-(trifluoromethyl)benzyl)-1,4-dihydroquinoline-3-carboxylate, $3 \mathbf{e}$<smiles>COC(=O)c1cn(Cc2ccc(C(F)(F)F)cc2)c2ccc(C(C)=O)cc2c1=O</smiles>

Brown powder, $0.680 \mathrm{~g}(68 \%), R_{f}=0.81(\mathrm{DCM} / \mathrm{MeOH} 10: 1)$ m.p. $133-136{ }^{\circ} \mathrm{C} ;{ }^{1} \mathrm{H}$ NMR (300 MHz, DMSO) $\delta 9.02$ (s, $\left.1 \mathrm{H}, \mathrm{H}-2\right)$, $8.76(\mathrm{~d}, J=3.4 \mathrm{~Hz}, 1 \mathrm{H}, \mathrm{H}-5) 8.15(\mathrm{dd}, J=9.1,3.4 \mathrm{~Hz}, 1 \mathrm{H}, \mathrm{H}-7), 7.73$ $(\mathrm{d}, J=8.0, \mathrm{~Hz}, 2 \mathrm{H}, \mathrm{H}-1 \mathrm{c}), 7.60(\mathrm{~d}, J=7.1 \mathrm{~Hz}, 2 \mathrm{H}, \mathrm{H}-1 \mathrm{~d}), 7.43(\mathrm{~d}, J=$ $9.1 \mathrm{~Hz}, 1 \mathrm{H}, \mathrm{H}-8), 5.82$ (s, 2H, H-1a), 3.89 (s, 3H, H-3c), 2.49 (s, 3H, H-6b). ${ }^{13} \mathrm{C}$ NMR (75 MHz, DMSO) $\delta 197.1$ (C-6a), 173.9 (4), 164.4 (3a), 151.4 (C-2), 142.2 (C-3), 140.2 (C-1b), 135.7 (C-1d), 133.3 (C-6), 132.3 (C-1c), 132.0 (C-5), 129.2 (C-7), 128.2 (C-1e), 127.6 (C-4a), 121.5 (C-8), 118.8 (C-8a), 111.6 (C-1f), 55.3 (C-3c), 53.7 (C-1a), 26.6 (6b). IR (neat, $\mathrm{cm}^{-1}$ ): 3100, 2970, 2921, 1700, 1680. ESI-HRMS $m / z[\mathrm{M}+\mathrm{H}]^{+}$calcd for $\mathrm{C}_{21} \mathrm{H}_{16} \mathrm{~F}_{3} \mathrm{NO}_{4}$ 404.1104, found 404.1107.

Ethyl 6-acetyl-1-benzyl-4-oxo-1,4-dihydroquinoline-3-carboxylate, $3 \mathbf{f}$<smiles>CCOC(=O)c1cn(Cc2ccccc2)c2ccc(C(C)=O)cc2c1=O</smiles>

White powder, $0.80 \mathrm{~g}(58 \%), R_{f}=0.81$ (DCM/MeOH 10:1) m.p. 142-144 ${ }^{\circ} \mathrm{C} ;{ }^{1} \mathrm{H}$ NMR (300 MHz, DMSO) $\delta 9.00$ (s, 1H, H-2), 8.81 (s, $1 \mathrm{H}, \mathrm{H}-5), 8.19(\mathrm{~d}, J=8.8 \mathrm{~Hz}, 1 \mathrm{H}, \mathrm{H}-8), 7.77(\mathrm{~d}, J=8.9 \mathrm{~Hz}, 1 \mathrm{H}, \mathrm{H}-7)$, 7.49-7.21 (m, 5H, H-1c/H-1g), 5.77 (s, 2H, H-1a), 4.31 (q, J = 7.0 $\mathrm{Hz}, 2 \mathrm{H}, \mathrm{H}-3 \mathrm{c}), 2.55$ (s, 3H, H-6b), 1.40-1.26 (m, 3H, H-3d). ${ }^{13} \mathrm{C}$ NMR (75 MHz, DMSO) $\delta 197.1$ (C-6a), 173.3 (C-4), 164.7 (C-3a), 151.1 (C-2), 142.4 (C-3), 136.2 (C-1b), 133.2 (C-6), 131.8 (C-5), 129.4 (C-1g), 128.4 (C-4a), 128.3 (C-1f), 127.7 (C-7), 126.9 (C-1e), 118.8 (C-8), 111.9 (C-8a), 60.5 (C-3c), 56.2 (C-1a), 27.2 (C-6a), 14.7 (C-3d). IR (neat, $\mathrm{cm}^{-1}$ ): 3083, 2970, 2921, 1705, 1681, ESI-HRMS $m / z[\mathrm{M}+\mathrm{H}]^{+}$calcd for $\mathrm{C}_{21} \mathrm{H}_{20} \mathrm{NO}_{4} 350.1387$, found 350.1391.
Methyl 6-acetyl-1-(4-bromobenzyl)-4-oxo-1,4-dihydroquinoline-3carboxylate, $3 \mathrm{~g}$<smiles>COC(=O)c1cn(Cc2ccc(Br)cc2)c2ccc(C(C)=O)cc2c1=O</smiles>

Brown powder, $0.58 \mathrm{~g}(62 \%), R_{f}=0.81(\mathrm{DCM} / \mathrm{MeOH} 10: 1)$, m.p. $173-175^{\circ} \mathrm{C} ;{ }^{1} \mathrm{H}$ NMR $(300 \mathrm{MHz}$, DMSO) $\delta 8.99(\mathrm{~s}, 1 \mathrm{H}, \mathrm{H}-2), 8.75$ (s, $1 \mathrm{H}, \mathrm{H}-5), 8.16$ (d, $J=8.6 \mathrm{~Hz}, 1 \mathrm{H}, \mathrm{H}-7), 7.81-7.52$ (m, 3H, H-1c, $\mathrm{H}-8), 7.19$ (d, J = 7.6 Hz, 2H, H-1d), 5.72 (s, 2H, H-1a), 3.79 (s, 3H, H-3c), 2.50 (s, 3H, H-6b). ${ }^{13} \mathrm{C}$ NMR (75 MHz, DMSO) $\delta 197.4$ (C-6a), 173.1 (C-4), 166.4 (C-3a), 151.4 (C-2), 142.2 (C-3), 135.7 (C-1d), 133.3 (C-6), 132.3 (C-1c), 132.0 (C-5), 129.2 (C-7), 128.3 (C-1b), 127.6 (C-4a), 127.5 (C-8), 119.8 (C-8a), 111.6 (C-1e), 55.3 (C-3c), 53.7 (C-1a), 26.6 (6b). IR (neat, $\left.\mathrm{cm}^{-1}\right)$ : 3048, 2972, 2931, 1702, 1682. ESI-HRMS $m / z[\mathrm{M}+\mathrm{H}]^{+}$calcd for $\mathrm{C}_{20} \mathrm{H}_{17} \mathrm{BrNO}_{4}$ 414.0335, found 414.0333 .

Methyl 6-acetyl-1-(2,4-dichlorobenzyl)-4-oxo-1,4-dihydroquinoline-3-carboxylate, $3 \mathrm{~h}$<smiles>COC(=O)c1cn(Cc2ccc(Cl)cc2Cl)c2ccc(C(C)=O)cc2c1=O</smiles>

Brown powder, $0.28 \mathrm{~g}(48 \%), R_{f}=0.81(\mathrm{DCM} / \mathrm{MeOH} 10: 1)$, m.p. $197-1199{ }^{\circ} \mathrm{C} ;{ }^{1} \mathrm{H}$ NMR (300 MHz, DMSO) $\delta 9.16$ (s, $\left.1 \mathrm{H}, \mathrm{H}-2\right)$, $8.92(\mathrm{~d}, J=2.2 \mathrm{~Hz}, 1 \mathrm{H}, \mathrm{H}-5), 8.26(\mathrm{dd}, J=8.9,2.2 \mathrm{~Hz}, 1 \mathrm{H}, \mathrm{H}-7), 7.85$ $(\mathrm{d}, J=9.0 \mathrm{~Hz}, 1 \mathrm{H}, \mathrm{H}-8), 7.72-7.59$ (m, 2H, H-1d, H-1g), 7.21 (dd, $J=8.3,2.2 \mathrm{~Hz}, 1 \mathrm{H}, \mathrm{H}-1 \mathrm{f}), 5.87$ (s, 2H, H-1a), 3.77 (s, 3H, H-3c), 2.70 (s, 3H, H-6b). ${ }^{13} \mathrm{C}$ NMR (75 MHz, DMSO) $\delta 197.1$ (C-6a), 176.3 (C-4), 164.0 (C-3a), 150.2 (C-2), 142.1 (C-3), 137.4 (C-6), 133.4 (C-1b), 132.1 (C-5), 131.9 (C-1g), 131.6 (C-1c), 131.1 (C-1e), 129.4 (C-1d), 127.7 (C-7), 127.4 (C-1f), 127.2 (C-4a), 118.7 (C-8), 112.8 (C-8a), 55.5 (C-1a), 52.3 (C-3c), 27.2 (C-6b). IR (neat, $\mathrm{cm}^{-1}$ ): 3073, $2972,2941,1702,1683$. ESI-HRMS $\mathrm{m} / \mathrm{z}[\mathrm{M}+\mathrm{H}]^{+}$calcd for $\mathrm{C}_{20} \mathrm{H}_{16} \mathrm{Cl}_{2} \mathrm{NO}_{4}$ 404.0451, found 404.0452.

\subsubsection{General Method for the Preparation of Amides $4 \mathbf{4}-\mathbf{j}$}

A mixture of 3 ( $1 \mathrm{~g}$, 1 eq.), DBU $(320 \mu \mathrm{L}, 0.33 \mathrm{~g}$, $2.1 \mathrm{mmol})$, an appropriate amine (5 eq.), and chloroform $(15 \mathrm{~mL})$ in a $100 \mathrm{~mL}$ round-bottom flask was stirred under reflux for $24-30 \mathrm{~h} .{ }^{34} \mathrm{Upon}$ reaction completion as indicated by TLC, the mixture was evaporated to dryness and resultant crude subjected to silica gel column chromatography eluting with $\mathrm{CH}_{2} \mathrm{Cl}_{2} / \mathrm{MeOH}$ (10:1). Fractions containing the desired product were combined, evaporated to dryness and recrystallized from ethanol. Compounds 4a-j were obtained in 30-50 \% yield following this procedure.

6-Acetyl-1-ethyl-N-(2-methoxyethyl)-4-oxo-1,4-dihydroquinoline-3carboxamide, $\mathbf{4 a}$<smiles>CCn1cc(C(=O)NCCOC)c(=O)c2cc(C(C)=O)ccc21</smiles> 
Orange powder, $0.028 \mathrm{~g}(32 \%), R_{f}=0.48(\mathrm{DCM} / \mathrm{MeOH} 10: 1)$, m.p. $163-165{ }^{\circ} \mathrm{C} ;{ }^{1} \mathrm{H}$ NMR (300 MHz, DMSO) $\delta 9.93(\mathrm{~s}, 1 \mathrm{H}, \mathrm{NH})$, $8.88(\mathrm{~s}, 1 \mathrm{H}, \mathrm{H}-2), 8.83(\mathrm{~d}, J=1.5 \mathrm{~Hz}, 1 \mathrm{H}, \mathrm{H}-5), 8.32-8.22(\mathrm{~m}, 1 \mathrm{H}$, $\mathrm{H}-7), 7.97(\mathrm{~d}, J=9.0 \mathrm{~Hz}, 1 \mathrm{H}, \mathrm{H}-8), 4.55(\mathrm{q}, J=7.0 \mathrm{~Hz}, 2 \mathrm{H}, \mathrm{H}-1 \mathrm{a})$, 3.49 (s, 3H, H-3f), 3.42-3.04 (m, 4H, H-3c, H-3d), 2.68 (s, 3H, H-6b), 1.39 (t, $J=7.0 \mathrm{~Hz}, 3 \mathrm{H}, \mathrm{H}-1 \mathrm{~b}) .{ }^{13} \mathrm{C}$ NMR $(75 \mathrm{MHz}, \mathrm{DMSO}) \delta 197.6$ (C-6a), 175.9 (C-4), 164.2 (C-3a), 148.8 (C-2), 142.1 (C-3), 132.9 (C-6), 132.1 (C-5), 127.9 (C-7), 127.1 (C-4a), 118.4 (C-8), 112.6 (C-8a), 71.3 (C-3d), 58.3 (C-3f), 49.1 (C-1a), 38.8 (C-3c), 27.5 (C-6b), 14.9 (C-1b). IR (neat, $\mathrm{cm}^{-1}$ ): 3393, 3041, 2970, 2929, 1682, 1656. ESI-HRMS $m / z[\mathrm{M}+\mathrm{H}]^{+}$calcd for $\mathrm{C}_{17} \mathrm{H}_{21} \mathrm{~N}_{2} \mathrm{O}_{4} 317.1496$, found 317.1497.

6-Acetyl-1-ethyl-N-(2-(2-hydroxyethoxy)ethyl)-4-oxo-1,4-dihydroquinoline-3-carboxamide, $\mathbf{4 b}$<smiles>CCn1cc(C(=O)NCCOCCO)c(=O)c2cc(C(C)=O)ccc21</smiles>

White powder, $0.235 \mathrm{~g}(33 \%), R_{f}=0.39(\mathrm{DCM} / \mathrm{MeOH} 10: 1)$, m.p. $127-129^{\circ} \mathrm{C} ;{ }^{1} \mathrm{H} \mathrm{NMR}\left(400 \mathrm{MHz}, \mathrm{CDCl}_{3}\right) \delta 10.12(\mathrm{~s}, 1 \mathrm{H}, \mathrm{NH})$, 8.97 (s, 1H,H-2), 8.75 (s, 1H, H-5), 8.27 (d, J = 7.9 Hz, 1H, H-7), 7.54 $(\mathrm{d}, J=7.9 \mathrm{~Hz}, 1 \mathrm{H}, \mathrm{H}-8), 4.31(\mathrm{q}, J=7.1 \mathrm{~Hz}, 2 \mathrm{H}, \mathrm{H}-1 \mathrm{a}), 3.74-3.61(\mathrm{~m}$, $8 \mathrm{H}, \mathrm{H}-3 \mathrm{c}, \mathrm{H}-3 \mathrm{~d}, \mathrm{H}-3 \mathrm{f}, \mathrm{H}-3 \mathrm{~g}), 2.67$ (s, 3H, H-6b), 1.53 (t, $J=7.2 \mathrm{~Hz}$, $3 \mathrm{H}, \mathrm{H}-1 \mathrm{~b}) .{ }^{13} \mathrm{C}$ NMR $\left(101 \mathrm{MHz}, \mathrm{CDCl}_{3}\right) \delta 196.8$ (C-6a), 176.7 (C-4), 164.7 (C-3a), 147.9 (C-2), 141.5 (C-3), 133.6 (C-6), 131.9 (C-5), 129.2 (C-7), 127.9 (C-4a), 116.2 (C-8), 113.5 (C-8a), 72.7 (C-3g), 69.7 (C-3f), 61.7 (C-3d), 49.3 (C-1a), 39.0 (C-3c), 26.6 (C-6b), 14.6 (C-1b). IR (neat, $\left.\mathrm{cm}^{-1}\right)$ : 3333, 3252, 3001, 2970, 2929, 1682, 1654. ESI-HRMS $\mathrm{m} / \mathrm{z}[\mathrm{M}+\mathrm{H}]^{+}$calcd for $\mathrm{C}_{18} \mathrm{H}_{23} \mathrm{~N}_{2} \mathrm{O}_{5}$ 347.1601, found 347.1604.

6-Acetyl-1-ethyl-N-(2-((2-hydroxyethyl)amino)ethyl)-4-oxo-1,4dihydroquinoline-3-carboxamide, $4 \mathrm{c}$<smiles>CCn1cc(C(=O)NCCNCCO)c(=O)c2cc(C(C)=O)ccc21</smiles>

White powder, $0.475 \mathrm{~g}(48 \%), R_{f}=0.11(\mathrm{DCM} / \mathrm{MeOH} 10: 1)$, m.p. $157-159{ }^{\circ} \mathrm{C} ;{ }^{1} \mathrm{H}$ NMR $(300 \mathrm{MHz}, \mathrm{DMSO}) \delta 9.97(\mathrm{t}, J=5.9 \mathrm{~Hz}$, $1 \mathrm{H}, \mathrm{NH}-3 \mathrm{~b}), 8.91$ (s, 1H, H-2), 8.84 (d, J = 2.2 Hz, 1H, H-5), 8.30 $(\mathrm{dd}, J=9.0,2.2 \mathrm{~Hz}, 1 \mathrm{H}, \mathrm{H}-7), 8.01(\mathrm{~d}, J=9.0 \mathrm{~Hz}, 1 \mathrm{H}, \mathrm{H}-8), 5.27(\mathrm{~s}$, $1 \mathrm{H}, \mathrm{H}-3 \mathrm{~h}), 4.56$ (q, J = 7.1 Hz, 2H, H-1a), 3.67 (t, $J=6.3 \mathrm{~Hz}, 4 \mathrm{H}$, $\mathrm{H}-3 \mathrm{~d}, \mathrm{H}-3 \mathrm{f}), 3.15$ (t, $J=8.8 \mathrm{~Hz}, 2 \mathrm{H}, \mathrm{H}-3 \mathrm{~g}), 3.03(\mathrm{t}, J=5.4 \mathrm{~Hz}, 2 \mathrm{H}$, $\mathrm{H}-3 \mathrm{c}), 2.68$ (s, 3H, H-6b), 1.39 (t, $J=7.1 \mathrm{~Hz}, 3 \mathrm{H}, \mathrm{H}-1 \mathrm{~b}) .{ }^{13} \mathrm{C}$ NMR (75 MHz, DMSO) $\delta 197.2$ (C-6a), 175.8 (C-4), 165.1 (C-3a), 149.2 (C-2), 141.8 (C-3), 133.2 (C-6), 132.2 (C-5), 127.6 (C-7), 127.2 (C-4a), 118.5 (C-8), 112.3 (C-8a), 56.9 (C-3g), 49.7 (C-1a), 49.0 (C-3c), 47.1 (C-3f), 35.9 (C-3d), 27.2 (C-6b), 14.9 (C-1b). IR (neat, $\left.\mathrm{cm}^{-1}\right)$ : 3313, $3243,3081,2879,2819,1687,1656$. ESI-HRMS $m / z[\mathrm{M}+\mathrm{H}]^{+}$calcd for $\mathrm{C}_{18} \mathrm{H}_{24} \mathrm{~N}_{3} \mathrm{O}_{4}$ 346.1761, found 346.1762.

N-(3-(1H-imidazol-1-yl)propyl)-6-acetyl-1-ethyl-4-oxo-1,4-dihydroquinoline-3-carboxamide, $4 \mathrm{~d}$<smiles>CCn1cc(C(=O)NCCCn2ccnc2)c(=O)c2cc(C(C)=O)ccc21</smiles>

White powder, $0.521 \mathrm{~g}(57 \%), R_{f}=0.4(\mathrm{DCM} / \mathrm{MeOH} 10: 1)$, m.p. 207-209 ${ }^{\circ} \mathrm{C} ;{ }^{1} \mathrm{H}$ NMR $\left(300 \mathrm{MHz}, \mathrm{CDCl}_{3}\right) \delta 9.98$ (s, $\left.1 \mathrm{H}, \mathrm{NH}\right)$, $8.99(\mathrm{~s}, 1 \mathrm{H}, \mathrm{H}-2), 8.76(\mathrm{~d}, J=0.9 \mathrm{~Hz}, 1 \mathrm{H}, \mathrm{H}-5), 8.28(\mathrm{dd}, J=9.0,0.9$ $\mathrm{Hz}, 1 \mathrm{H}, \mathrm{H}-7), 7.57$ (d, J = 9.0 Hz, 1H, H-8), 7.49 (s, 1H, H-3g), 6.99 $(\mathrm{d}, J=9.2 \mathrm{~Hz}, 1 \mathrm{H}, \mathrm{H}-3 \mathrm{j}), 6.93(\mathrm{~d}, J=9.2 \mathrm{~Hz}, 1 \mathrm{H}, \mathrm{H}-3 \mathrm{i}), 4.32(\mathrm{q}, J=$ $7.2 \mathrm{~Hz}, 2 \mathrm{H}, \mathrm{H}-1 \mathrm{a}), 4.01(\mathrm{t}, J=7.0 \mathrm{~Hz}, 2 \mathrm{H}, \mathrm{H}-3 \mathrm{e}), 3.43(\mathrm{q}, J=6.3 \mathrm{~Hz}$, $2 \mathrm{H}, \mathrm{H}-3 \mathrm{c}), 2.66(\mathrm{~s}, 3 \mathrm{H}, \mathrm{H}-6 \mathrm{~b}), 2.05(\mathrm{dt}, J=6.8,6.3 \mathrm{~Hz}, 2 \mathrm{H}$, $\mathrm{H}-3 \mathrm{~d}), 1.54-1.49$ (t, $J=7.2 \mathrm{~Hz}, 3 \mathrm{H}, \mathrm{H}-1 \mathrm{~b}) .{ }^{13} \mathrm{C} \mathrm{NMR}(75 \mathrm{MHz}$, $\left.\mathrm{CDCl}_{3}\right) \delta 196.6$ (C-6a), 176.5 (C-4), 164.8 (C-3a), 147.9 (C-2), 141.6 (C-3), 137.2 (C-3g), 133.4 (C-6), 131.7 (C-5), 129.5 (C-3j), 128.9 (C-7), 127.4 (C-4a), 118.9 (C-3i), 116.4 (C-8), 112.9 (C-8a), 49.4 (C-1a), 44.5 (C-3c), 36.1 (C-3e), 31.3 (C-3d), 26.6 (C-6b), 14.6 (C-1b). IR (neat, $\mathrm{cm}^{-1}$ ): 3303, 3087, 2960, 2912, 1687, 1655. ESI-HRMS $m / z[\mathrm{M}+\mathrm{H}]^{+}$calcd for $\mathrm{C}_{20} \mathrm{H}_{23} \mathrm{~N}_{4} \mathrm{O}_{3} 367.1765$, found 367.1767.

6-Acetyl-1-(4-bromobenzyl)-N-(2-methoxyethyl)-4-oxo-1,4-dihydroquinoline-3-carboxamide, $\mathbf{4 e}$<smiles>COCCNC(=O)c1cn(Cc2ccc(Br)cc2)c2ccc(C(C)=O)cc2c1=O</smiles>

White powder, $0.432 \mathrm{~g}(43 \%), R_{f}=0.4(\mathrm{DCM} / \mathrm{MeOH} 10: 1)$, m.p. 136-138 ${ }^{\circ} \mathrm{C} ;{ }^{1} \mathrm{H}$ NMR $(300 \mathrm{MHz}, \mathrm{DMSO}) \delta 9.94(\mathrm{t}, J=5.0 \mathrm{~Hz}, 1 \mathrm{H}$, $\mathrm{NH}), 9.10(\mathrm{~s}, 1 \mathrm{H}, \mathrm{H}-2), 8.86(\mathrm{~d}, J=2.1 \mathrm{~Hz}, 1 \mathrm{H}, \mathrm{H}-5), 8.19(\mathrm{dd}, J=$ 9.0, $2.2 \mathrm{~Hz}, 1 \mathrm{H}, \mathrm{H}-7), 7.79$ (d, J = 9.0 Hz, 1H, H-8), 7.62-7.45 (m, 2H, H-1d), 7.29-7.16 (m, 2H, H-1c), 5.79 (s, 2H, H-1a), 3.51 (t, J = $4.6 \mathrm{~Hz}, 2 \mathrm{H}, \mathrm{H}-3 \mathrm{c}), 3.48-3.06$ (m, 5H, H-3d, H-3f), 2.65 (s, 3H, $\mathrm{H}-6 \mathrm{~b}) .{ }^{13} \mathrm{C}$ NMR (75 MHz, DMSO) $\delta 197.1$ (C-6a), 176.2 (C-4), 164.1 (C-3a), 150.2 (C-2), 142.2 (C-3), 135.7 (C-1b), 133.3 (C-6), 132.3 (C-5), 132.0 (C-1c), 129.2 (C-1d), 127.7 (C-7), 127.3 (C-1e), 121.5 (C-4a), 118.9 (C-8), 112.7 (C-8a), 71.2 (C-3d), 58.5 (C-3f), 55.8 (C-1a), 38.8 (C-3c), 27.2 (C-6b). IR (neat, $\mathrm{cm}^{-1}$ ): 3317, 3051, 2960, $2900,1686,1657$. ESI-HRMS $m / z[\mathrm{M}+\mathrm{H}]^{+}$calcd for $\mathrm{C}_{22} \mathrm{H}_{22} \mathrm{BrN}_{2} \mathrm{O}_{4}$ 459.0763 , found 459.0751 .

6-Acetyl-1-(4-bromobenzyl)-N-(2-((2-hydroxyethyl)amino)ethyl)-4oxo-1,4-dihydroquinoline-3-carboxamide, $\mathbf{4 f}$

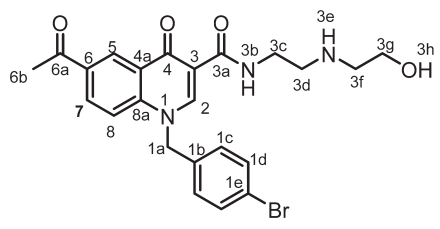

White powder, $0.20 \mathrm{~g}(48 \%), R_{f}=0.11$ (DCM/MeOH 10:1), m.p. 178-180 ${ }^{\circ} \mathrm{C} ;{ }^{1} \mathrm{H} \mathrm{NMR}(300 \mathrm{MHz}, \mathrm{DMSO}) \delta 9.93(\mathrm{t}, J=4.8 \mathrm{~Hz}, 1 \mathrm{H}$, $\mathrm{NH}), 9.10$ (s, 1H, H-2), 8.85 (d, $J=1.7 \mathrm{~Hz}, 1 \mathrm{H}, \mathrm{H}-5), 8.19$ (dd, $J=$ $8.9,1.7 \mathrm{~Hz}, 1 \mathrm{H}, \mathrm{H}-7), 7.79$ (d, J = 9.0 Hz, 1H, H-8), 7.54 (d, $J=8.3$ $\mathrm{Hz}, 2 \mathrm{H}, \mathrm{H}-1 \mathrm{~d}), 7.20$ (d, J = 8.3 Hz, 2H, H-1c), 5.79 (s, 2H, H-1a), $4.62(\mathrm{t}, J=5.2 \mathrm{~Hz}, 2 \mathrm{H}, \mathrm{H}-3 \mathrm{c}), 3.60-3.49$ (m, 6H, H-3d, H-3f, $\mathrm{H}-3 \mathrm{~g}), 2.43$ (s, 3H, H-6b). ${ }^{13} \mathrm{C}$ NMR (75 MHz, DMSO) $\delta 197.1$ (C-6a), 176.2 (C-4), 164.1 (C-3a), 150.2 (C-2), 142.2 (C-3), 135.7 (C-1d), 133.4 (C-6), 132.2 (C-1c), 132.0 (C-5), 129.3 (C-7), 127.4 (C-1b), 121.6 (C-4a), 118.9 (C-8), 112.7 (C-8a), 111.9 (C-1e), 58.7 (C-3g), 55.8 (C-1a), 49.4 (C-3f), 48.9 (C-3d), 36.9 (C-3c), 27.2 (C-6b). IR (neat, $\mathrm{cm}^{-1}$ ): 3320, 3202, 3000, 2970, 2929, 1682, 1657. ESI-HRMS $m / z[\mathrm{M}+\mathrm{H}]^{+}$calcd for $\mathrm{C}_{23} \mathrm{H}_{25} \mathrm{BrN}_{3} \mathrm{O}_{4} 486.1023$, found 486.1021. 
6-Acetyl-1-(4-bromobenzyl)-N-[2-(2-hydroxyethoxy)ethyl]-4-oxo1,4-dihydroquinoline-3-carboxamide, $\mathbf{4 g}$<smiles>CC(=O)c1ccc2c(c1)c(=O)c(C(=O)NCCOCCO)cn2Cc1ccc(Br)cc1</smiles>

White powder, $0.20 \mathrm{~g}(48 \%), R_{f}=0.4$ (DCM/MeOH 10:1), m.p. 183-185 ${ }^{\circ} \mathrm{C} ;{ }^{1} \mathrm{H}$ NMR $(300 \mathrm{MHz}, \mathrm{DMSO}) \delta 9.93(\mathrm{t}, J=4.8 \mathrm{~Hz}, 1 \mathrm{H}$, $\mathrm{NH}), 9.10(\mathrm{~s}, 1 \mathrm{H}, \mathrm{H}-2), 8.85(\mathrm{~d}, J=1.7 \mathrm{~Hz}, 1 \mathrm{H}, \mathrm{H}-5), 8.19(\mathrm{dd}, J=$ $8.9,1.7 \mathrm{~Hz}, 1 \mathrm{H}, \mathrm{H}-7), 7.79$ (d, $J=9.0 \mathrm{~Hz}, 1 \mathrm{H}, \mathrm{H}-8), 7.54$ (d, $J=8.3$ $\mathrm{Hz}, 2 \mathrm{H}, \mathrm{H}-1 \mathrm{~d}), 7.20$ (d, J = 8.3 Hz, 2H, H-1c), 5.79 (s, 2H, H-1a), 4.62 (t, $J=5.2 \mathrm{~Hz}, 2 \mathrm{H}, \mathrm{H}-3 \mathrm{c}), 3.60-3.49$ (m, 6H, H-3d, H-3f, H-3g), 2.43 (s, 3H, H-6b). ${ }^{13} \mathrm{C}$ NMR (75 MHz, DMSO) $\delta 197.1$ (C-6a), 176.2 (C-4), 1- 64.1 (C-3a), 150.2 (C-2), 142.2 (C-3), 135.7 (C-1d), 133.4 (C-6), 132.2 (C-1c), 132.0 (C-5), 129.3 (C-7), 127.4 (C-1b), 121.6 (C-4a), 118.9 (C-8), 112.7 (C-8a), 111.9 (C-1e), 72.7 (C-3d), 69.7 (C-3f), 60.7 (C-3g), 55.0 (C-1a), 39.7 (C-3c), 27.2 (C-6b). IR (neat, $\left.\mathrm{cm}^{-1}\right): 3397,3252,3041,2950,2861,1686,1654$. ESI-HRMS $\mathrm{m} / \mathrm{z}$ calcd for $\mathrm{C}_{23} \mathrm{H}_{24} \mathrm{BrN}_{2} \mathrm{O}_{5} 487.0863$, found $487.0665[\mathrm{M}+\mathrm{H}]^{+}$. HPLC purity $>96 \%$, retention time $=9.89 \mathrm{~min}$.

6-Acetyl-1-benzyl-N-(2-((2-hydroxyethyl)amino)ethyl)-4-oxo-1,4dihydroquinoline-3-carboxamide, $4 \mathbf{h}$<smiles>CC(=O)c1ccc2c(c1)c(=O)c(C(=O)NCCNCCO)cn2Cc1ccccc1</smiles>

Orange powder, $0.320 \mathrm{~g}(48 \%), R_{f}=0.11$ (DCM/MeOH 10:1), m.p. $169-171{ }^{\circ} \mathrm{C} ;{ }^{1} \mathrm{H}$ NMR (300 MHz, DMSO) $\delta 9.93(\mathrm{t}, J=4.8 \mathrm{~Hz}$, $1 \mathrm{H}, \mathrm{NH}), 9.10(\mathrm{~s}, 1 \mathrm{H}, \mathrm{H}-2), 8.85(\mathrm{~d}, J=1.7 \mathrm{~Hz}, 1 \mathrm{H}, \mathrm{H}-5), 8.19$ (dd, $J=8.9,1.7 \mathrm{~Hz}, 1 \mathrm{H}, \mathrm{H}-7), 7.79(\mathrm{~d}, J=9.0 \mathrm{~Hz}, 1 \mathrm{H}, \mathrm{H}-8), 7.54-7.20(\mathrm{~m}$, $5 \mathrm{H}, \mathrm{H}-1 \mathrm{c}, \mathrm{H}-1 \mathrm{~d}, \mathrm{H}-1 \mathrm{f}, \mathrm{H}-1 \mathrm{~g}), 5.79$ (s, 2H, H-1a), 4.62 (t, $J=5.2 \mathrm{~Hz}$, 2H, H-3c), 3.60-3.49 (m, 6H, H-3d, H-3f, H-3g), 2.43 (s, 3H, H-6b). ${ }^{13} \mathrm{C}$ NMR (75 MHz, DMSO) $\delta 197.1$ (C-6a), 176.2 (C-4), 164.1 (C-3a), 150.2 (C-2), 142.2 (C-3), 135.7 (C-1d), 133.4 (C-6), 132.2 (C-1c), 132.0 (C-5), 129.3 (C-7), 127.4 (C-1b), 121.6 (C-4a), 118.9 (C-8), 112.7 (C-8a), 111.9 (C-1e), 72.7 (C-3d), 69.7 (C-3f), 60.7 (C-3g), 55.02 (C-1a), 39.7 (C-3c), 27.2 (C-6b). IR (neat, $\left.\mathrm{cm}^{-1}\right)$ : 3328, $3212,3038,2971,2921,1682,1659$. ESI-HRMS m/z [M+H] ${ }^{+}$calcd for $\mathrm{C}_{23} \mathrm{H}_{26} \mathrm{~N}_{3} \mathrm{O}_{4} 408.1918$, found 408.1923 .

6-Acetyl-1-(2,4-dichlorobenzyl)-N-(2-methoxyethyl)-4-oxo-1,4-dihydroquinoline-3-carboxamide, $\mathbf{4 i}$<smiles>COCCNC(=O)c1cn(Cc2ccc(Cl)cc2Cl)c2ccc(C(C)=O)cc2c1=O</smiles>

Brown powder, $0.370 \mathrm{~g}(44 \%), R_{f}=0.4(\mathrm{DCM} / \mathrm{MeOH} 10: 1)$. m.p. $203-205^{\circ} \mathrm{C} ;{ }^{1} \mathrm{H}$ NMR $\left(300 \mathrm{MHz}, \mathrm{DMSO}-d_{6}\right) \delta 9.99(\mathrm{t}, J=5.1$ $\mathrm{Hz}, 1 \mathrm{H}, \mathrm{NH}), 9.16$ (s, 1H, H-2), 8.92 (d, J = 2.2 Hz, 1H, H-5), 8.26 $(\mathrm{dd}, J=8.9,2.2 \mathrm{~Hz}, 1 \mathrm{H}, \mathrm{H}-7), 7.85(\mathrm{~d}, J=9.0 \mathrm{~Hz}, 1 \mathrm{H}, \mathrm{H}-8)$, 7.72-7.59 (m, 2H, H-1d, H-1f), 7.21 (d, J = 8.3, Hz, 1H, H-1g), 5.87 (s, 2H, H-1a), 3.56-3.13 (m, 4H, H-3c, H-3d), 3.37 (s, 3H, H-3f), 2.70 (s, 3H, H-6b). ${ }^{13} \mathrm{C}$ NMR (75 MHz, DMSO) $\delta 197.1$ (C-6a), 176.3 (C-4), 164.0 (C-3a), 150.2 (C-2), 142.1 (C-3), 137.4 (C-6), 133.4 (C-1b), 132.1 (C-5), 131.9 (C-1g), 131.6 (C-1c), 131.1 (C-1e), 129.4 (C-1d), 127.7 (C-7), 127.4 (C-1f), 127.2 (C-4a), 118.7 (C-8), 112.8 (C-8a), 71.2 (C-3d), 58.5 (C-3f), 55.3 (C-1a), 39.0 (C-3c), 27.2 (C-6b). IR (neat, $\mathrm{cm}^{-1}$ ): 3298, 3071, 2971, 2929, 1682, 1655. ESI-HRMS m/z $[\mathrm{M}+\mathrm{H}]^{+}$calcd for $\mathrm{C}_{22} \mathrm{H}_{21} \mathrm{Cl}_{2} \mathrm{~N}_{2} \mathrm{O}_{4} 447.0873$, found 447.0878.

6-Acetyl-N-(2-((2-hydroxyethyl)amino)ethyl)-4-oxo-1-(4-(trifluoromethyl)benzyl)-1,4-dihydroquinoline-3-carboxamide, $\mathbf{4 j}$<smiles>CC(=O)c1ccc2c(c1)c(=O)c(C(=O)NCCNCCO)cn2-c1ccc(C(F)(F)F)cc1</smiles>

Orange powder, $0.367 \mathrm{~g}(44 \%), R_{f}=0.11(\mathrm{DCM} / \mathrm{MeOH} 10: 1)$, m.p. $193-195^{\circ} \mathrm{C} ;{ }^{1} \mathrm{HNMR}(300 \mathrm{MHz}, \mathrm{DMSO}) \delta 10.03(\mathrm{t}, J=5.9 \mathrm{~Hz}$, $1 \mathrm{H}, \mathrm{NH}), 9.22(\mathrm{~s}, 1 \mathrm{H}, \mathrm{H}-2), 8.92(\mathrm{~d}, J=2.1 \mathrm{~Hz}, 1 \mathrm{H}, \mathrm{H}-5), 8.28(\mathrm{dd}$, $J=8.9,2.2 \mathrm{~Hz}, 1 \mathrm{H}, \mathrm{H}-7), 7.87(\mathrm{~d}, J=9.0 \mathrm{~Hz}, 1 \mathrm{H}, \mathrm{H}-8), 7.79(\mathrm{~d}$, $J=8.1 \mathrm{~Hz}, 2 \mathrm{H}, \mathrm{H}-1 \mathrm{c}), 7.51(\mathrm{~d}, J=8.0 \mathrm{~Hz}, 2 \mathrm{H}, \mathrm{H}-1 \mathrm{~d}), 6.03(\mathrm{~s}, 2 \mathrm{H}$, $\mathrm{H}-1 \mathrm{a}), 5.36(\mathrm{t}, J=5.1 \mathrm{~Hz}, 1 \mathrm{H}, \mathrm{OH}), 3.83-3.70(\mathrm{~m}, 4 \mathrm{H}, \mathrm{H}-3 \mathrm{~d}, \mathrm{H}-3 \mathrm{f})$, $3.22(\mathrm{t}, J=6.3 \mathrm{~Hz}, 2 \mathrm{H}, \mathrm{H}-3 \mathrm{c}), 3.11(\mathrm{t}, J=5.3 \mathrm{~Hz}, 2 \mathrm{H}, \mathrm{H}-3 \mathrm{~g}), 2.70(\mathrm{~s}$, $3 \mathrm{H}, \mathrm{H}-6 \mathrm{~b}) .{ }^{13} \mathrm{C}$ NMR (75 MHz, DMSO) $\delta 197.1$ (C-6a), 176.1 (C-4), 165.0 (C-3a), 150.4 (C-2), 142.2 (C-3), 141.1 (C-1b), 133.5 (C-6), 132.4 (C-5), 129.1 (C-1e), 127.7 (C-7), 127.4 (C-1c), 127.3 (C-1d), 126.3 (C-1f), 126.3 (C-4a), 118.9 (C-8), 112.6 (C-8a), 56.9 (C-3g), 55.9 (C-1a), 49.6 (C-3f), 47.0 (C-3d), 35.9 (C-3c), 27.2 (C-6b). IR (neat, $\left.\mathrm{cm}^{-1}\right)$ : 3293, 3252, 3081, 2974, 2926, 1682, 1654. ESI-HRMS $\mathrm{m} / \mathrm{z}[\mathrm{M}+\mathrm{H}]^{+}$calcd for $\mathrm{C}_{24} \mathrm{H}_{25} \mathrm{~F}_{3} \mathrm{~N}_{3} \mathrm{O}_{4} 476.1792$, found 476.1797 .

\subsection{In vitro Anti-trypanosomal Assay}

Trypanosoma brucei brucei 427 trypomastigotes were cultured in Iscove's Modified Dulbecco's Medium (IMDM; Lonza) supplemented with $10 \%$ fetal calf serum, ${ }^{35}$ HMI-9 supplement, hypoxanthine and penicillin/streptomycin at $37^{\circ} \mathrm{C}$ in a $5 \% \mathrm{CO}_{2}$ incubator. Serial dilutions of test compounds were incubated with the parasites in 96-well plates for $24 \mathrm{~h}$ and residual parasite viability in the wells determined by adding $20 \mu \mathrm{L}$ of $0.54 \mathrm{mM}$ resazurin in phosphate buffered saline (PBS) and incubating for an additional 2-4 h. Reduction of resazurin to resorufin by viable parasites was assessed by fluorescence readings (excitation $560 \mathrm{~nm}$, emission $590 \mathrm{~nm}$ ) in a Spectramax M3 plate reader. Fluorescence readings were converted to $\%$ parasite viability relative to the average readings obtained from untreated control wells. $\mathrm{IC}_{50}$ values were determined by plotting $\%$ viability $v s$. $\log$ [compound] and performing non-linear regression using GraphPad Prism (v. 5.02) software.

\subsection{In vitro Cytotoxicity Assay}

HeLa cells (Cellonex) were cultured in Dulbecco's modified Eagle's medium (DMEM; Lonza) supplemented with $10 \%$ fetal calf serum and antibiotics (penicillin/streptomycin/amphotericin $\mathrm{B}$ ) at $37 \stackrel{\circ}{\circ} \mathrm{C}$ in a $5 \% \mathrm{CO}_{2}$ incubator. Cells were plated in 96-well plates at a cell density of $2 \times 10^{4}$ cells per well and grown overnight. Serial dilutions of test compounds were incubated with the cells for an additional $24 \mathrm{~h}$, and cell viability in the wells assessed by adding $20 \mu \mathrm{L} 0.54 \mathrm{mM}$ resazurin in PBS for an additional $2-4 \mathrm{~h}$. Fluorescence readings (excitation $560 \mathrm{~nm}$, emission $590 \mathrm{~nm}$ ) obtained for the individual wells were converted to $\%$ cell viability relative to the average readings obtained from 
untreated control wells. Plots of \% cell viability vs. log[compound] were used to determine $\mathrm{IC}_{50}$ values by non-linear regression using GraphPad Prism (v. 5.02).

\section{Supplementary Material}

Supplementary information is provided in the online supplement.

\section{Acknowledgements}

The authors acknowledge the financial support by the National Research Foundation (SDK), Rhodes University for a Postdoctoral fellowship (RMB) and Rhodes University Sandisa Imbewu (SDK) towards this research. The bioassay component of the project was funded by the South African Medical Research Council (MRC) with funds from National Treasury under its Economic Competitiveness and Support Package awarded to $\mathrm{HCH}$.

\section{${ }^{s}$ ORCID iDs}

\section{S.D. Khanye: (iD orcid.org/0000-0003-0725-5738 \\ R.M. Beteck: (ID) orcid.org/0000-0002-6282-043X}

\section{References}

1 R. Brun, R. Schumacher, C. Schmid, C. Kunz and C. Burri, The phenomenon of treatment failures in human African trypanosomiasis, Trop. Med. Int. Health., 2001, 6, 906-914.

2 WHO. Neglected tropical diseases http://www.who.int/neglected diseases/diseases/en accessed on 14 August 2017.

3 M. Kaiser, M. Bray, M. Cal, B. Trunz, E. Torreele and R. Brun, Antitrypanosomal activity of fexinidazole, a new oral nitroimidazole drug candidate for treatment of sleeping sickness, Antimicrob. Agents Chemother., 2011, 55, 5602-5608.

4 M. Berninger, I. Schmidt, A. Ponte-Sucreb and U. Holzgrabe, Novel lead compounds in pre clinical development against African sleeping sickness, Med. Chem. Commun., 2017, 8, 1872-1890.

5 WHO. Trypanosomiasis, human African (Sleeping sickness), http://www.who.int/mediacentre/factsheets/fs259/en/ accessed on 14 August 2017

6 H.-H. Tran, Z. Zheng, X. Wen, S. Manivannan, A. Pastor, M. Kaiser, R. Brun, F. Snyder and T. Back, Synthesis and activity of nucleosidebased antiprotozoan compounds, Bioorg. Med. Chem., 2017, 25 , 2091-2104.

7 X. Wang, D. Inaoka, T. Shiba, E. Balogun, S. Allmann, Y. Watanabe, M. Boshart, K. Kita and S. Harada, Expression, purification, and crystallization of type 1 isocitrate dehydrogenase from Trypanosoma brucei brucei, Protein Expr. Purif., 2017, 138, 56-62.

8 H. Gordhan, S. Patrick, M. Swasy, A. Hackler, M. Anayee, J. Golden, J. Morris and D. Whitehead, Evaluation of substituted ebselen derivatives as potential trypanocidal agents, Bioorg. Med. Chem. Lett., 2017, $27,537-541$.

9 M. Beig, F. Oellien, L. Garoff, S. Noack, L. Krauth-Siegel and P. Selzer, Trypanothione reductase: a target protein for a combined in vitro and in silico screening approach, PLOS Negl. Trop., 2015, 9, e0003773.

10 I. Kuepfer, E. Hhary, M. Allan, A. Edielu, C. Burri and J. Blum, Clinical presentation of $T . b$. rhodesiense sleeping sickness in second stage patients from Tanzania and Uganda, PLOS Negl. Trop. Dis., 2011, 5, e968.

11 F. Wamwiri and R. Changasi, Tsetse flies (Glossina) as vectors of human African trypanosomiasis: a review, BioMed. Res. Int., 2016, 2016, 1-8.

12 D. Steverding, The history of African trypanosomiasis, Parasites $\mathcal{E}$ Vectors, 2008, 1, 3 .

13 M. Banerjee, D. Paraia, P. Dhar, M. Roy, R. Barik, S. Chattopadhyay and S. Mukherje, Andrographolide induces oxidative stress-dependent cell death in unicellular protozoan parasite Trypanosoma brucei, Acta Trop., 2017, 176, 58-67.

14 F. Ranjbarian, M. Vodnala, K. Alzahrani, G. Ebiloma, H. Koning and A. Hofer, 9 -(2'-Deoxy-2'-fluoro- $\beta$-D-Arabinofuransosyl)adenine is a potent antitrypanosomal adenosine analogue that circumvents transport-related drug resistance, Antimicrob. Agents Chemother., 2017, 61, e02719-16.

15 L. MacLean, H. Reiber, P. Kennedy and J. Sternberg, Stage progression and neurological symptoms in Trypanosoma brucei rhodesience sleeping sickness: role of the CNS inflammatory response, PLOS Negl. Trop. Dis., 2012, 6, e1857.

16 P. Kennedy, The continuing problem of human African trypanosomiasis (sleeping sickness), Ann. Neurol., 2008, 64, 116-126.

17 N. Tiberti, A, Hainard and J.-C. Sanchez, Translation of human African trypanosomiasis biomarkers towards field application, Transl. Prot., 2013, 12, 12-24.

18 P. Babokhov, A. Sanyaolu, W. Oyibo, A. Fagbenro-Beyioku and N. Iriemenam, A current analysis of chemotherapy strategies for the treatment of human African trypanosomiasis, Pathog. Glob. Health, 2013, 107, 242-252.

19 J. Song, N. Baker, M. Rothert, B. Henke, L. Jeacock, D. Horn and E. Beitz, Pentamidine is not a permeant but a nanomolar inhibitor of the Trypanosoma brucei aquaglyceroporin-2, PLOS Pathog., 2016, 12, e1005436.

20 E. Alirol, D. Schrumpf, J. Amici Heradi, A. Riedel, C. de Patoul, M. Quere and F. Chappuis, Nifurtimox-eflornithine combination therapy for second-stage gambiense human African trypanosomiasis: Médecins San Frontières experience in the Democratic Republic of Congo, Clin. Infect. Dis., 2013, 56, 195-203.

21 R. Jacobs, B. Nare and M. Phillips, State of the art in African trypanosome drug discovery, Curr. Top. Med. Chem., 2011, 11, 1255-1274.

22 M. Barrett, D. Boykin, R. Brun and R. Tidwe, Human African trypanosomiasis: pharmacological re-engagement with a neglected disease, Br. J. Pharmacol., 2007, 152, 1155-1171.

23 D. Malvy and F. Chappuis, Sleeping sickness, Clin. Microbiol. Infect., 2011, 17, 986-995.

24 G. Pohlig, S.C. Bernhard, J. Blum, C. Burri, A. Mpanya, J.-P. Fina Lubaki, A. Mpoto, B. Munungu, M. Bilenge, V. Mesu, J. Franco, N. Dituvanga, R. Tidwell and C. Olson, Efficacy and safety of pafuramidine versus pentamidine maleate for treatment of first stage sleeping sickness in a randomized, comparator-controlled, international phase 3 clinical trial, PLOS Negl. Trop. Dis., 2016, 10, e0004363.

25 P. Kennedy, Clinical features, diagnosis, and treatment of human African tripanosomiasis (sleeping sickness), Lancet Neurol., 2013, 12, 186-194.

26 C. Burri, Chemotherapy against human African tripanosomiasis: Is there a road to success?, Parasitol., 2010, 137, 1987-1994.

27 R. Beteck, F. Smit, R. Haynes and D. N'Da, Recent progress in the development of anti-malarial quinolones, Mal. J., 2014, 13, 339.

28 E. Nenortas, C. Burri and T. Shapiro, Antitrypanosomal activity of fluoroquinolones, Antimicrob. Agents Chemother., 1999, 43, 2066-2068.

29 J. Keiser and C. Burri, Antitrypanosomal activities of fluoroquinolones with pyrrolidinyl substitutions, Trop. Med. Inter. Health., 2001, 6, 369-389.

30 E. Nenortas, C. Burri, T. Kulikowicz and T. Shapiro, Antitrypanosomal activities of fluoroquinolones with pyrrolidinyl substitutions, Antimicrob. Agents Chemother., 2003, 47, 3015-3017.

31 G. Hiltensperger, N. Jones, S. Niedermeier, A. Stich, M. Kaiser, J. Jung, S. Puhl, A. Damme, H. Braunschweig, L. Meinel, M. Engstler and U. Holzgrabe, Synthesis and structure-activity relationships of new quinolone-type molecules against Trypanosoma brucei, J. Med. Chem., 2012, 55, 2538-2548.

32 A. Wube, A. Hüfner, W. Seebacher, M. Kaiser, R. Brun, R. Bauer and F. Bucar, 1,2-Substituted 4-(1H)-quinolones: synthesis, antimalarial and antitrypanosomal activities in vitro, Molecules, 2014, 19, 14204-142020.

33 A. Gamble, J. Garner, C. Gordon, S. Conner and P. Keller, Aryl nitro reduction with iron powder or stannous chloride under ultrasonic irradiation, Syn. Comm., 2007, 37, 2777-2786.

34 Richard M. Beteck, D. Coertzen, FJ. Smit, L.-M. Birkholtz, R.K. Haynes and D.D. N'Da, Straightforward conversion of decoquinate into inexpensive tractable new derivatives with significant antimalarial activities, Boorg. Med. Chem. Lett., 2016, 26, 3006-3009.

$35 \mathrm{H}$. Hirumi and K. Hirumi, Continous cultivation of Trypanosoma brucei blood stream forms in a medium containing a low concentration of serum protein without feeder cell layers, J. Parasitol., 1989, 75, 985-989. 


\section{Supplementary material to:}

R.M. Beteck, M. Isaacs, H.C. Hoppe and S.D. Khanye,

Synthesis, in vitro Cytotoxicity and Trypanocidal Evaluation of Novel 1,3,6-Substituted Non-fluoroquinolones

S. Afr. J. Chem., 2018, 71, 188-195. 


\title{
Synthesis, in vitro cytotoxicity and trypanocidal evaluation of novel 1,3,6-substituted non-fluoroquinolones.
}

\author{
Richard M. Beteck ${ }^{a, *}$, Michelle Isaacs ${ }^{c}$, Heinrich C. Hoppe ${ }^{b, c}$, Setshaba D. Khanye ${ }^{a, c, d,{ }^{*}}$ \\ ${ }^{a}$ Department of Chemistry, Rhodes University, Grahamstown 6140, South Africa \\ ${ }^{b}$ Department of Biochemistry and Microbiology, Rhodes University, Grahamstown 6140, \\ South Africa
}

${ }^{c}$ Centre for Chemico- and Biomedical Research, Rhodes University, Grahamstown 6140,

South Africa

${ }^{d}$ Faculty of Pharmacy, Rhodes University, Grahamstown 6140, South Africa

* Corresponding Author. Tel.: +27 46603 8397; fax: +27 466037506.

E-mail: R.Beteck@ru.ac.za

* Corresponding Author. Tel.: +27 46603 8397; fax: +27 466037506.

E-mail: s.khanye@ru.ac.za 


\section{NMR $\left({ }^{1} \mathrm{H},{ }^{13} \mathrm{C}\right.$, DEPT135) AND MS SPECTRA AND BIOLOGICAL DATA OF COMPOUNDS}

\section{Compound 3a}

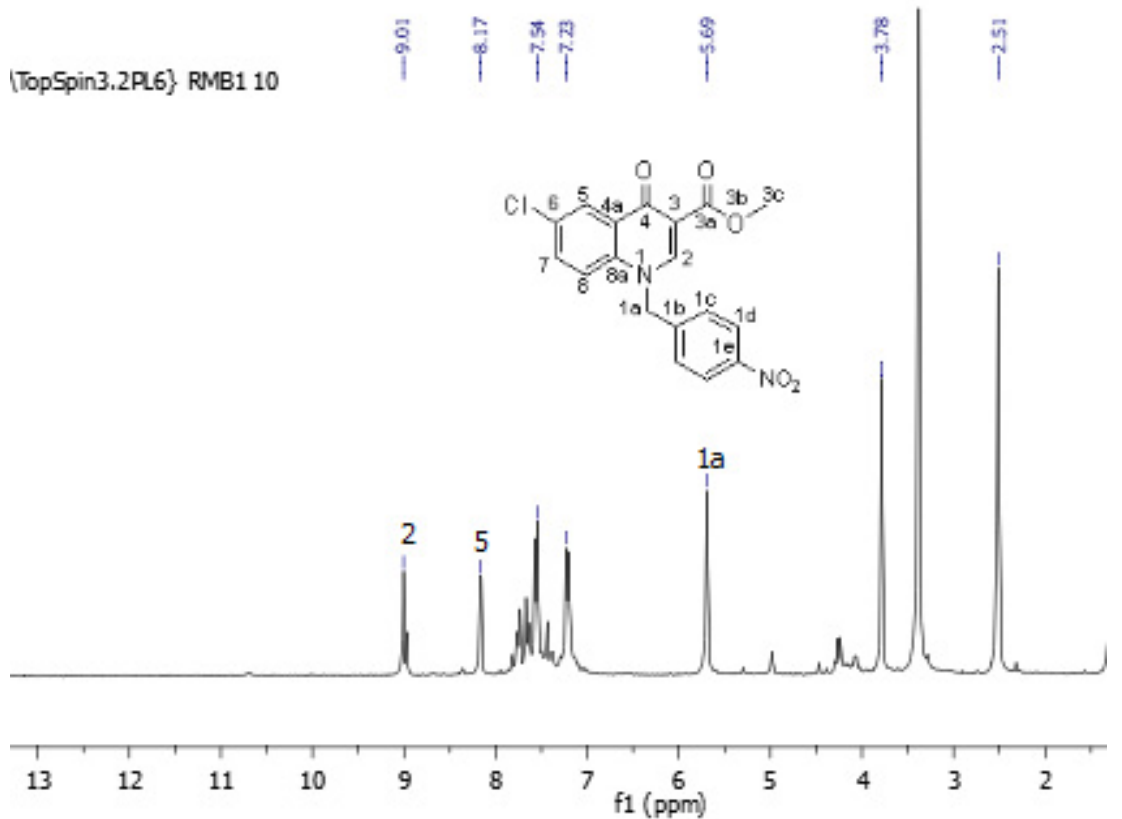

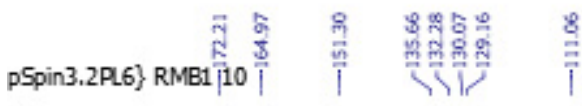
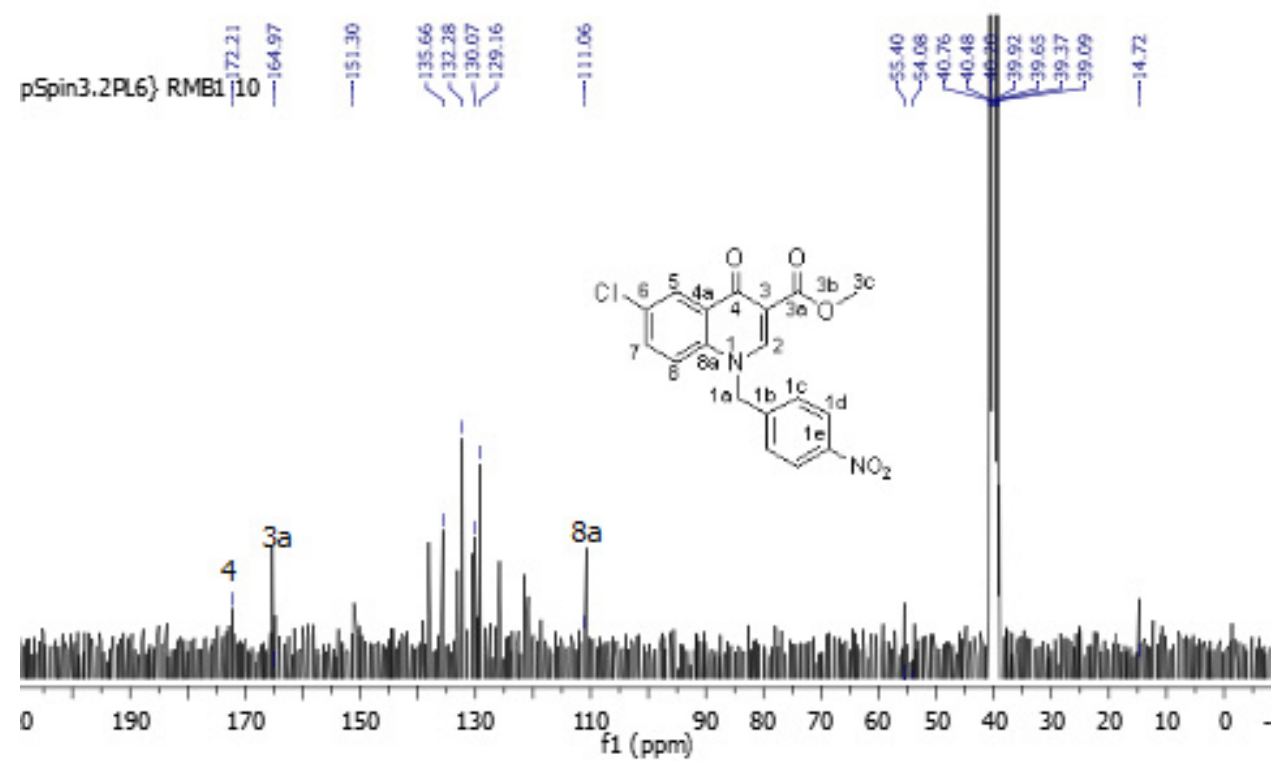

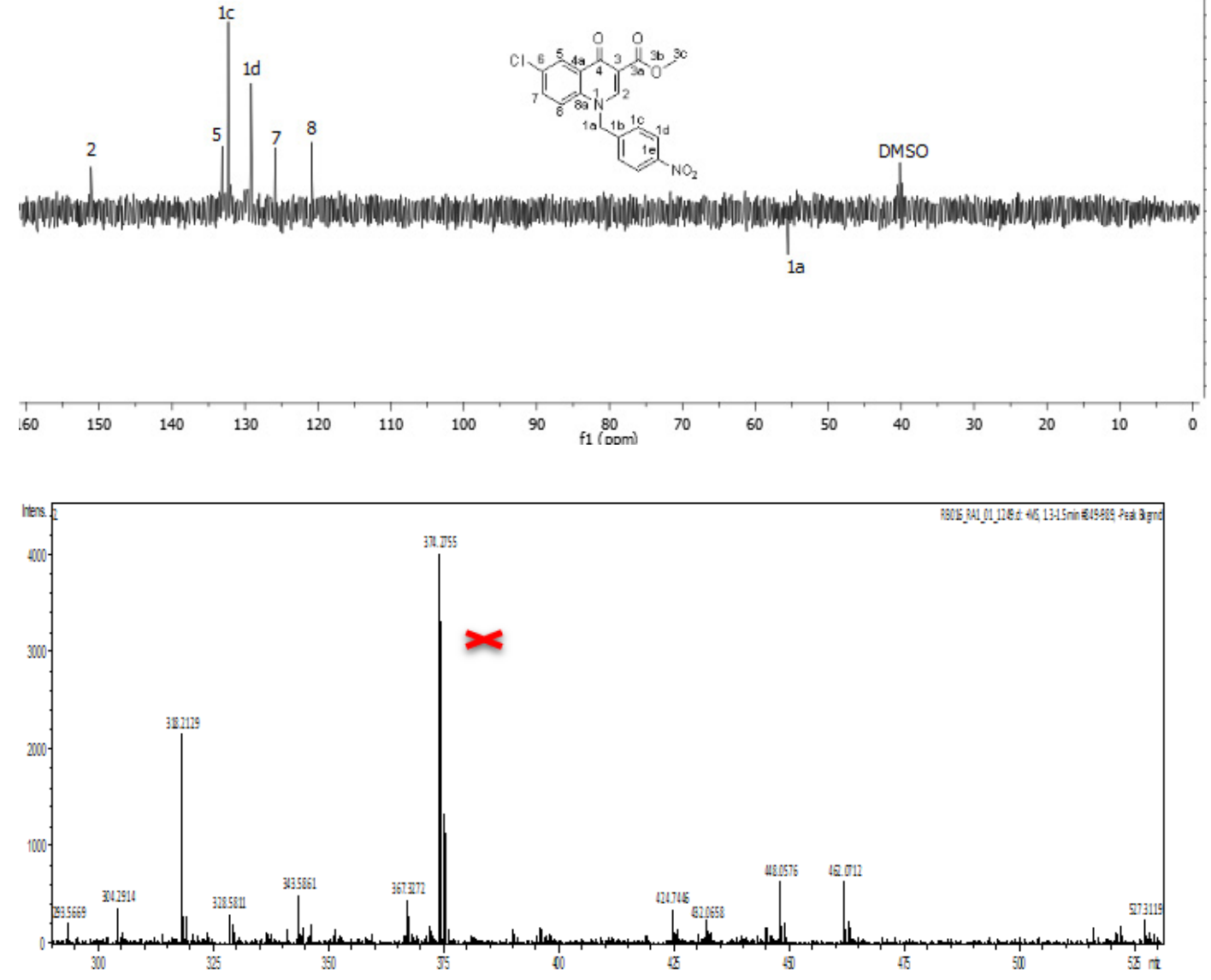

\section{Compound 3b}

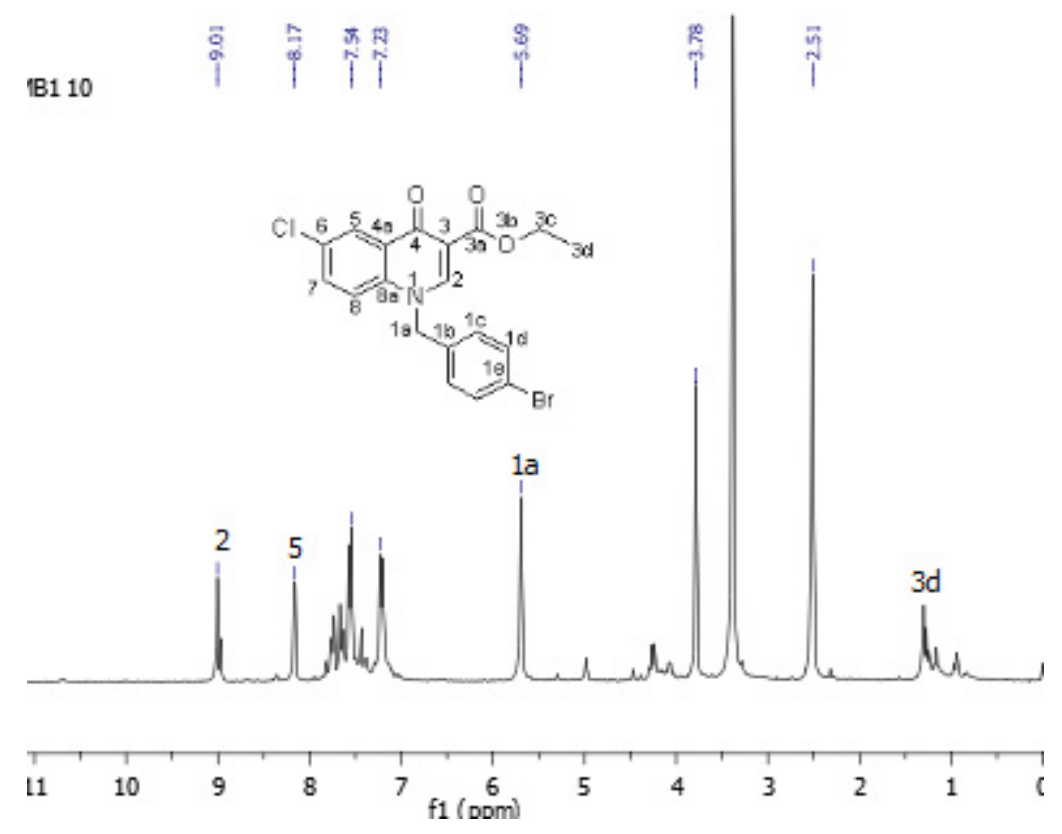




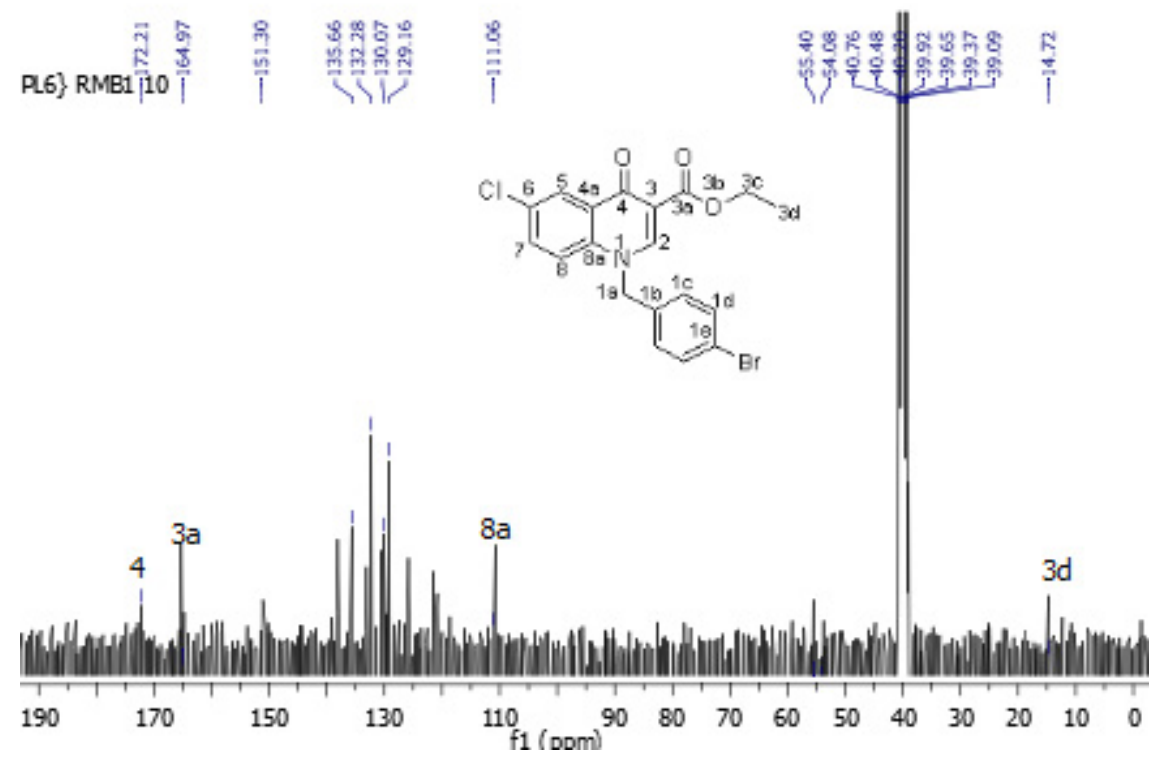

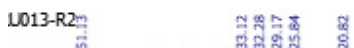

13DEPT1/15 DMSO \{ClBrukes\}Jop'Spin 3.2P, 6\} RMB1 10
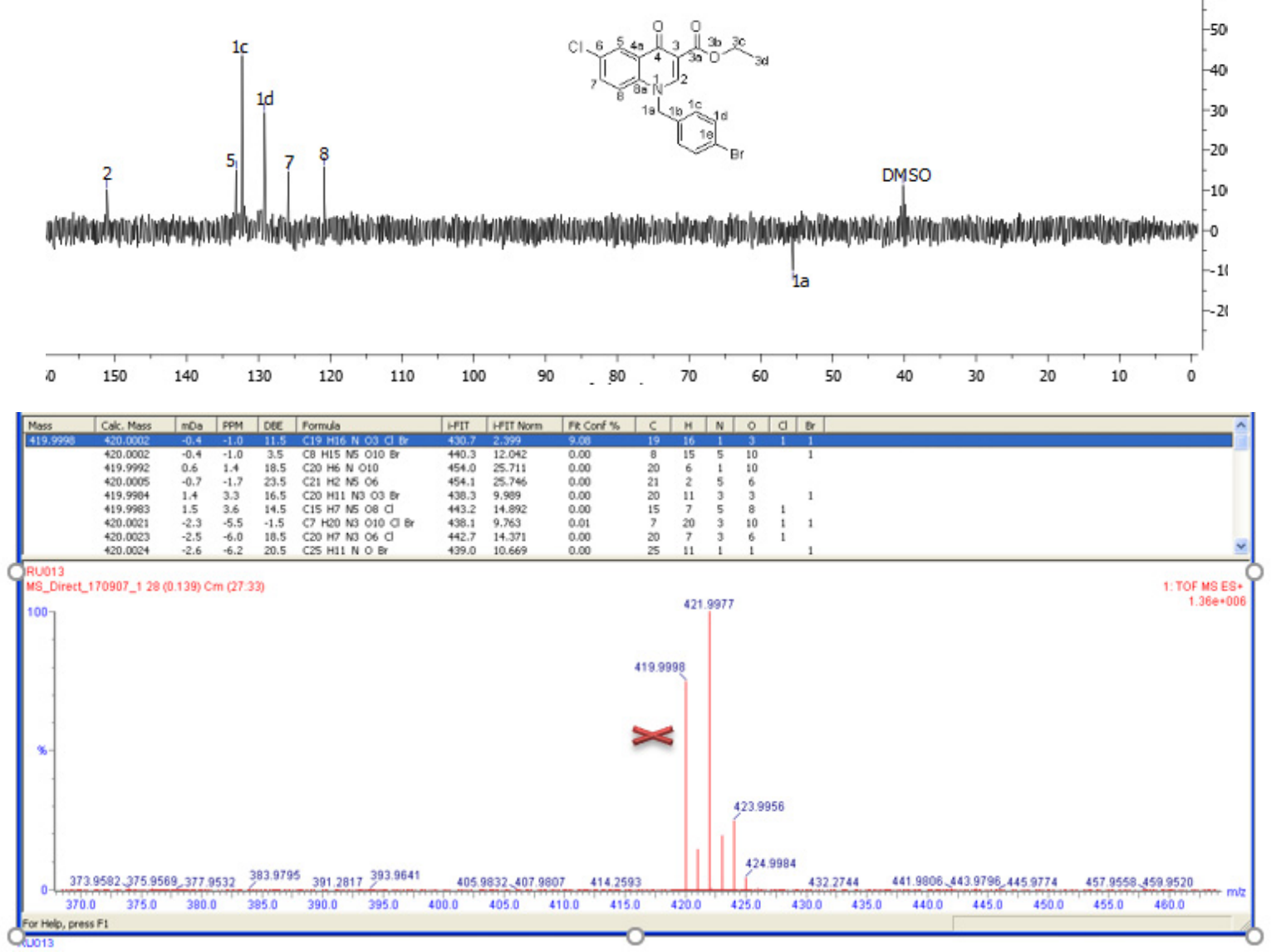


\section{Compound 3c}

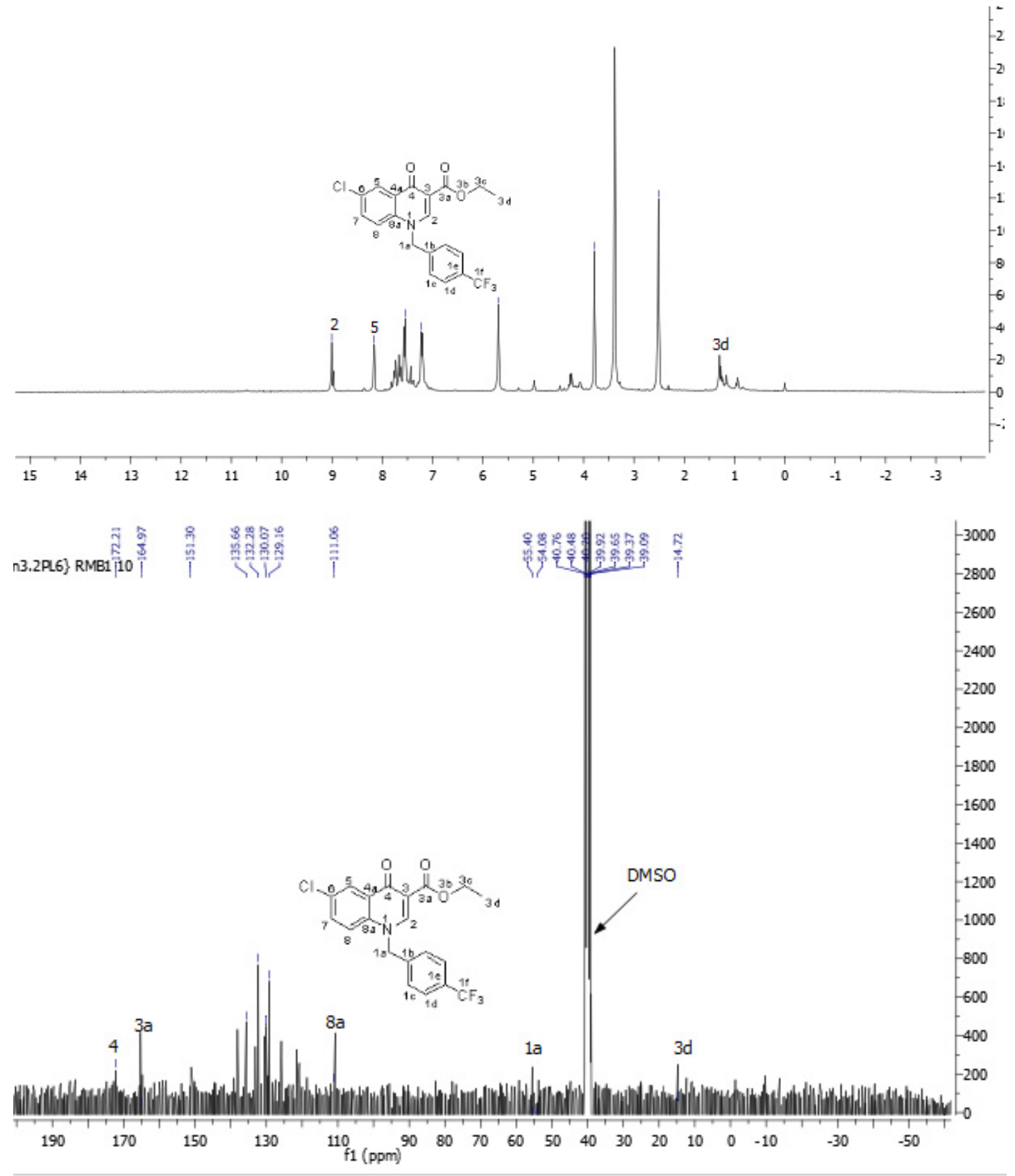



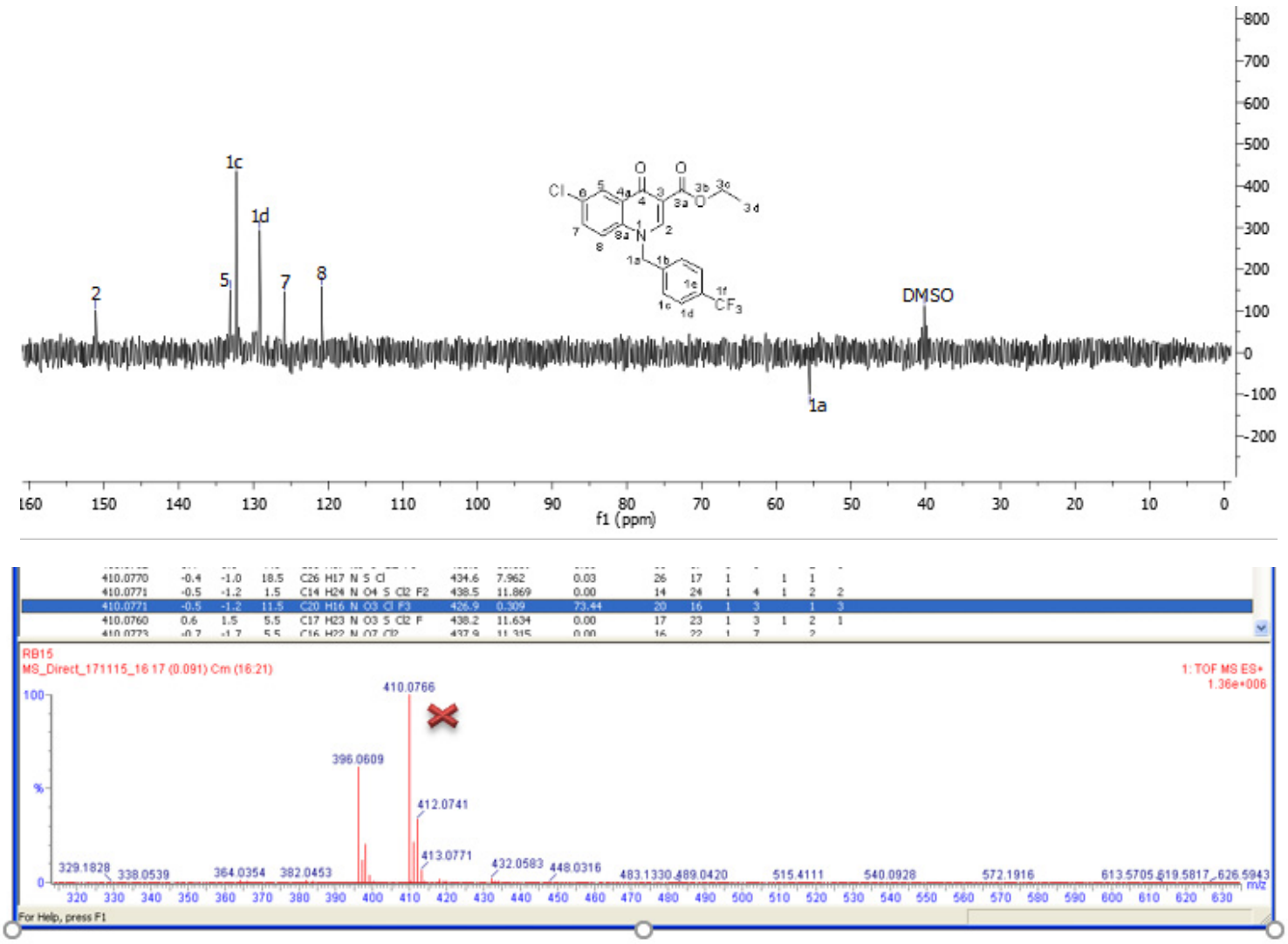

\section{Compound 3d}

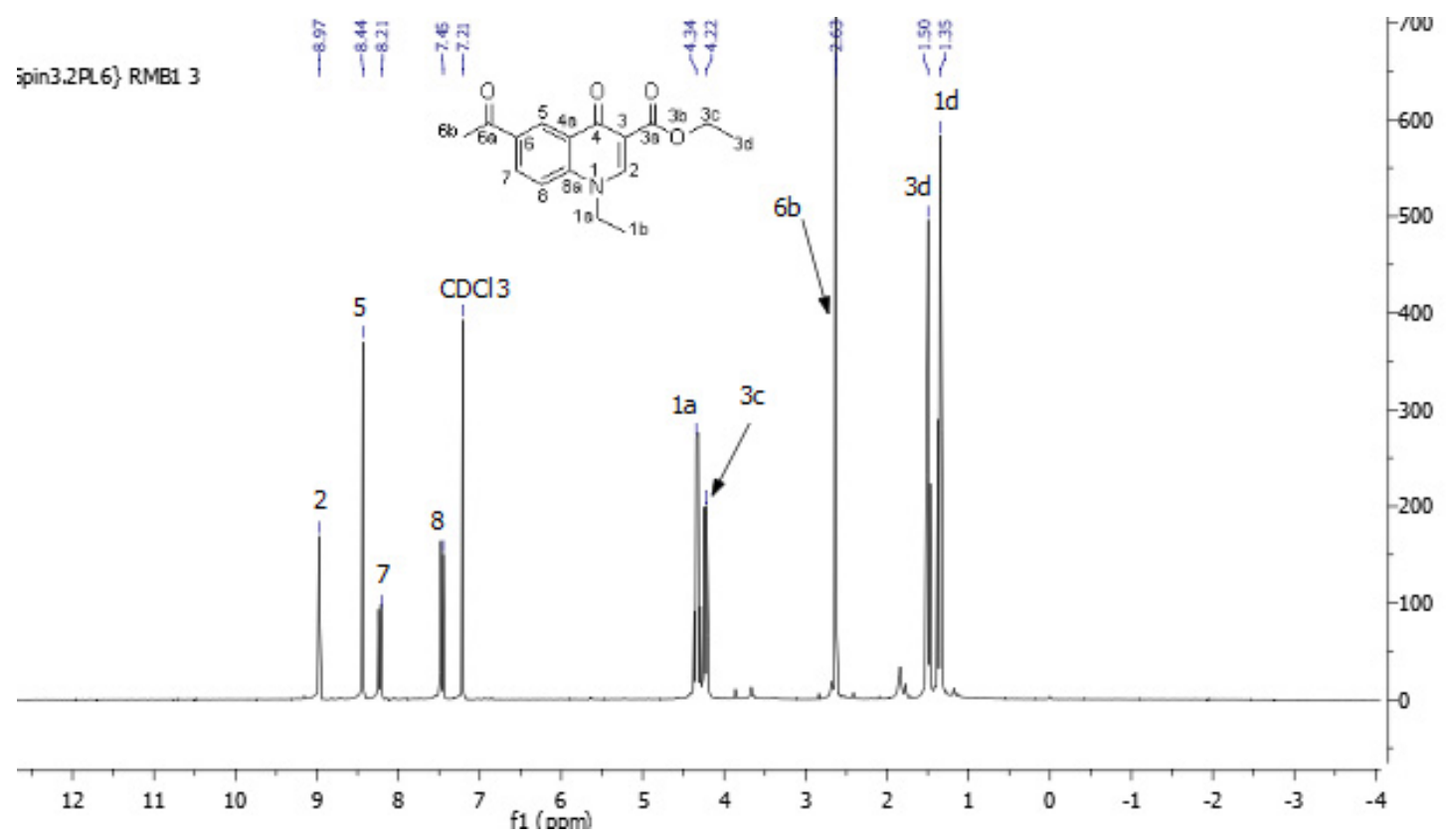



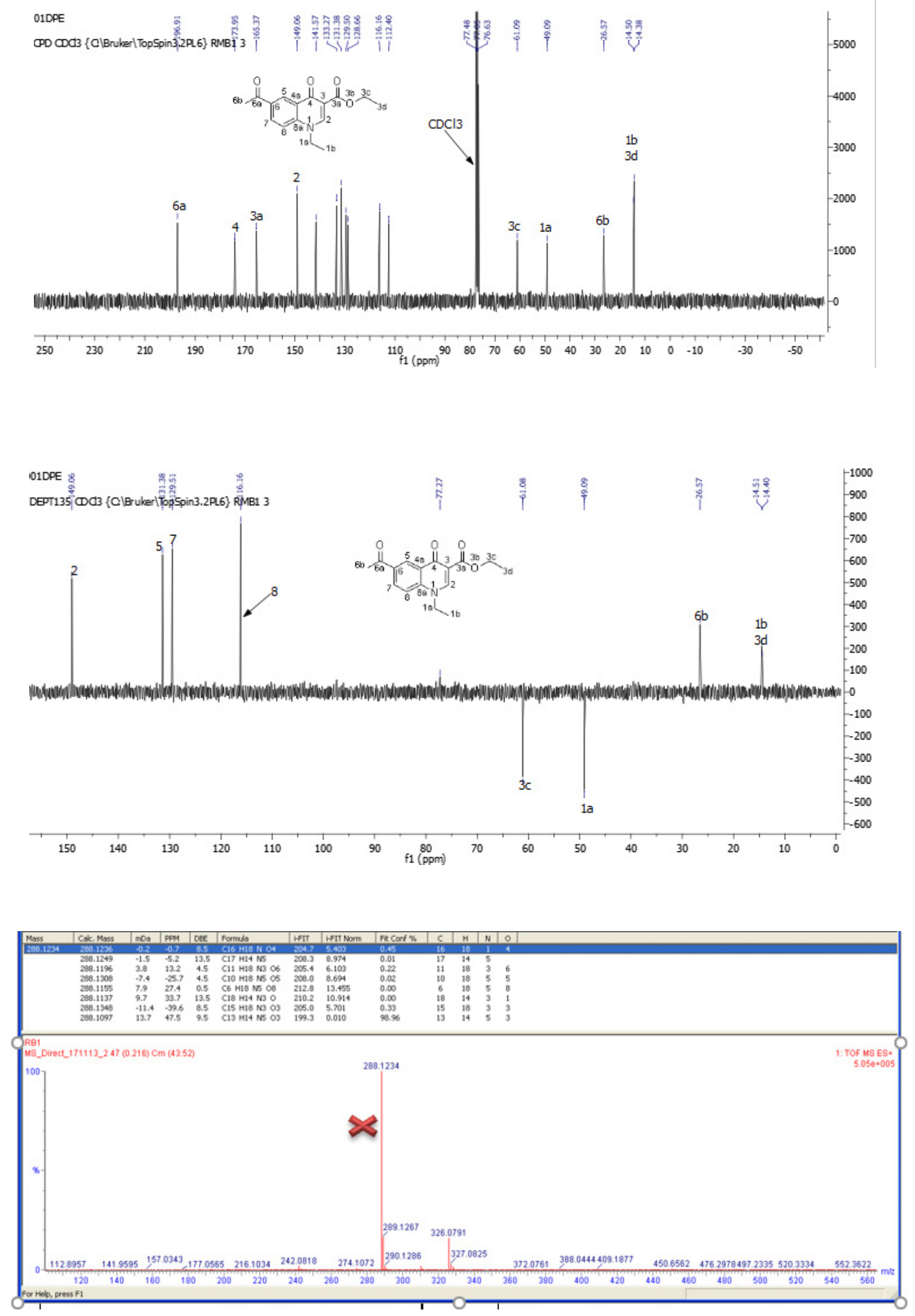


\section{Compound $3 e$}
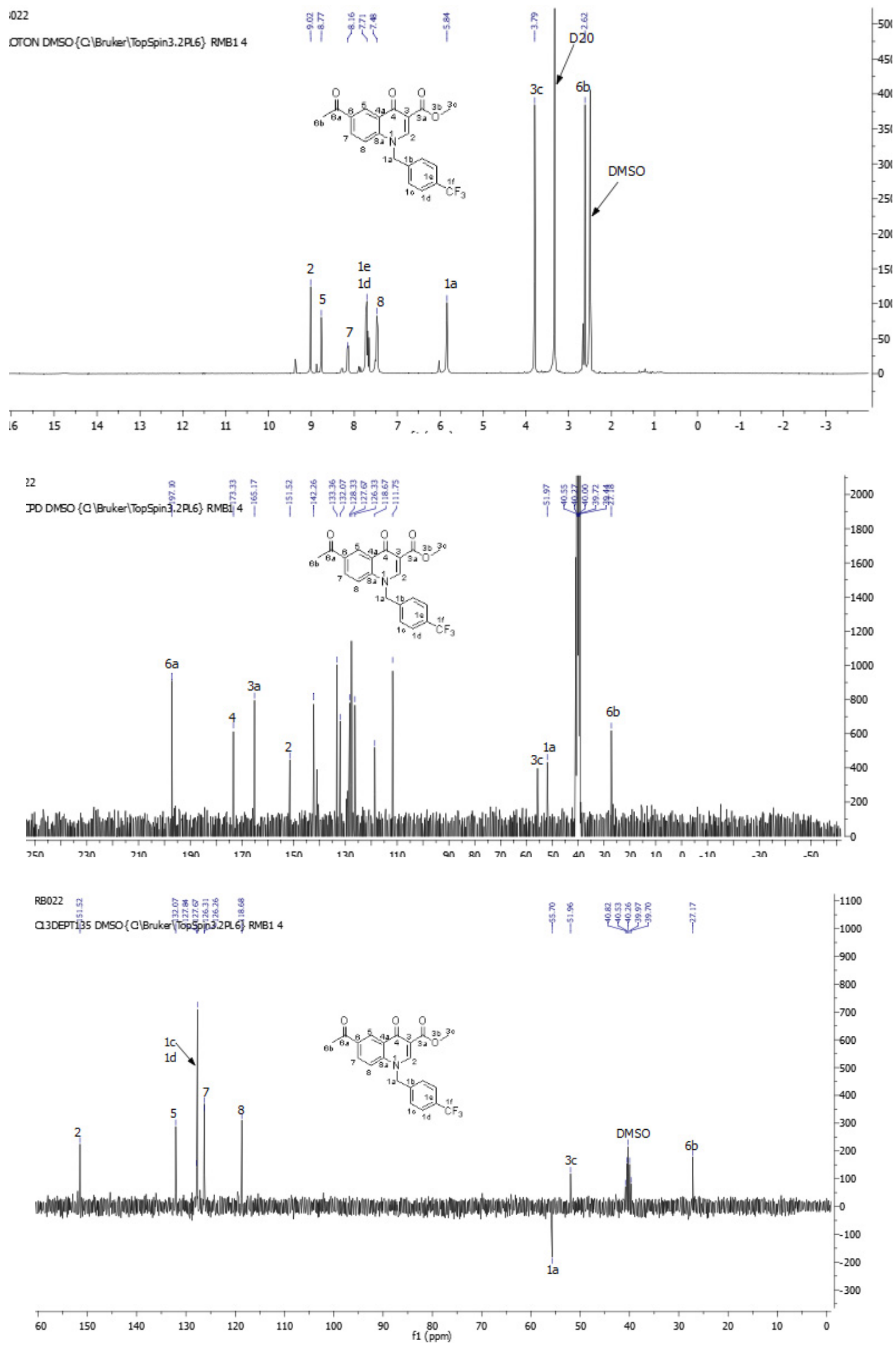


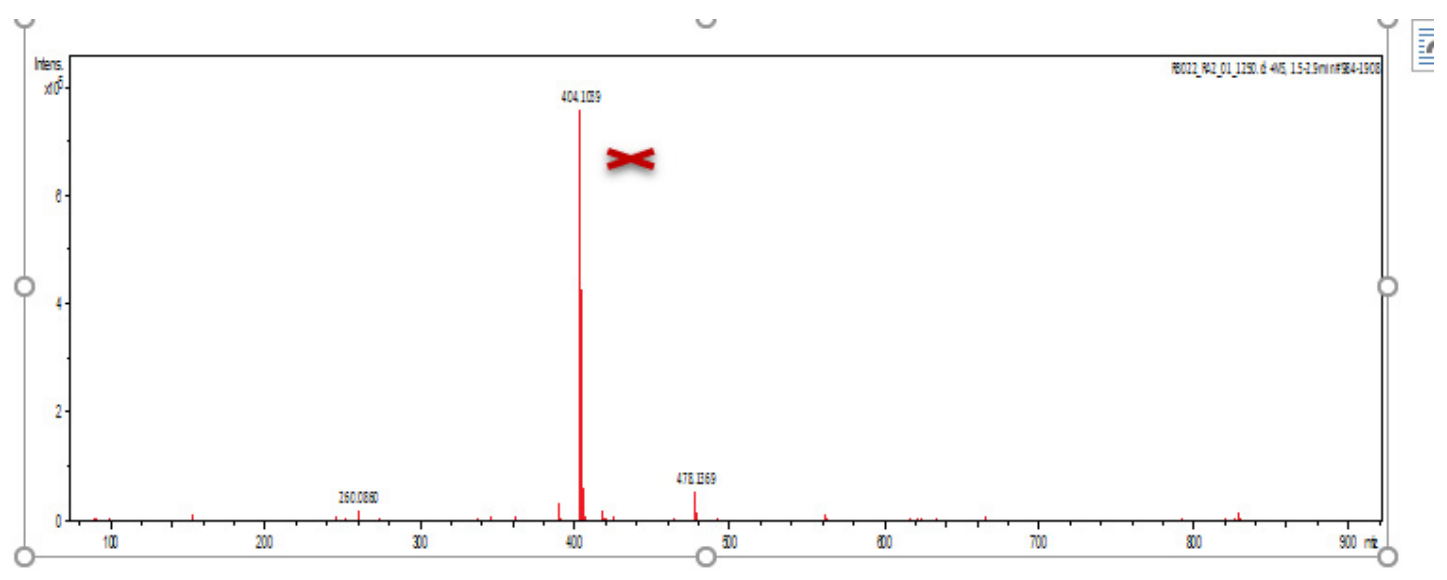

\section{Compound $3 f$}
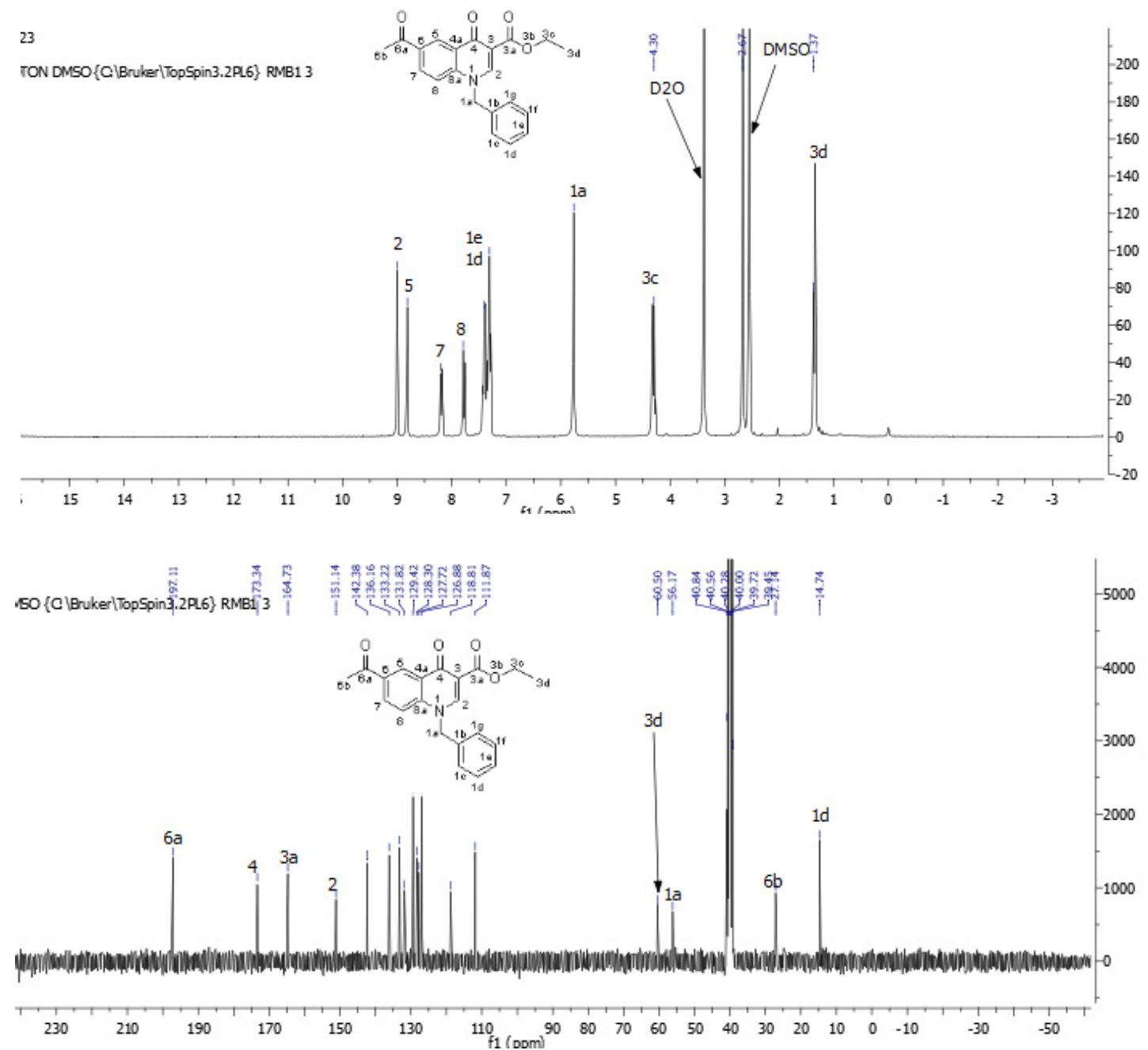


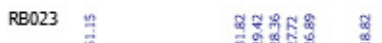

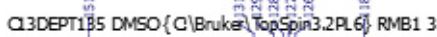
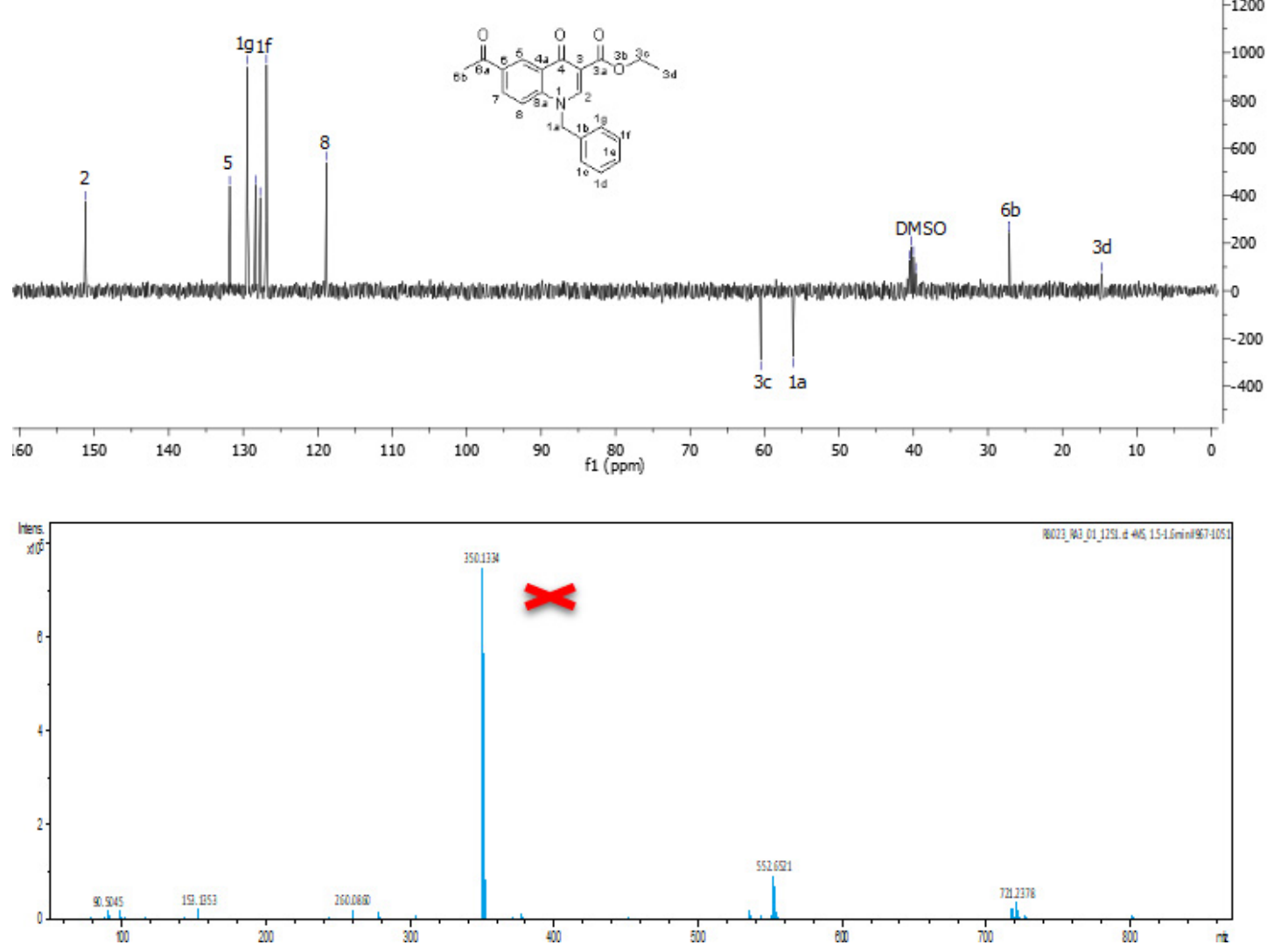

\section{Compound 3g}

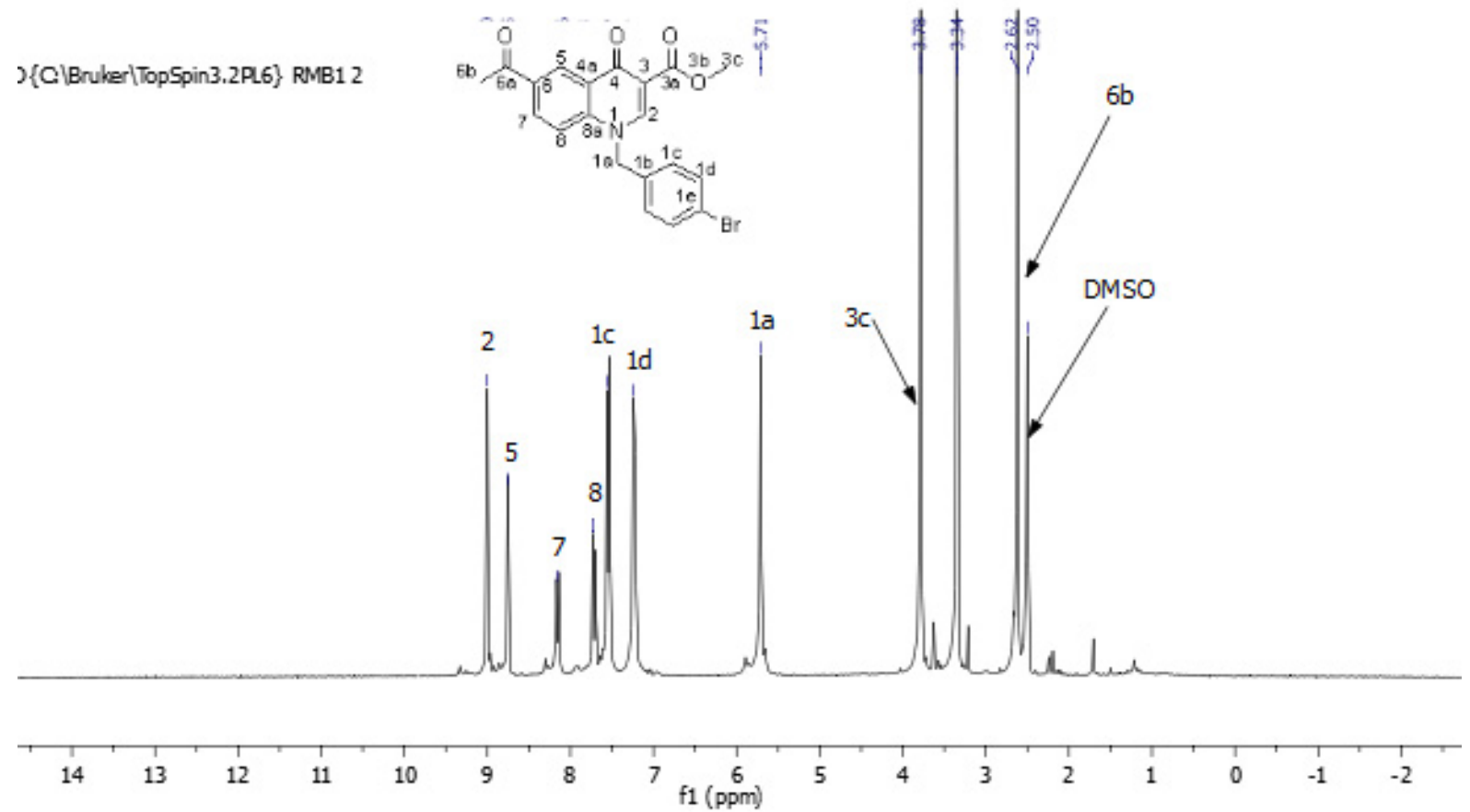



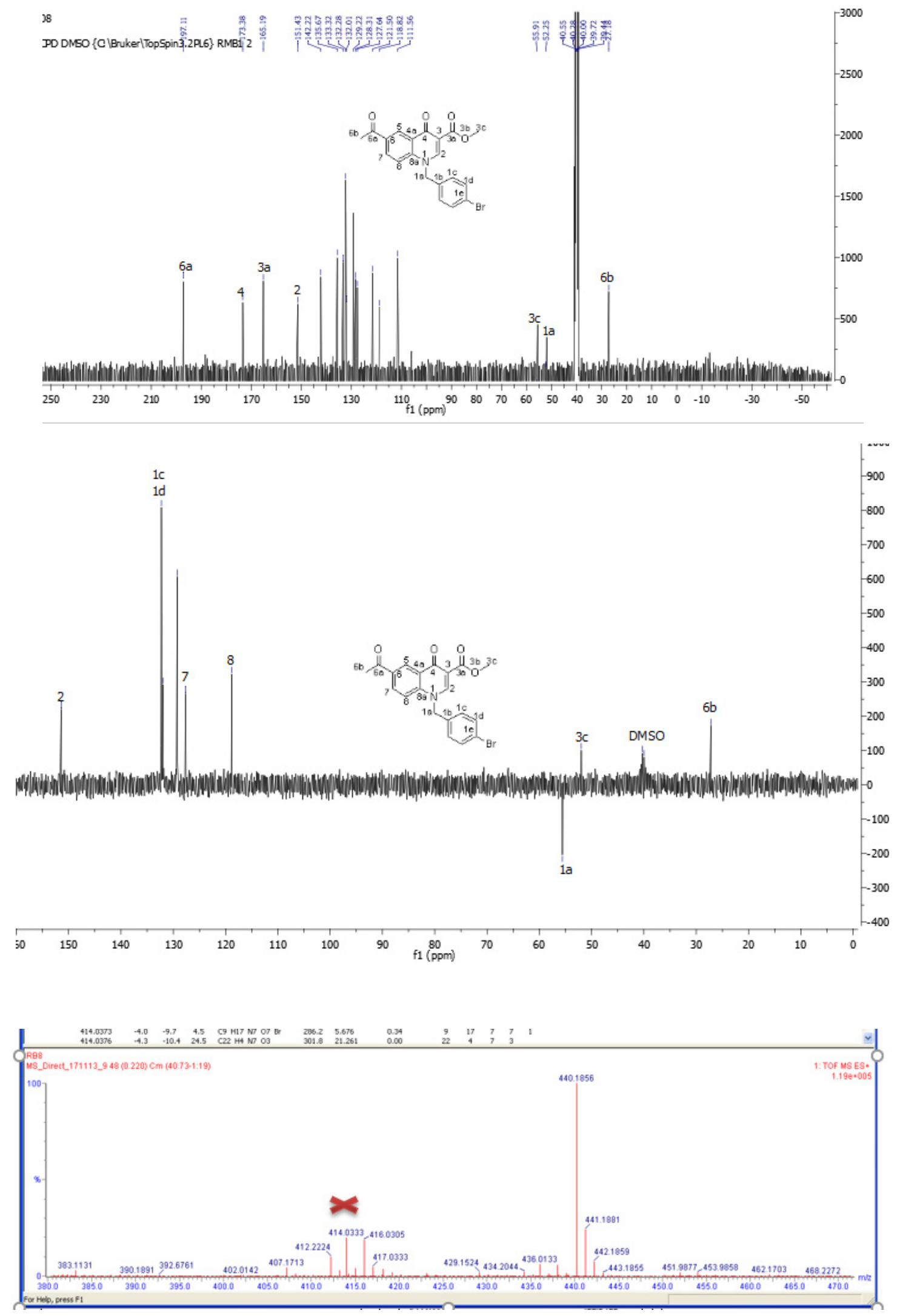


\section{Compound $3 \mathrm{~h}$}
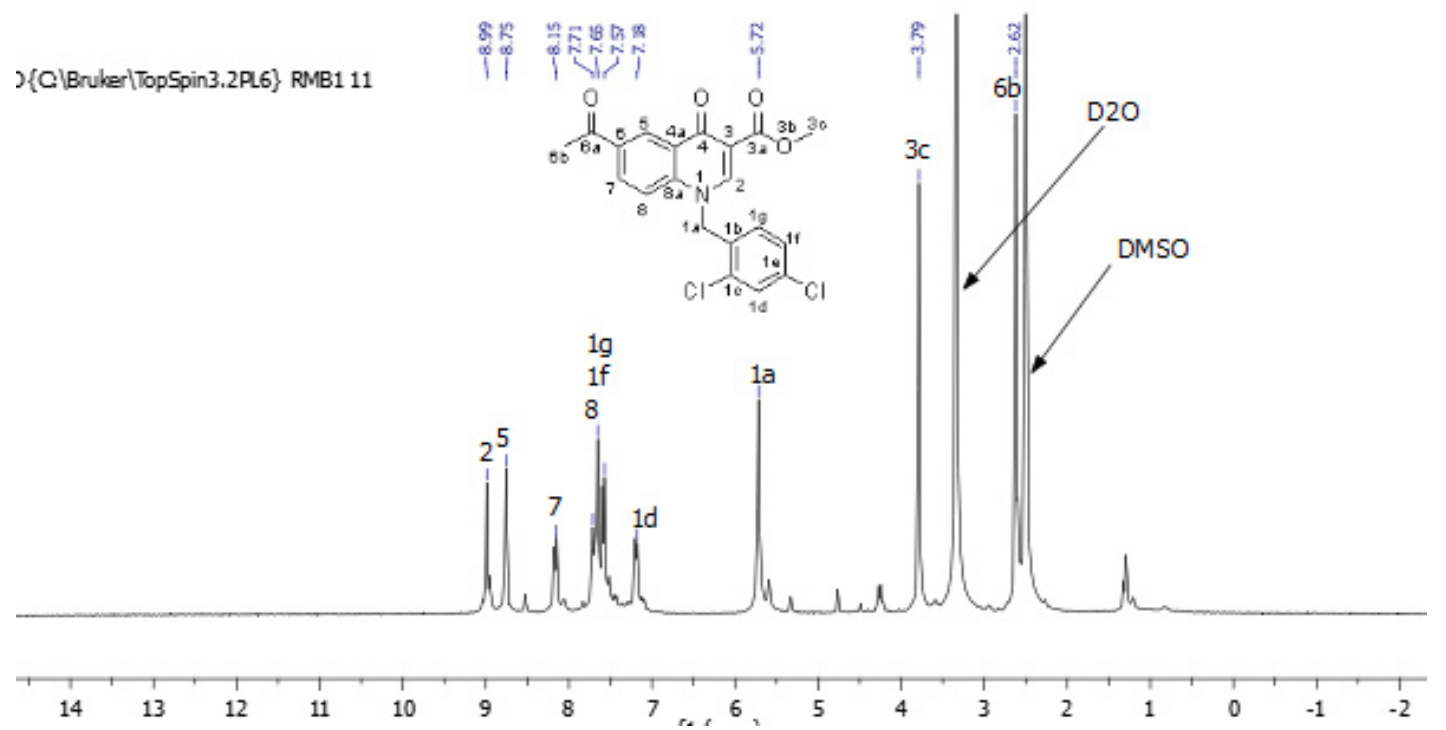

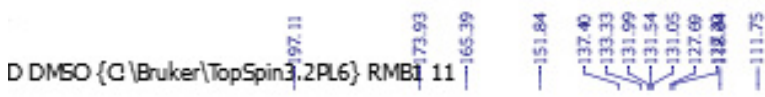
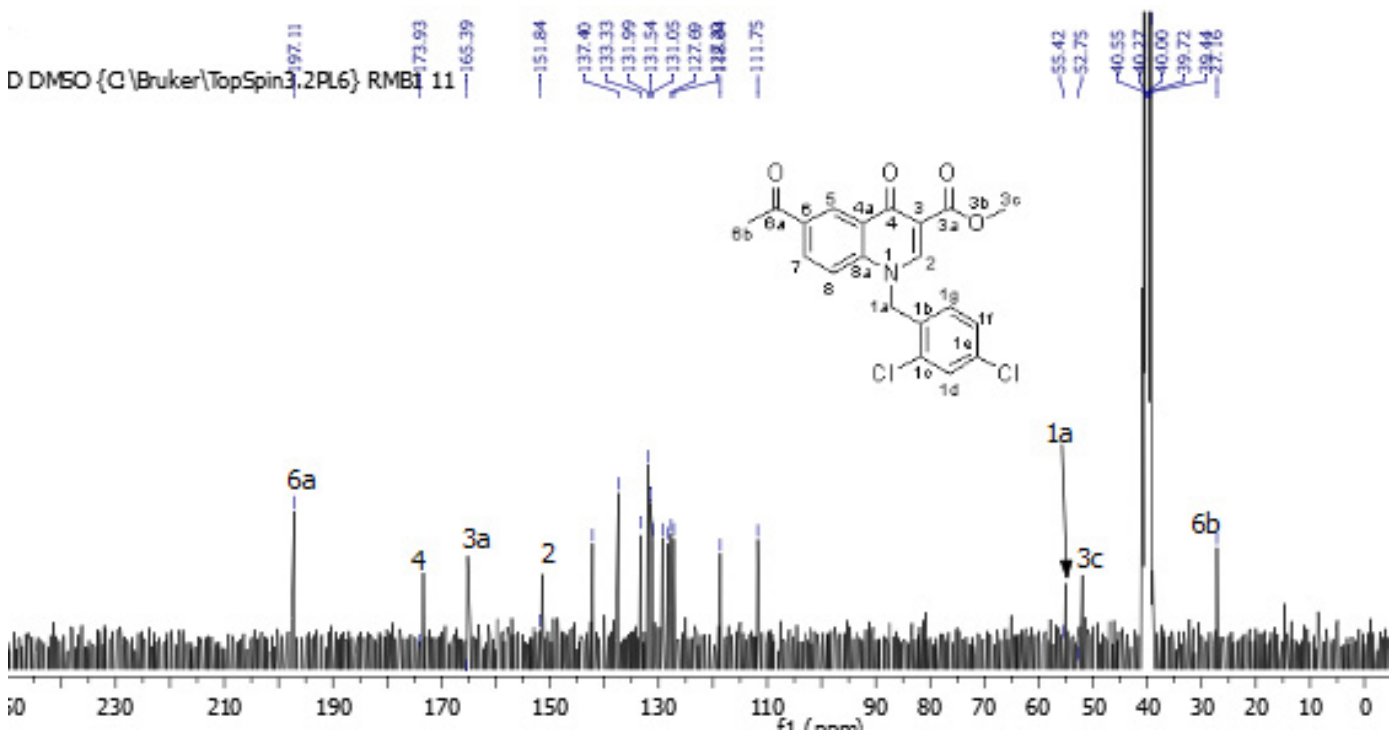

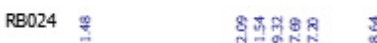

Q3DEPT135 DMSO \{ClBruke\}) Popsoin 3.2PL6\} RMB1 11
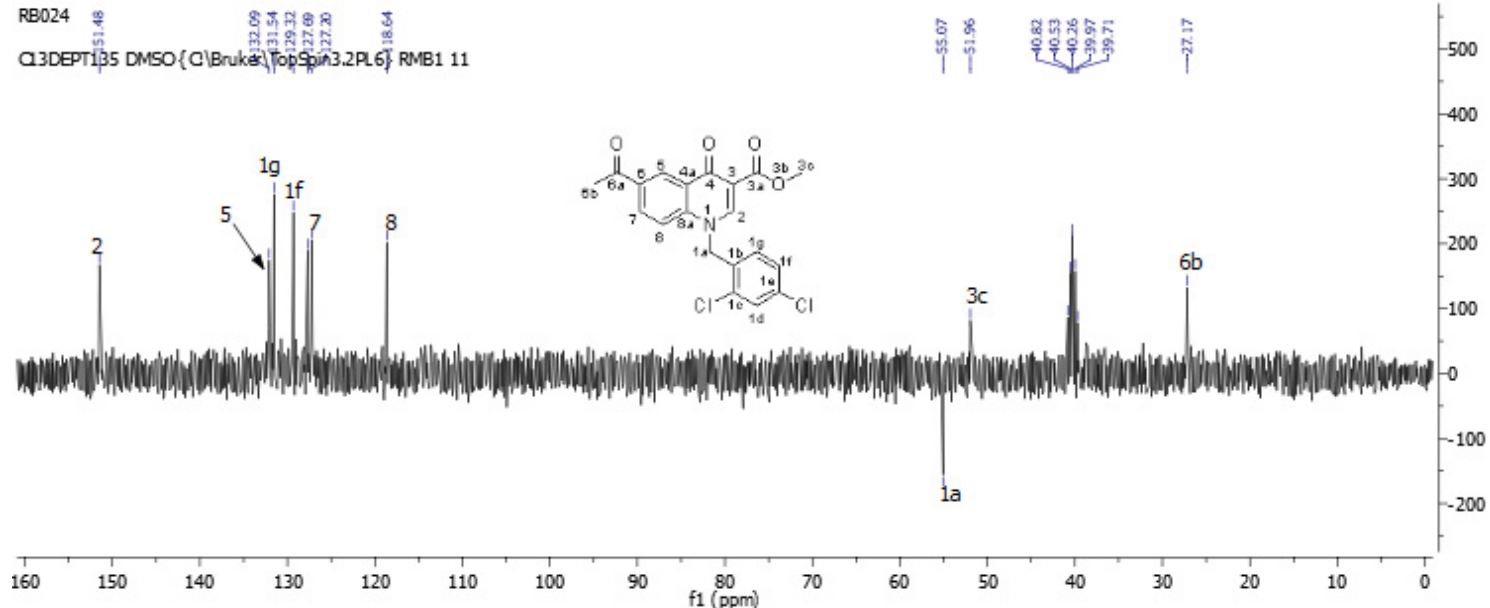


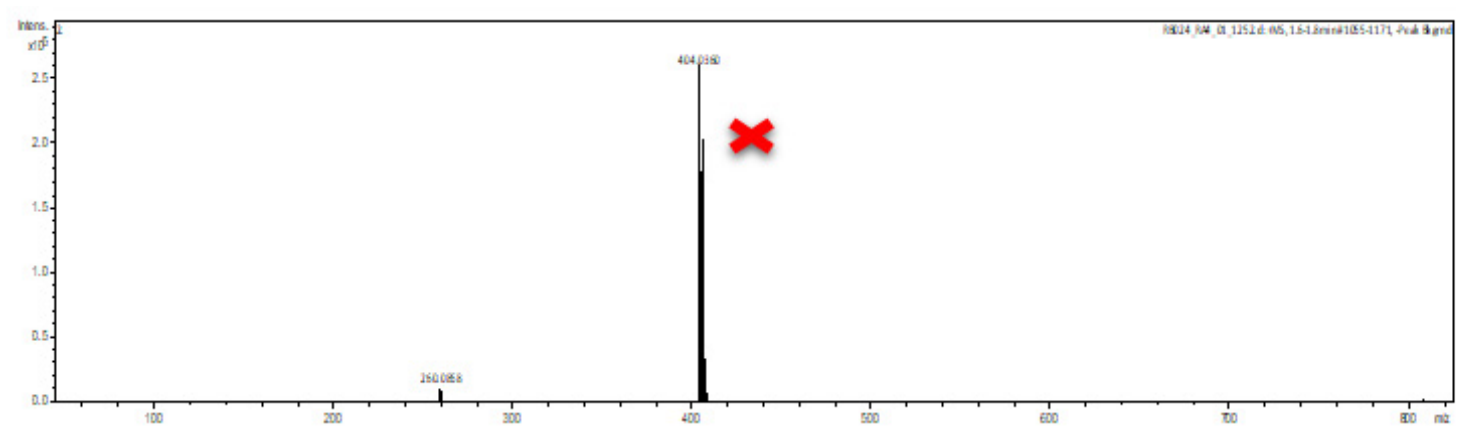

\section{Compound 4a}

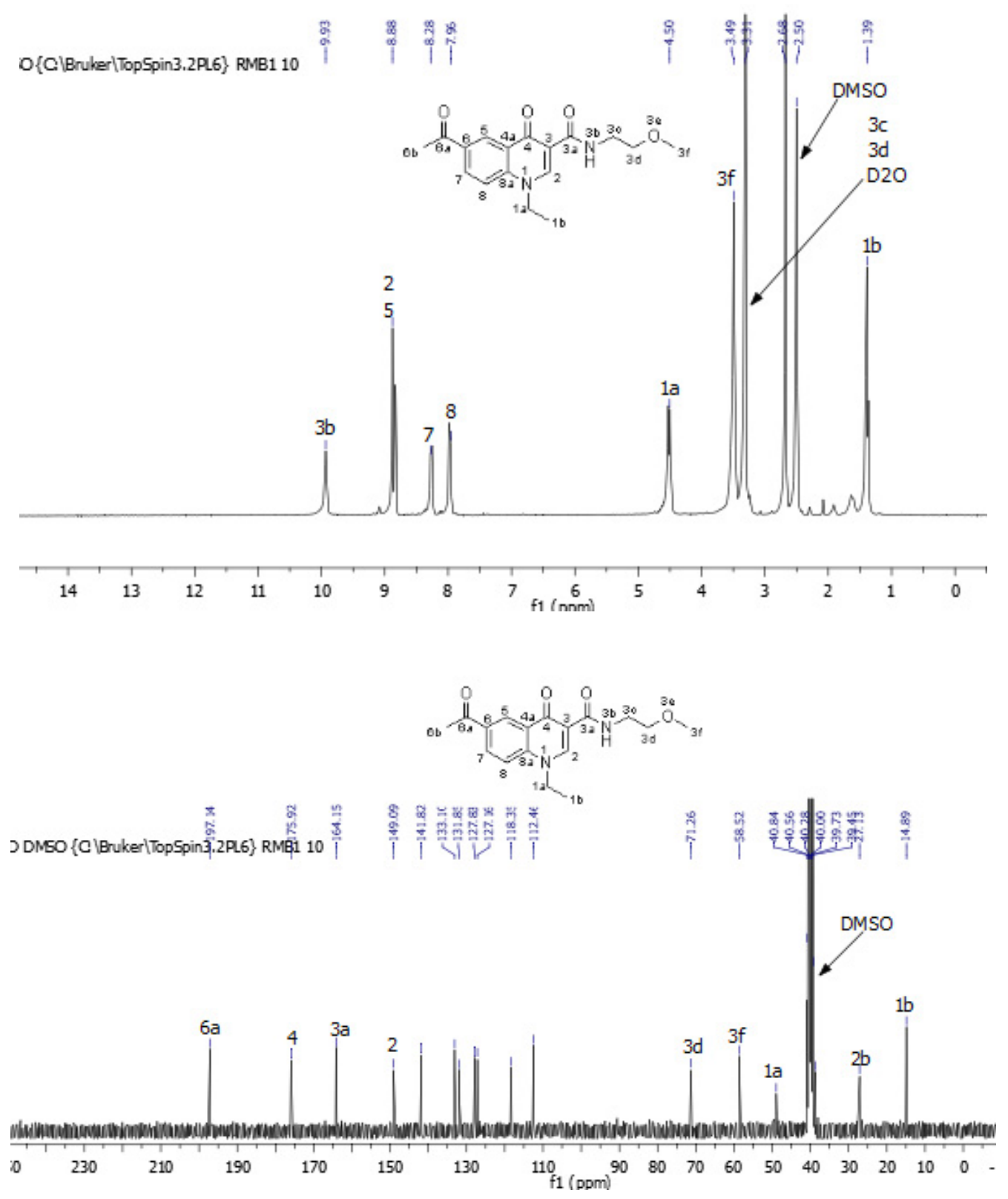




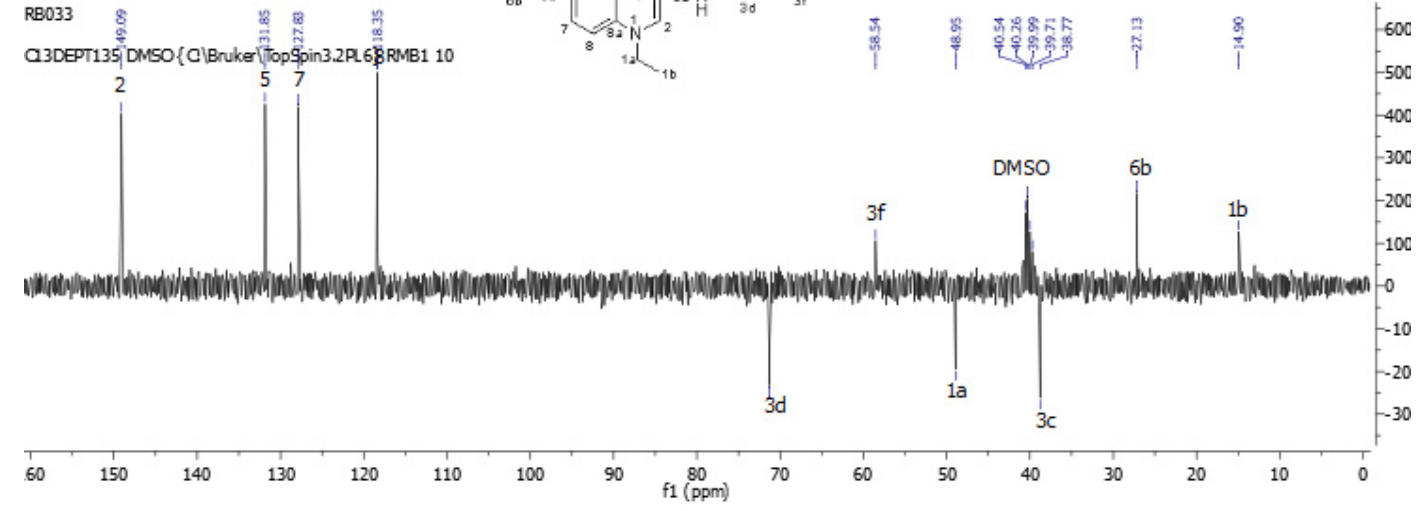

\section{Compound $4 \mathrm{~b}$}
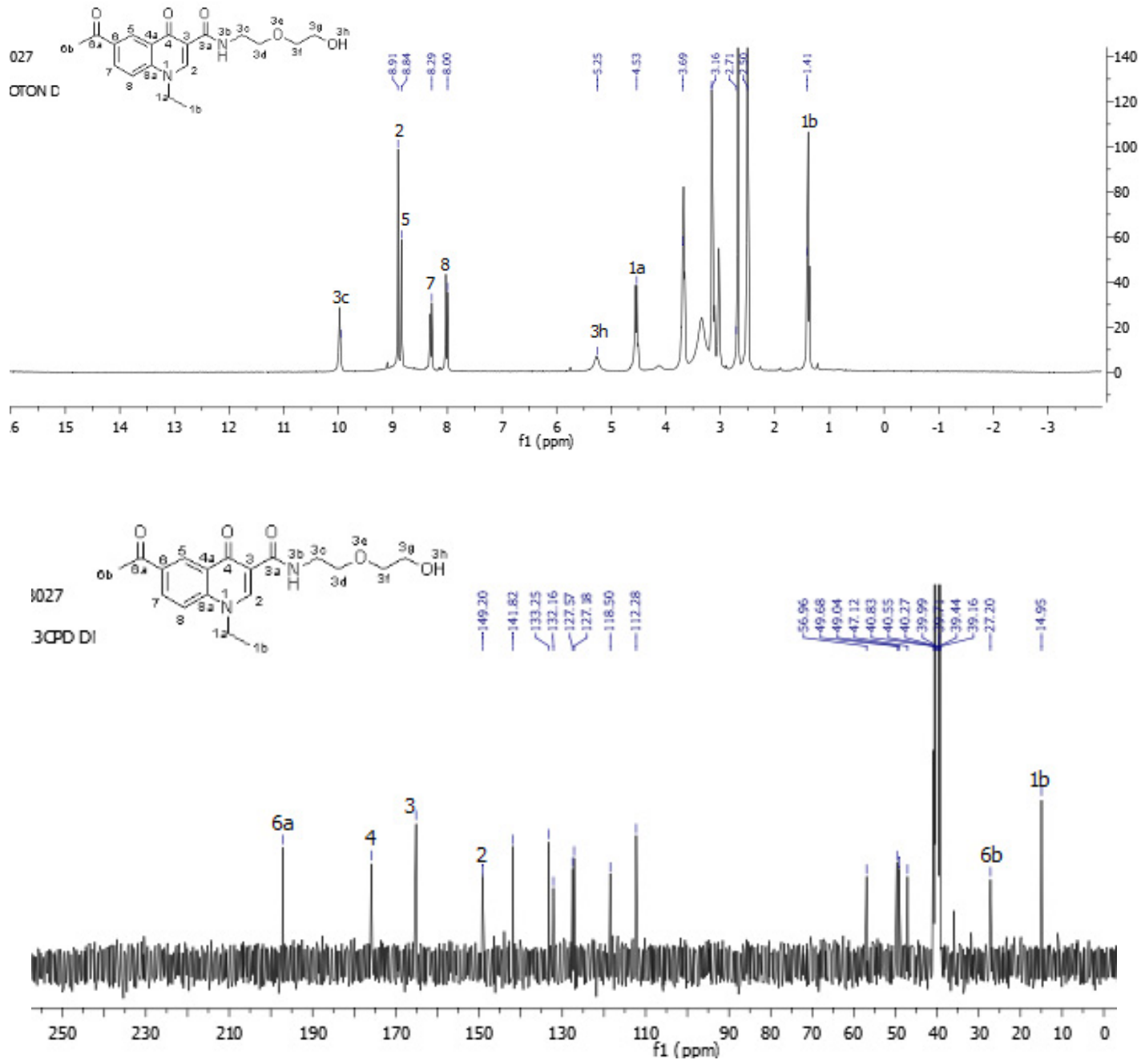

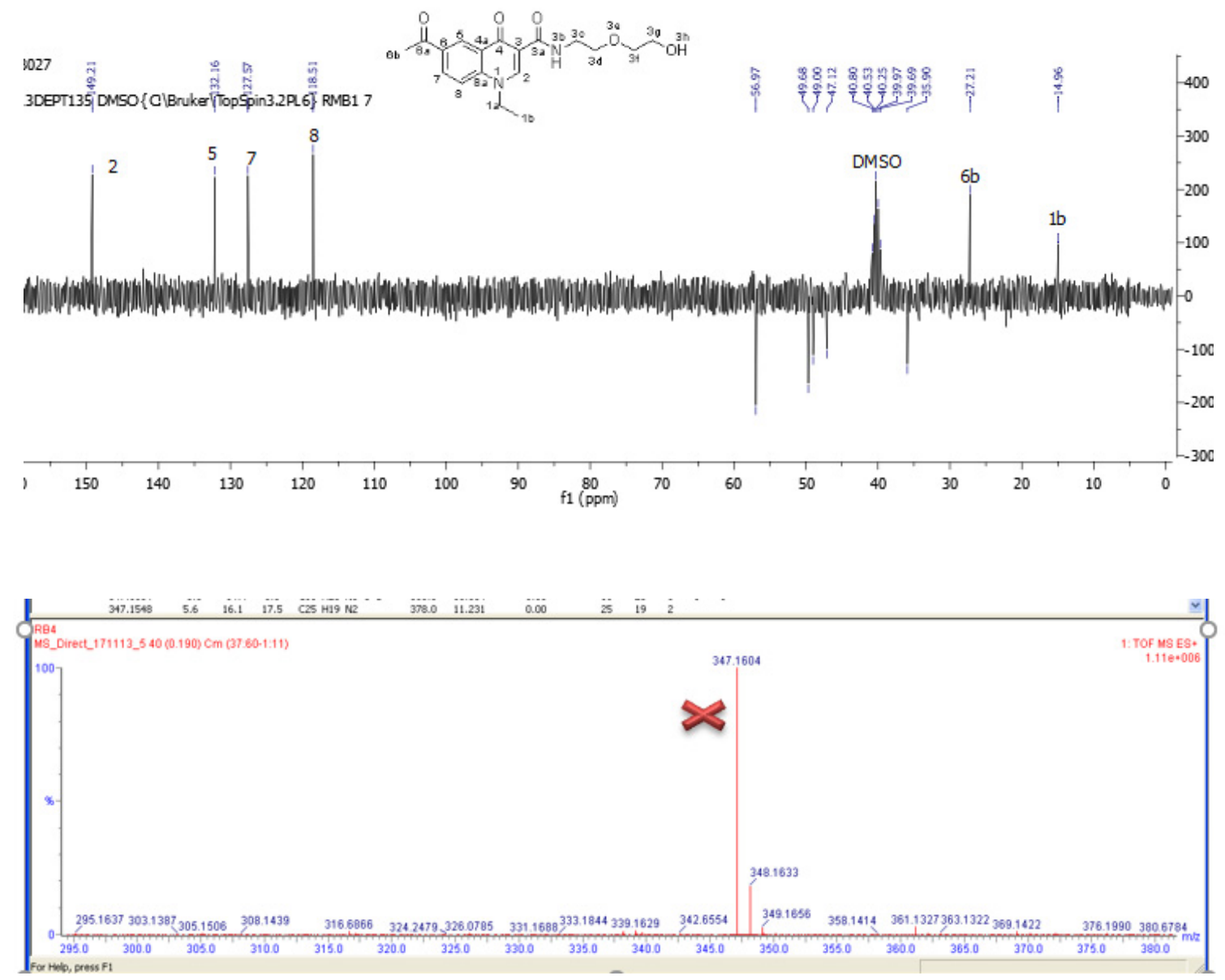

COMPOUND 4C

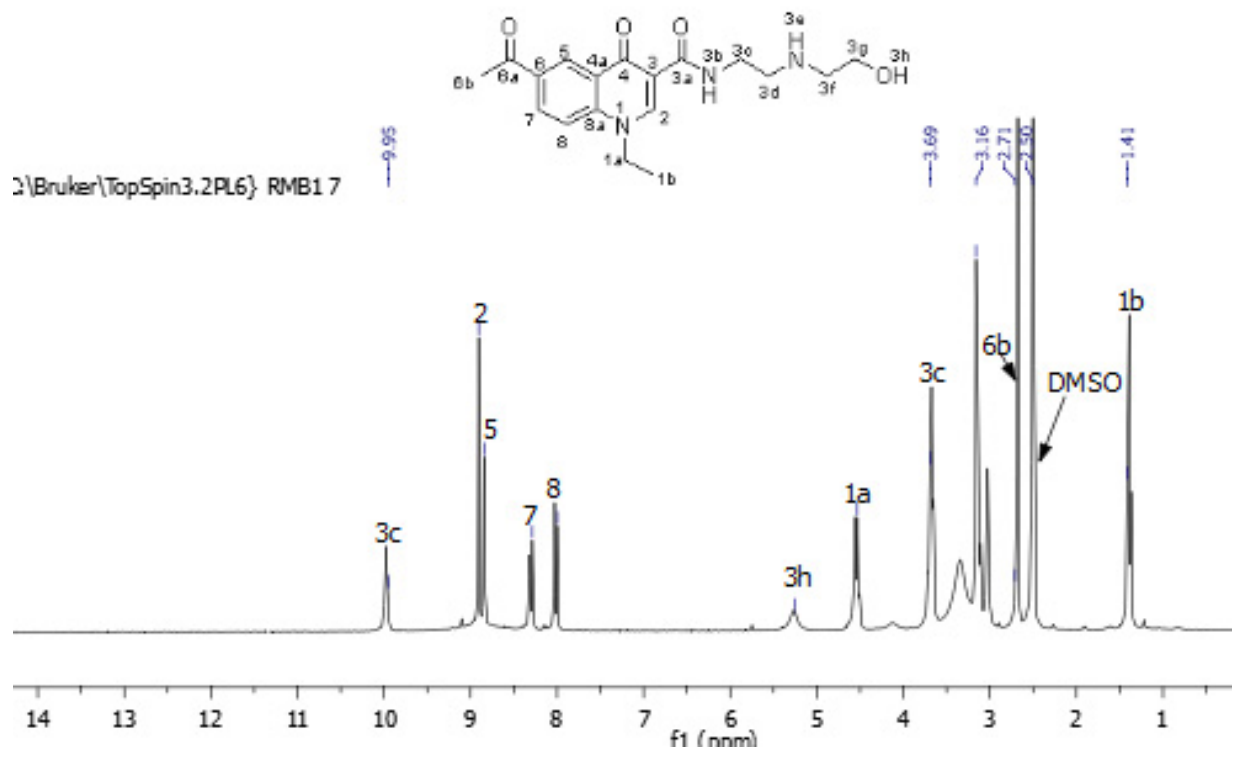




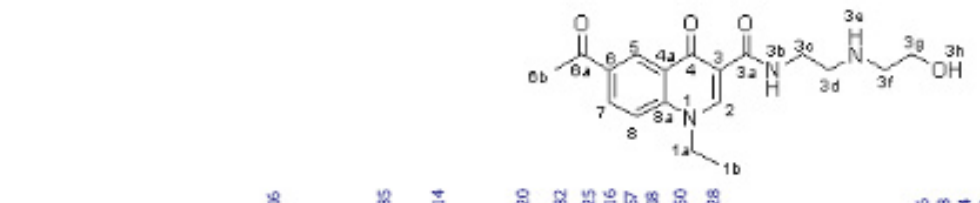

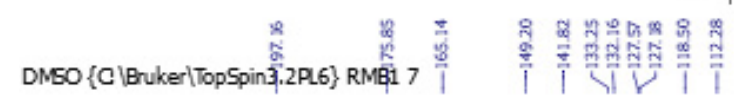

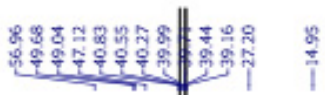

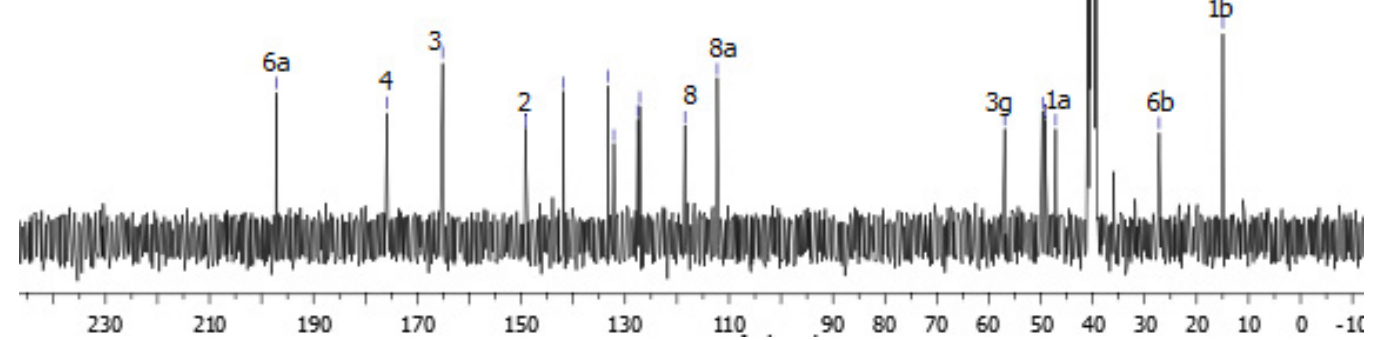

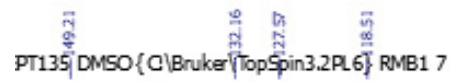

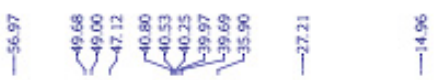

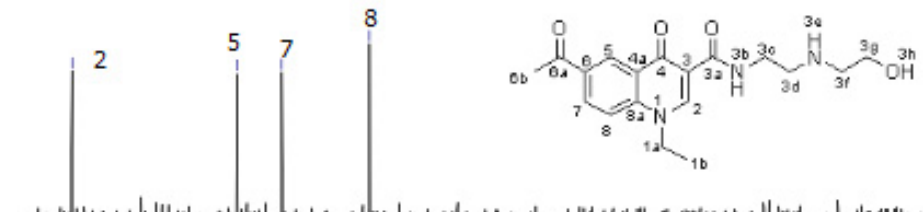

供
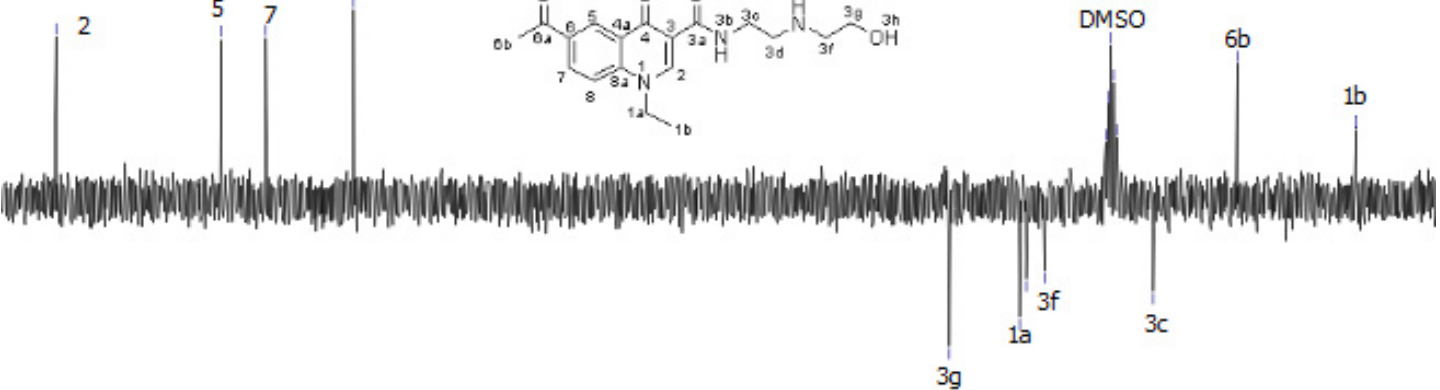

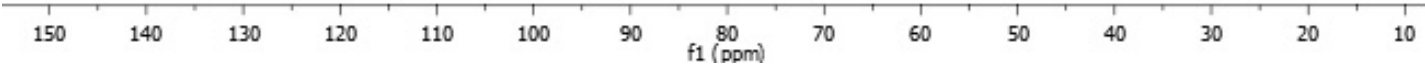

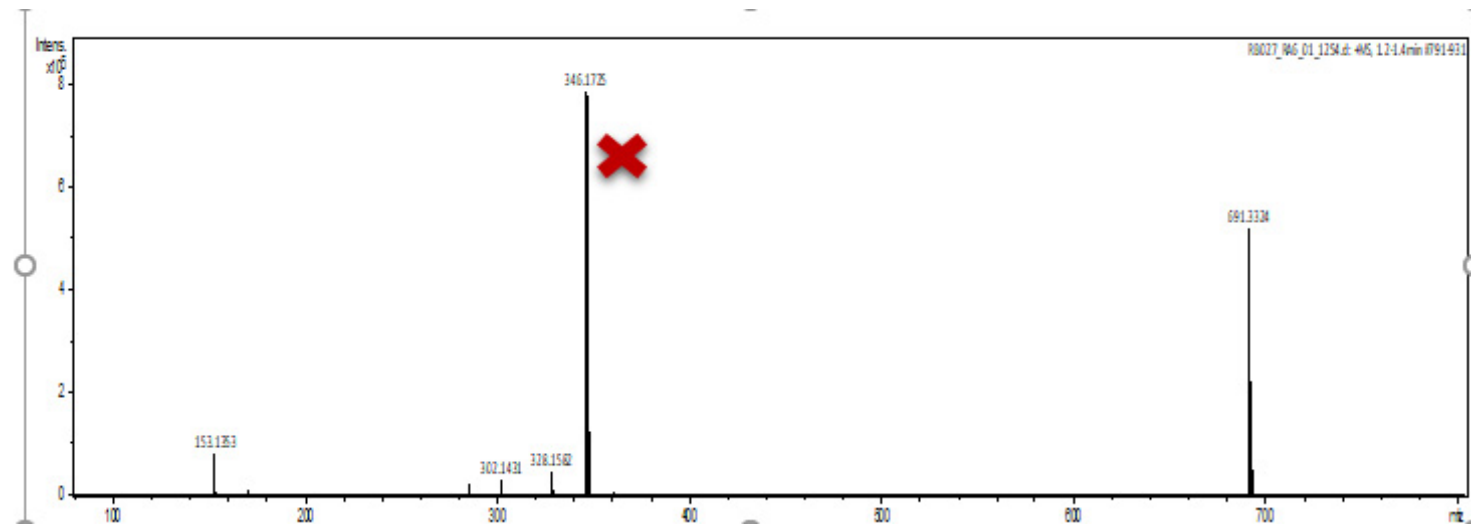



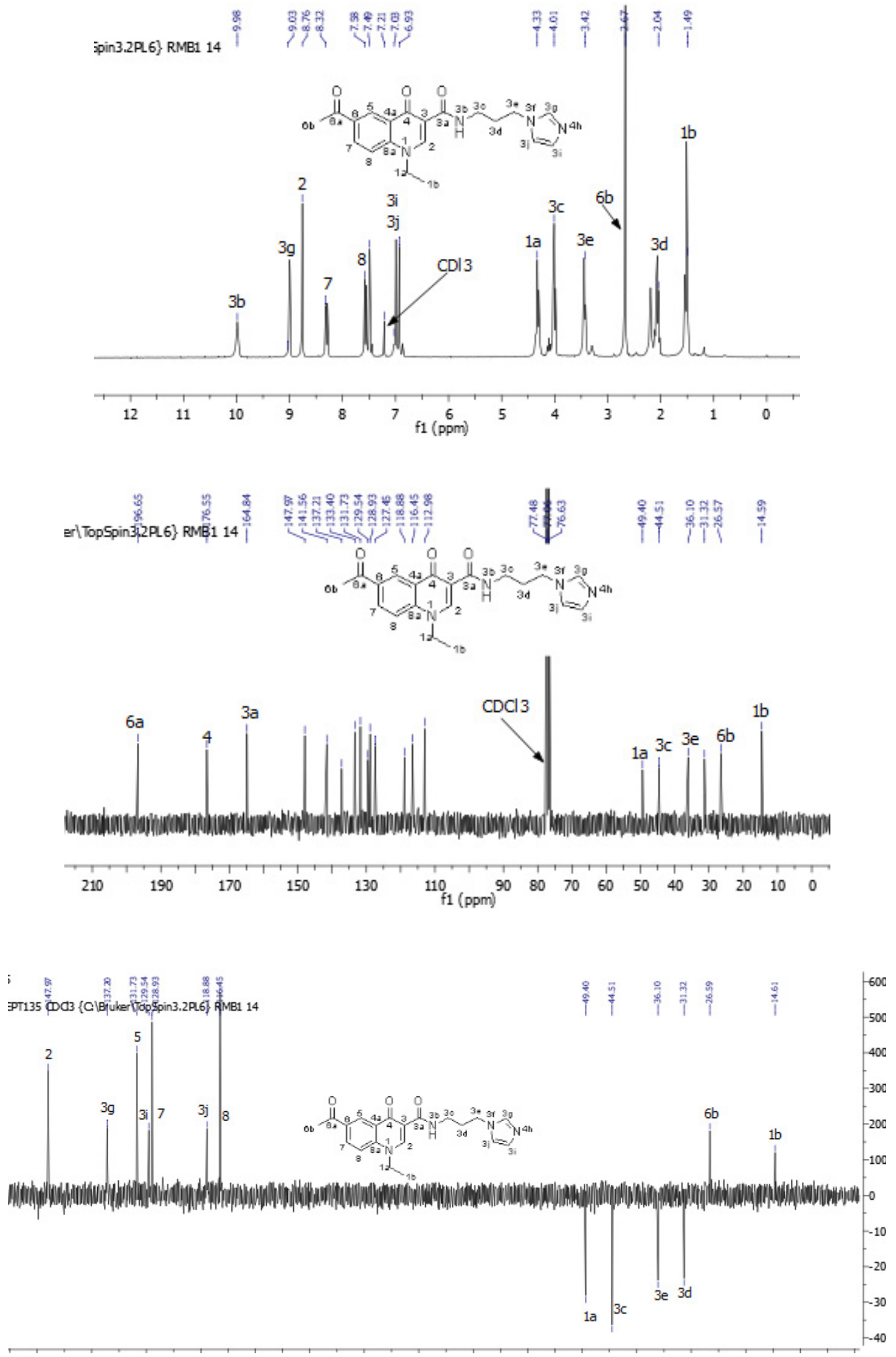


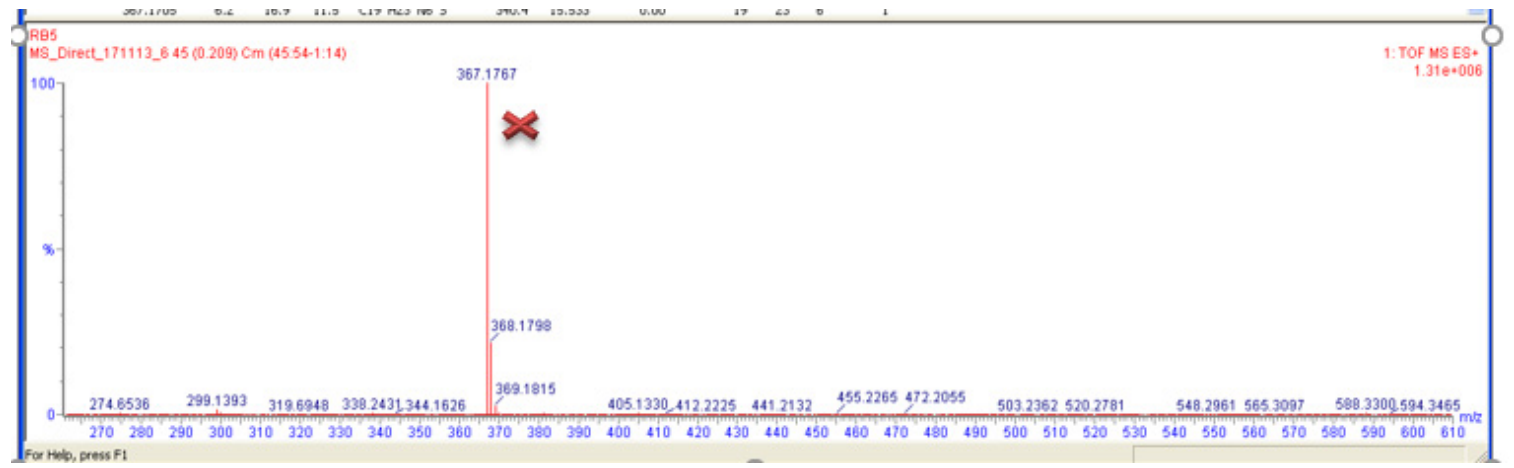

\section{Compound $4 e$}

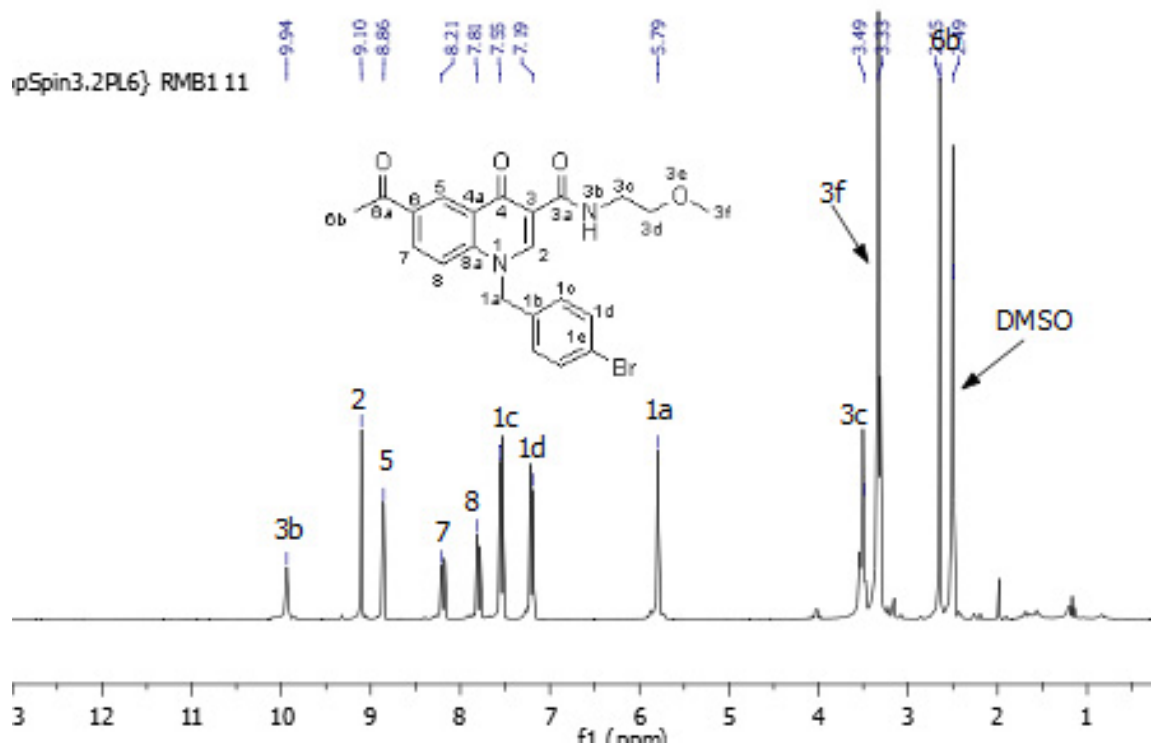

$$
\text { 每 }
$$

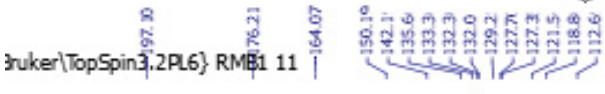

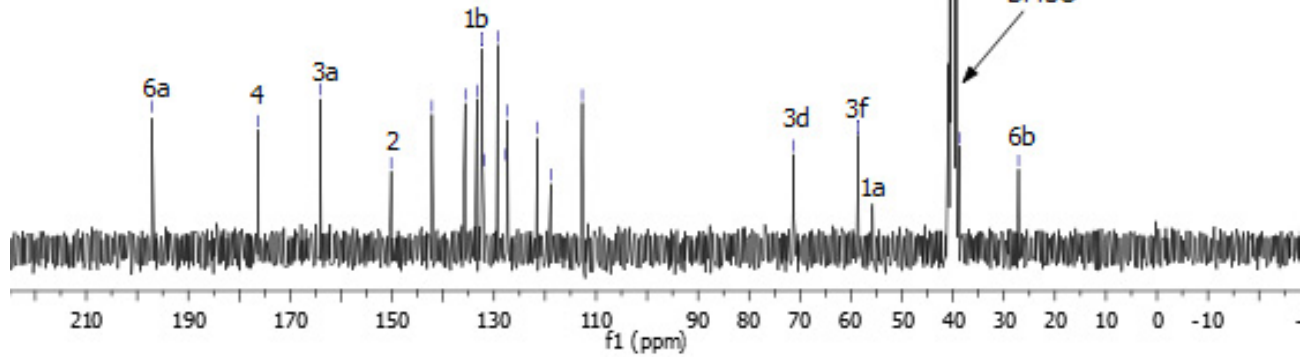



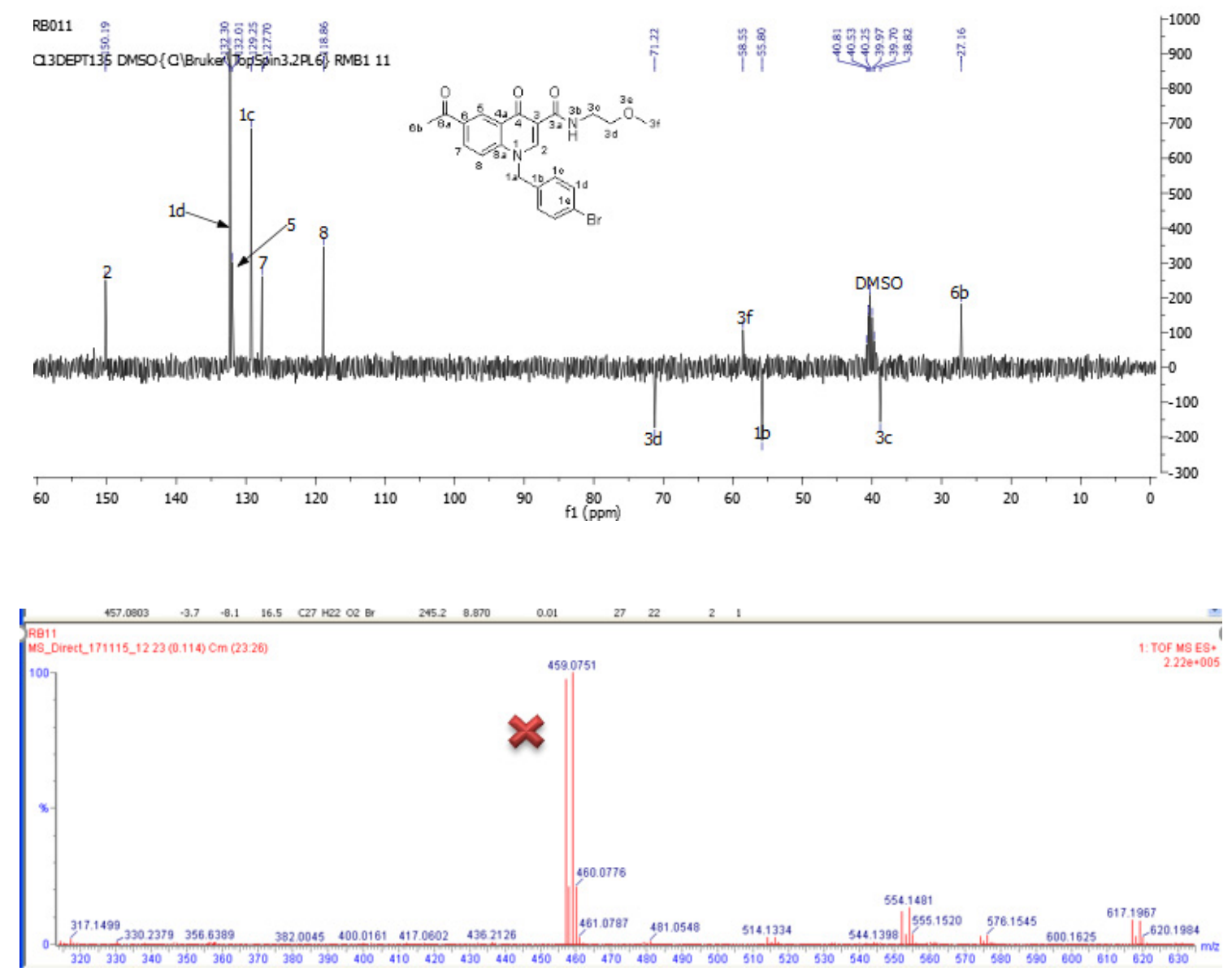

\section{Compound $4 f$}

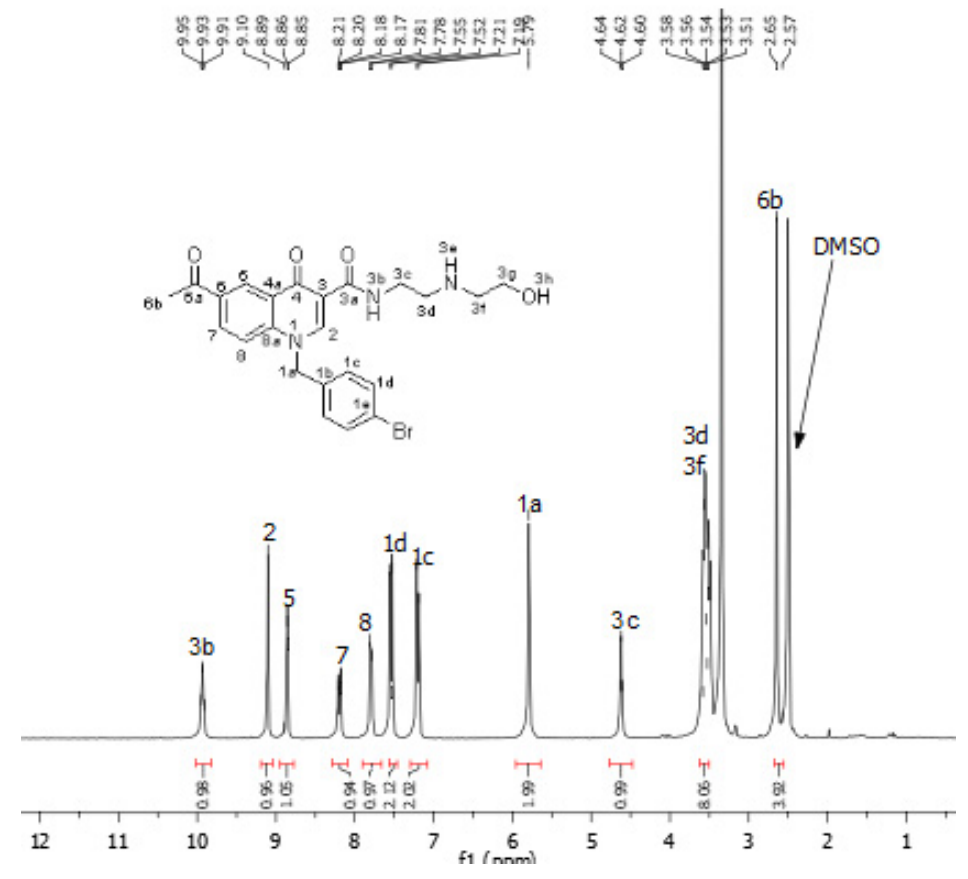



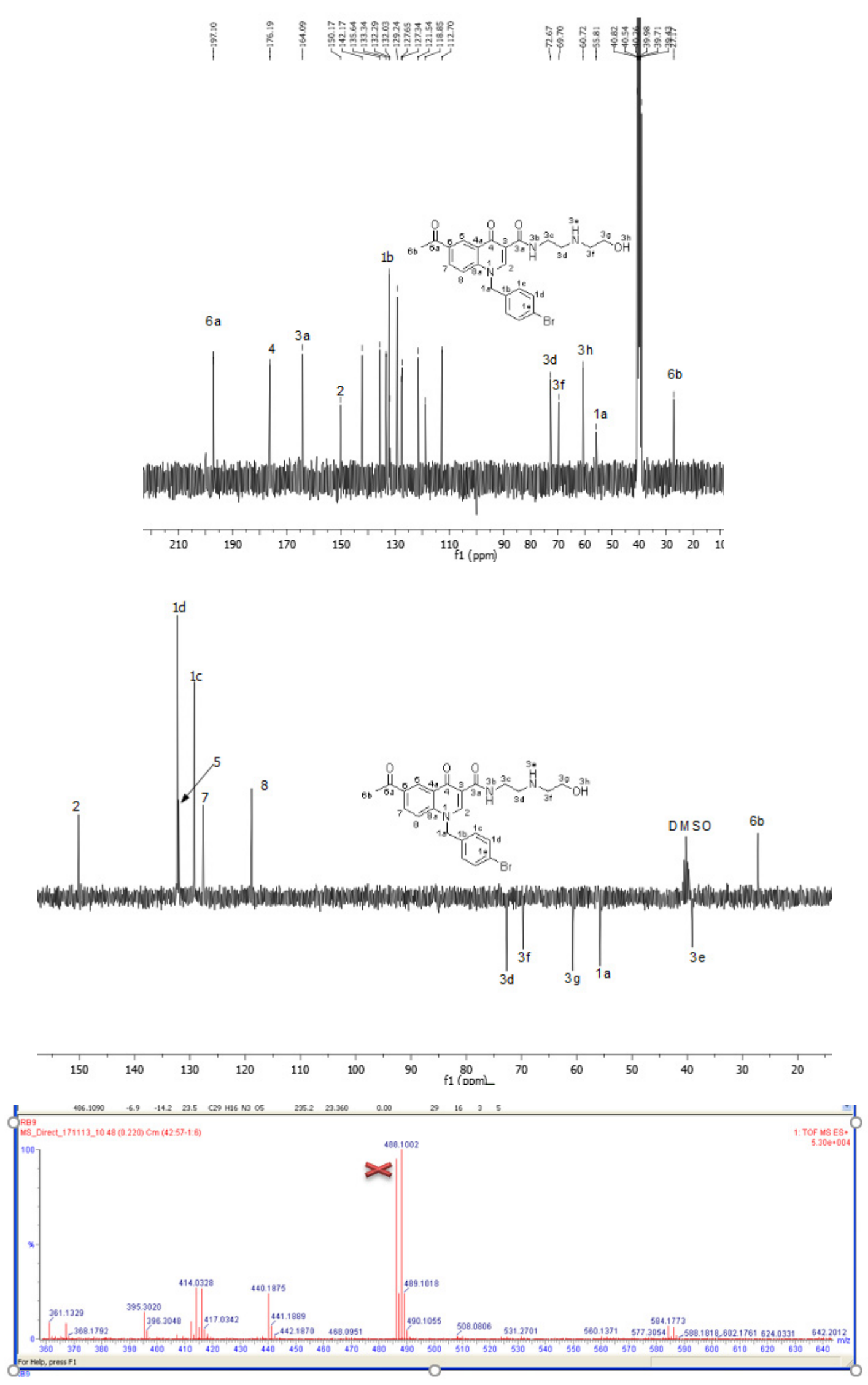


\section{Compound 4g, HIT Compound}
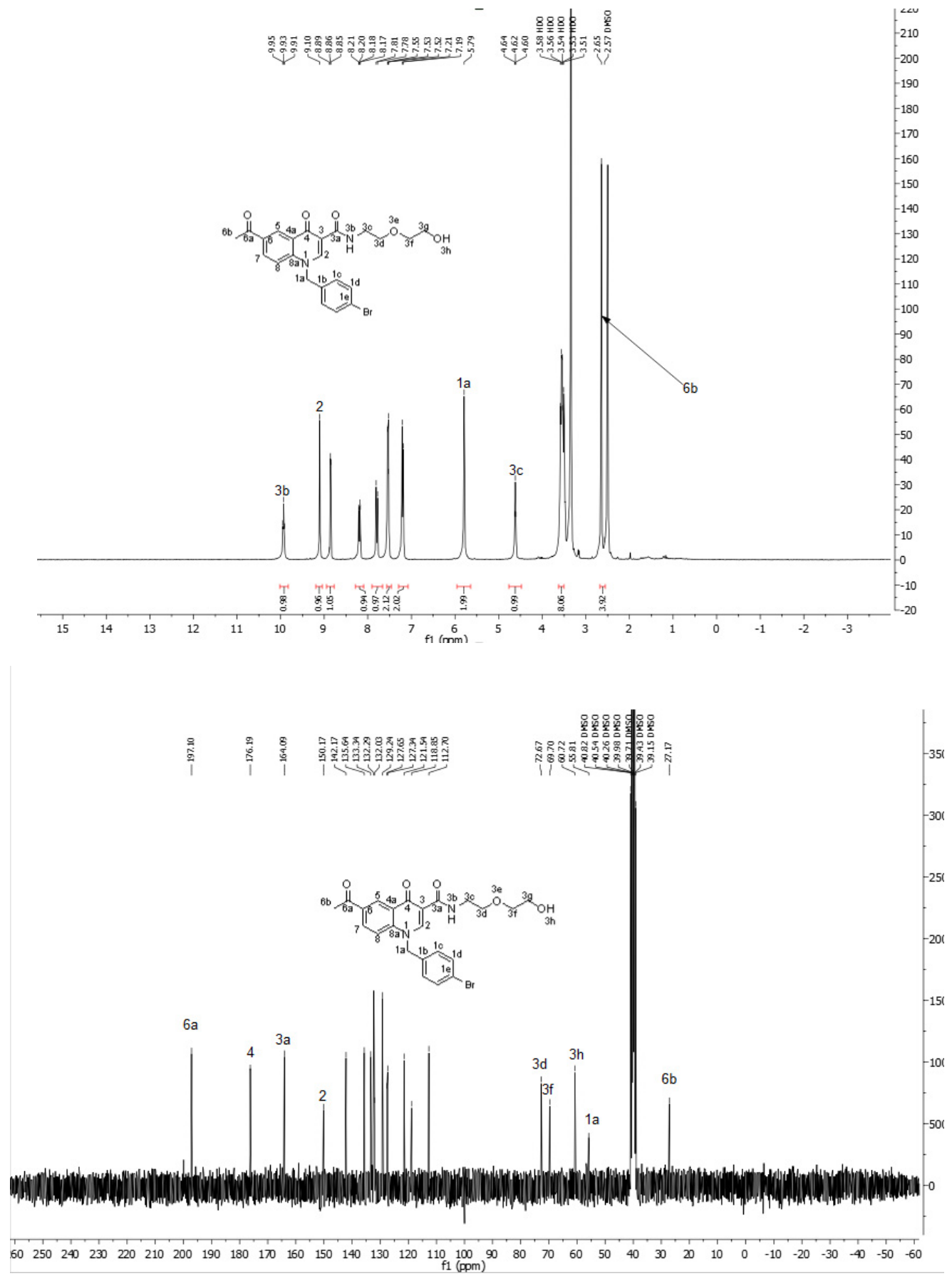

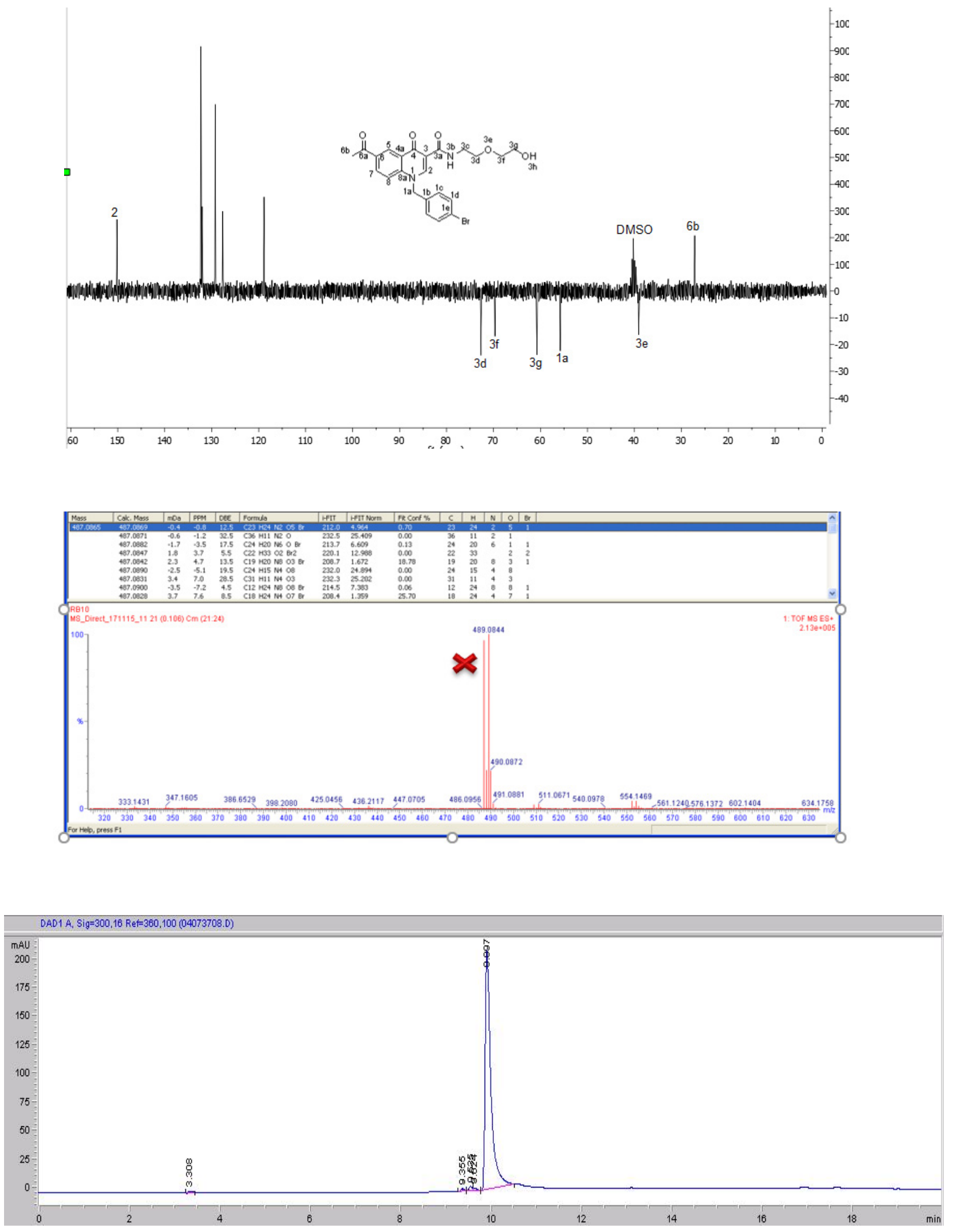


\section{Compound $4 \mathrm{~h}$}

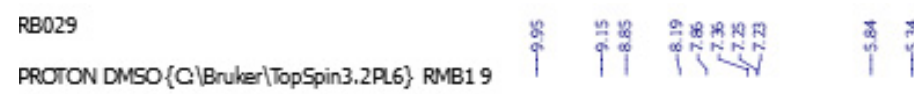
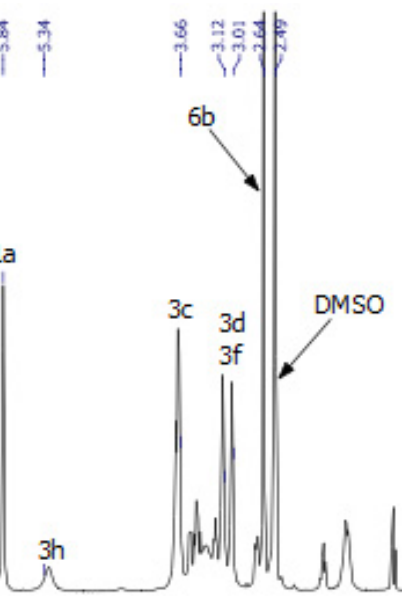

$\begin{array}{lllll}16 & 15 & 14 & 13 & 12\end{array}$

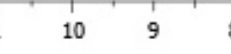

RB029

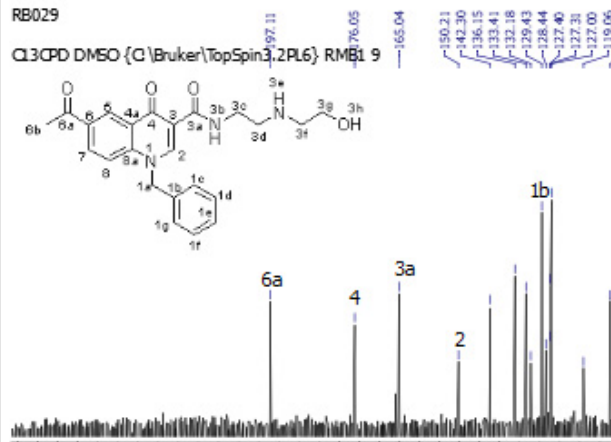

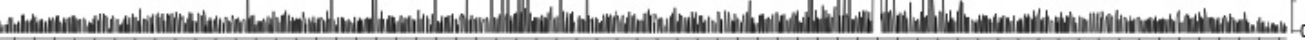

$\begin{array}{lllllllllllllllllllllll}250 & 230 & 210 & 190 & 170 & 150 & 130 & 110 & 90 & 90 & 70 & 60 & 50 & 40 & 30 & 20 & 10 & 0 & -10 & -30 & -50\end{array}$

RB029 تี

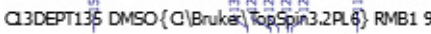
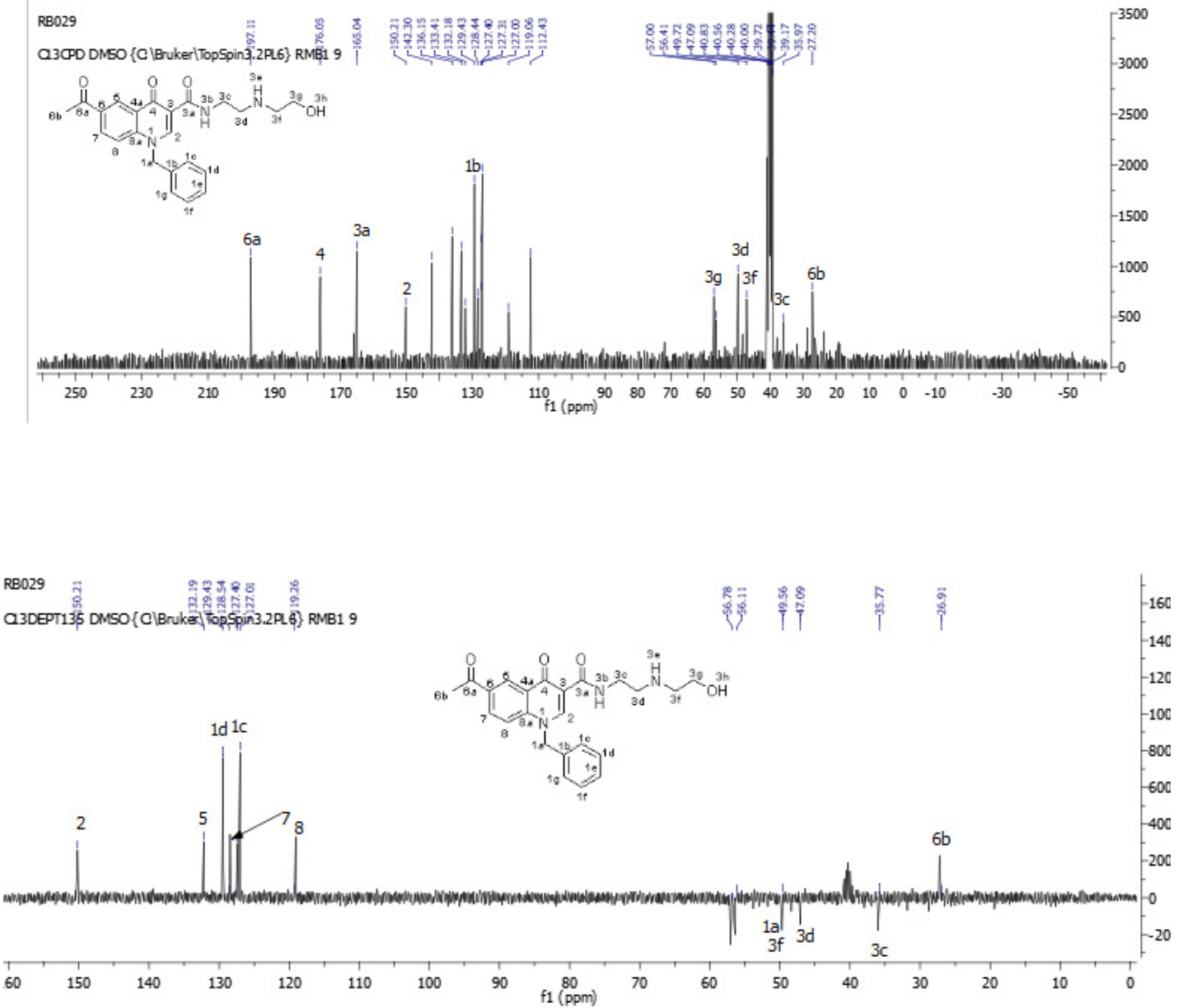

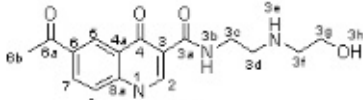

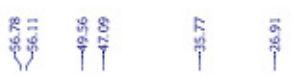

160 


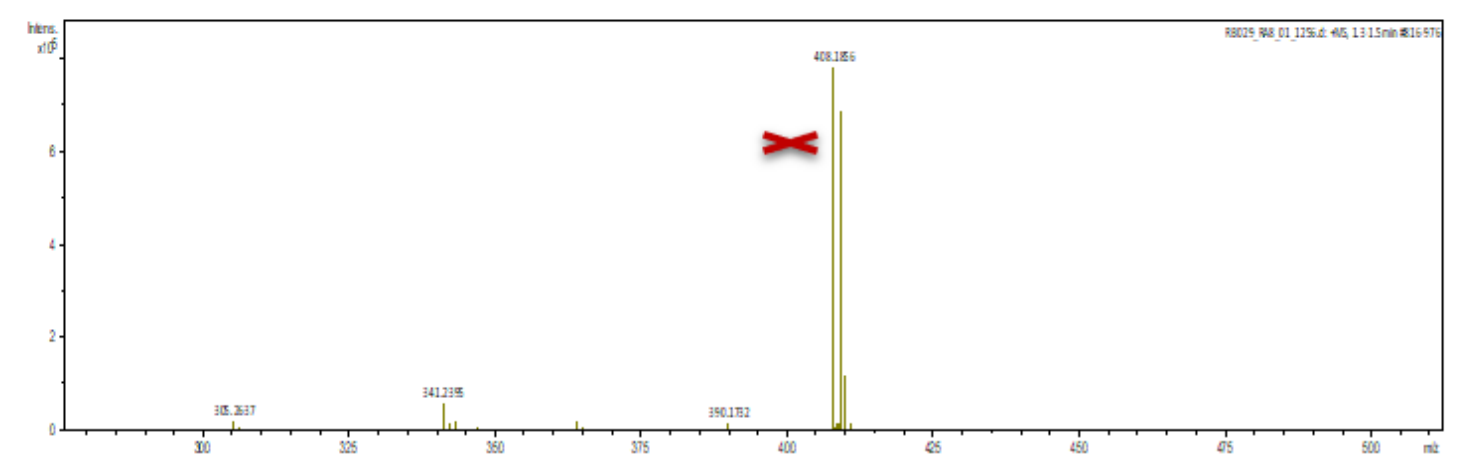

\section{Compound 4i}

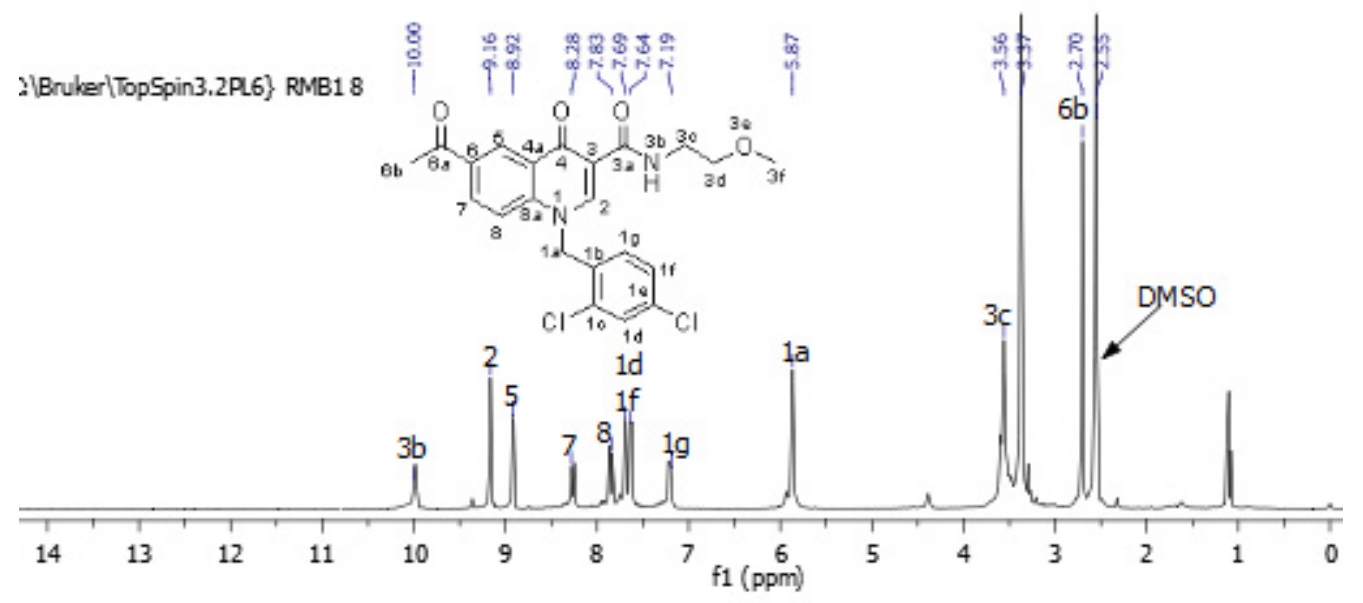

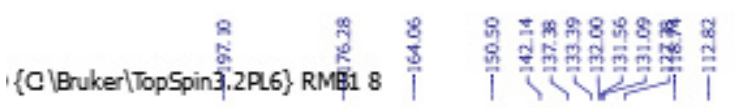

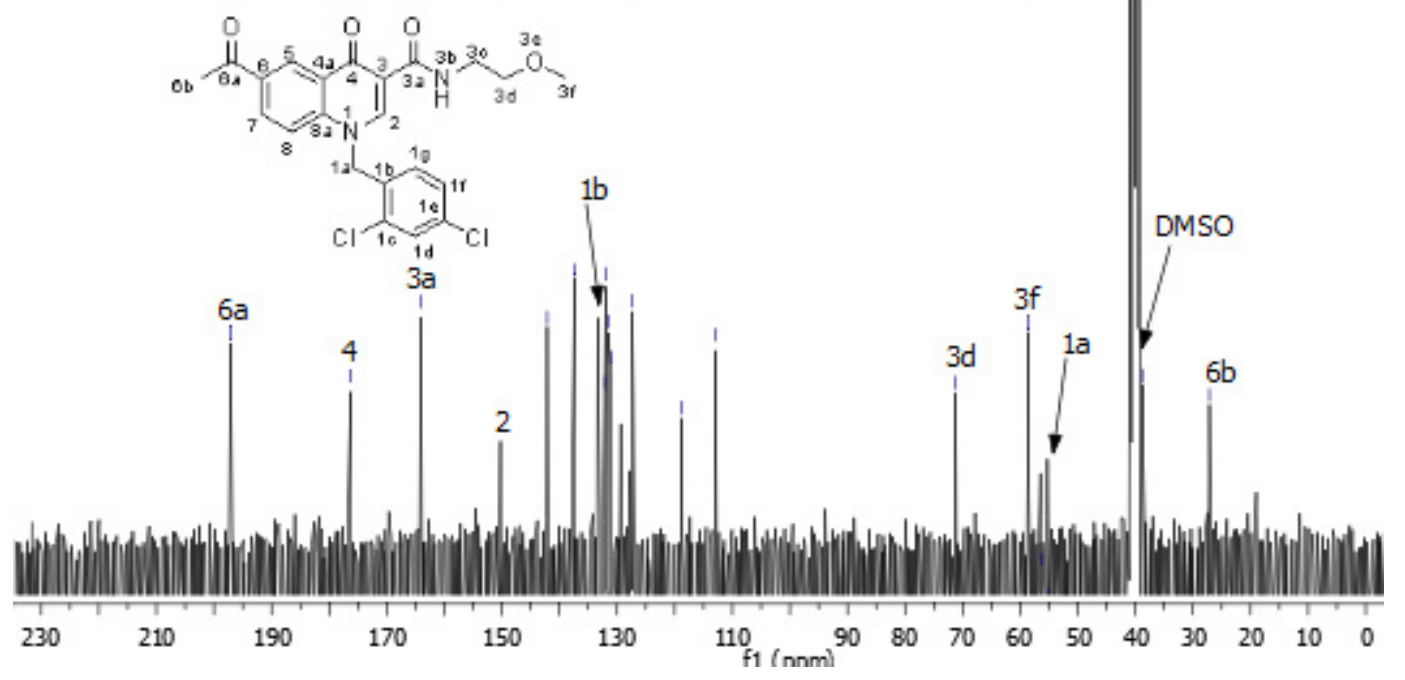




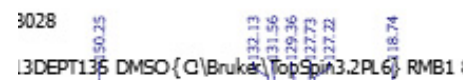
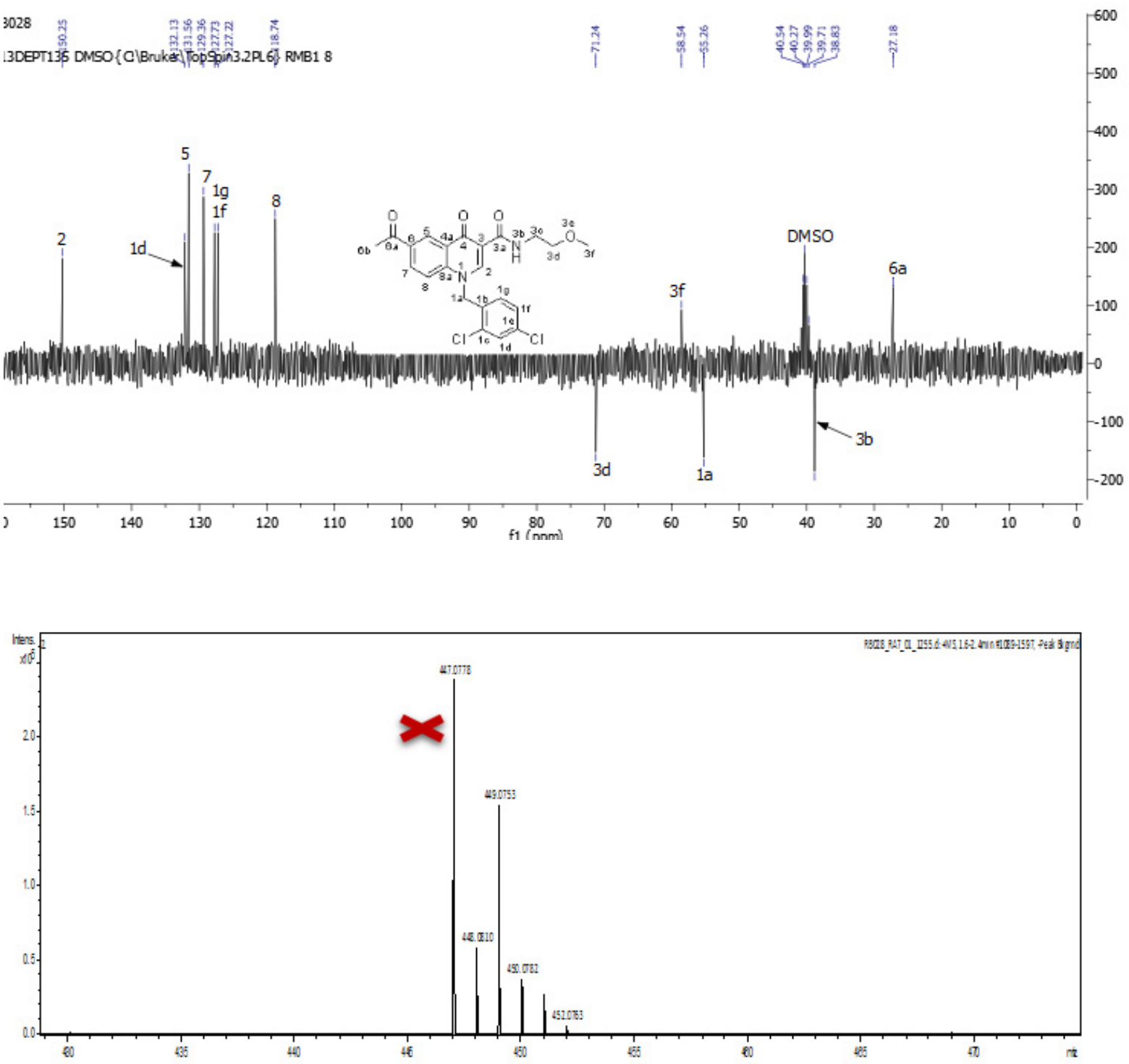


\section{Compound 4J}

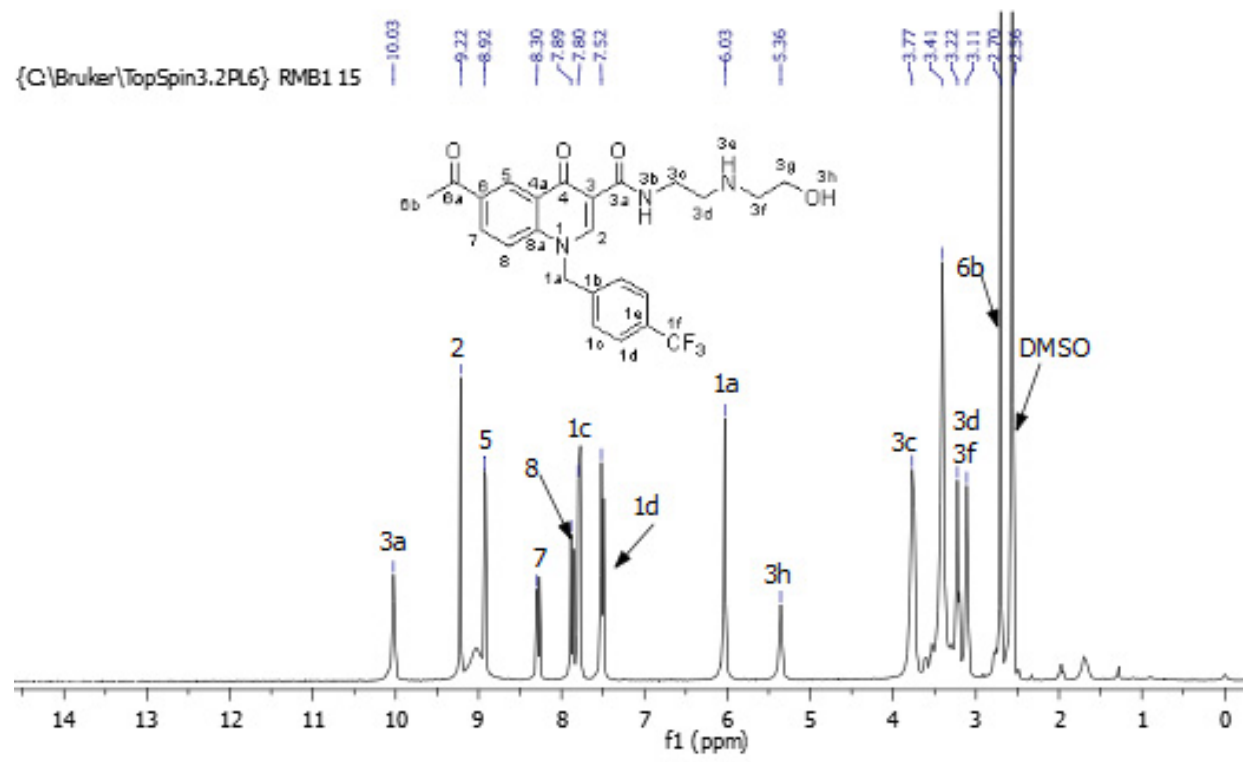

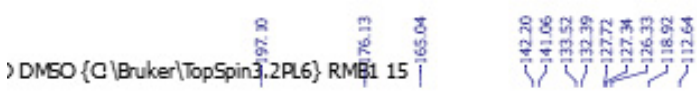
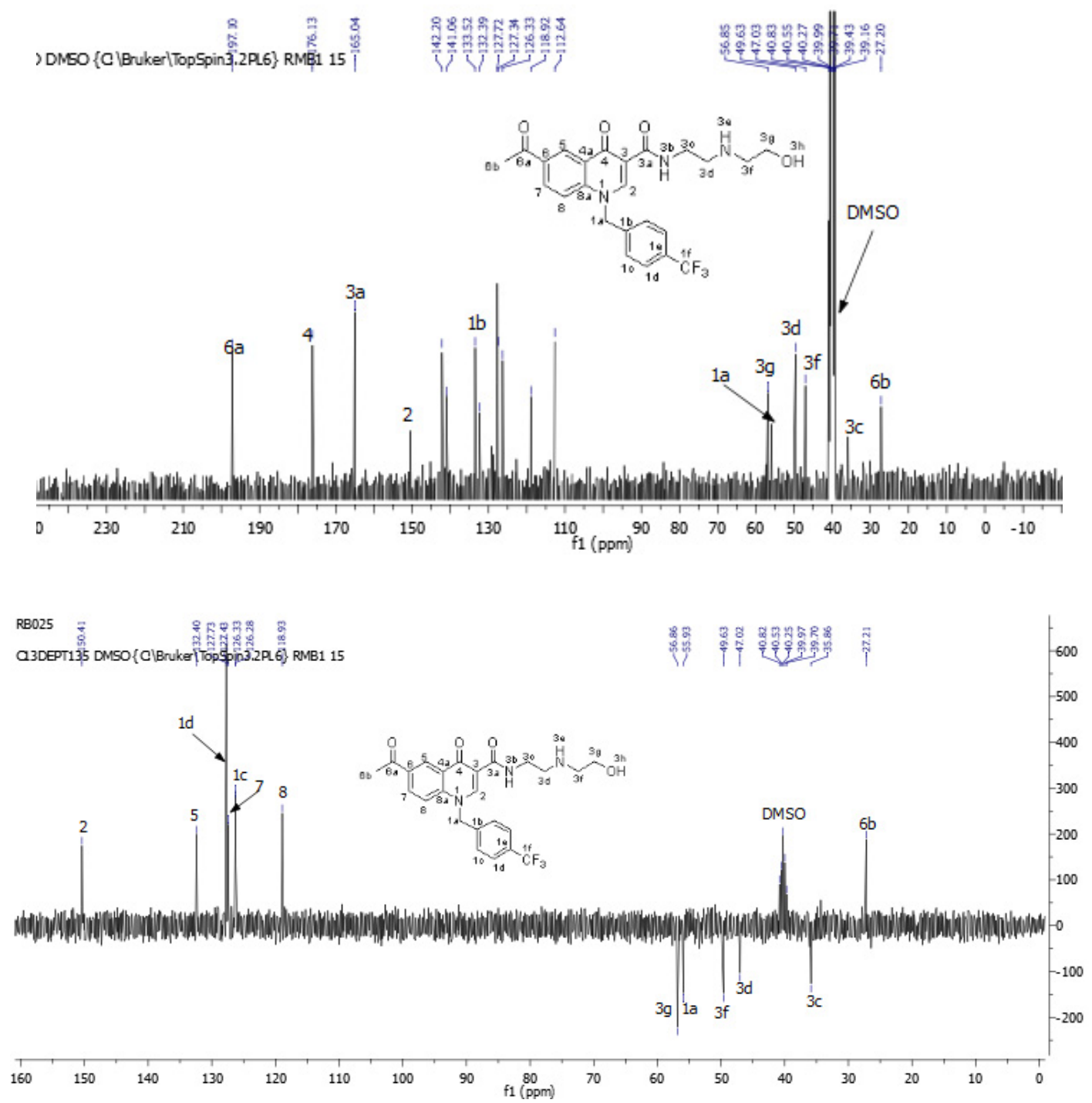


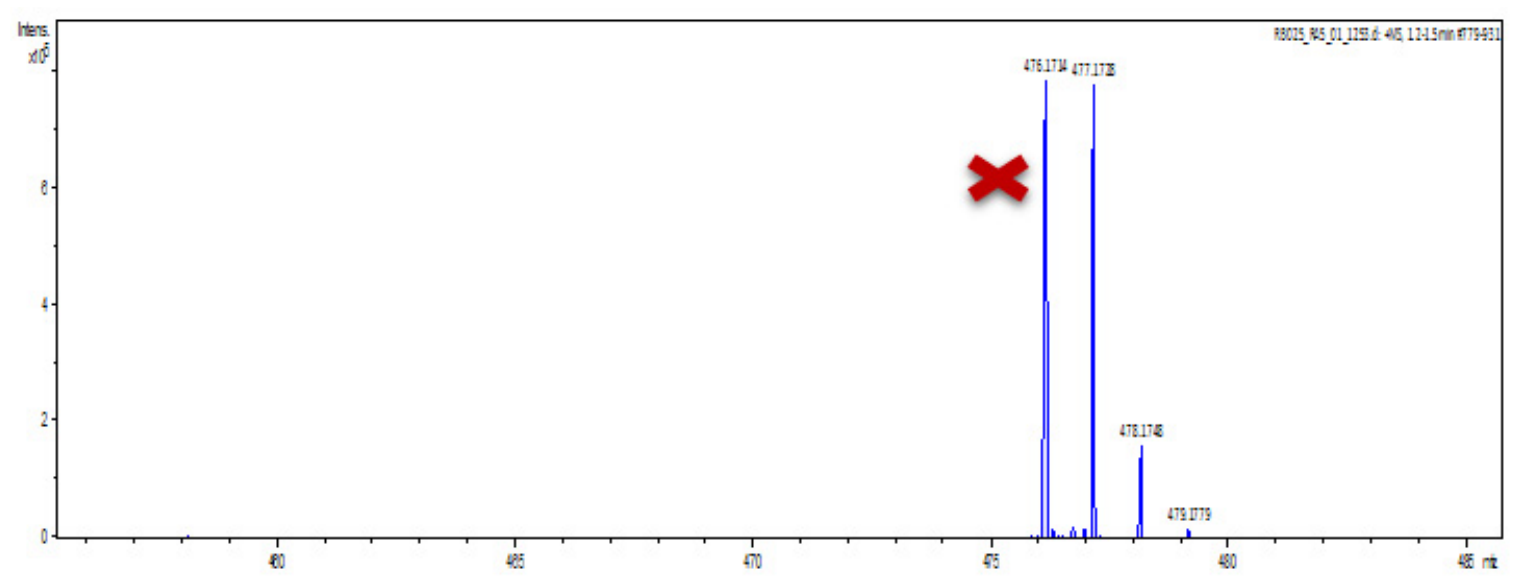

BIOLOGICAL DATA

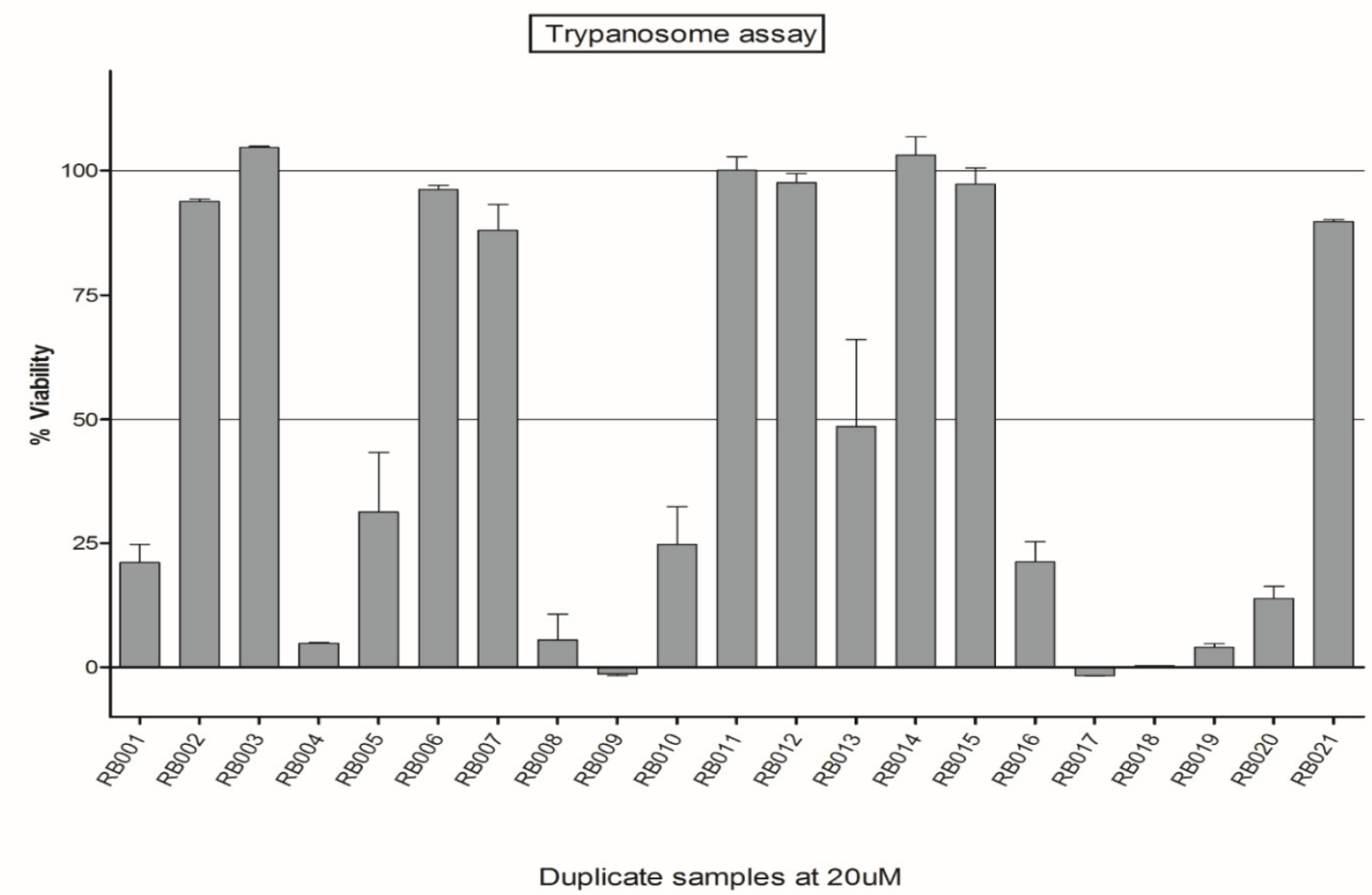

Figure S11a: Compounds inhibitory potential against T.b. brucei parasites at $20 \mu \mathrm{M}$.

Compounds were added to in vitro cultures of T.b. brucei in 96-well plates at a fixed concentration of $20 \mu \mathrm{M}$. After an incubation period of 48 hours, the numbers of parasites surviving drug exposure were determined by adding resazurin. Reduction of resazurin to resorufin by living cells was quantified in a multiwell fluorescence plate reader $\left(\mathrm{Exc}_{560} / \mathrm{Em}_{590}\right)$. The results are expressed as parasite \% viability relative to untreated controls. 
Compounds were tested in duplicate wells, and a standard deviation (SD) calculated. Only compounds exhibiting less than $20 \%$ parasite viability were considered for $\mathrm{IC}_{50}$ determination.

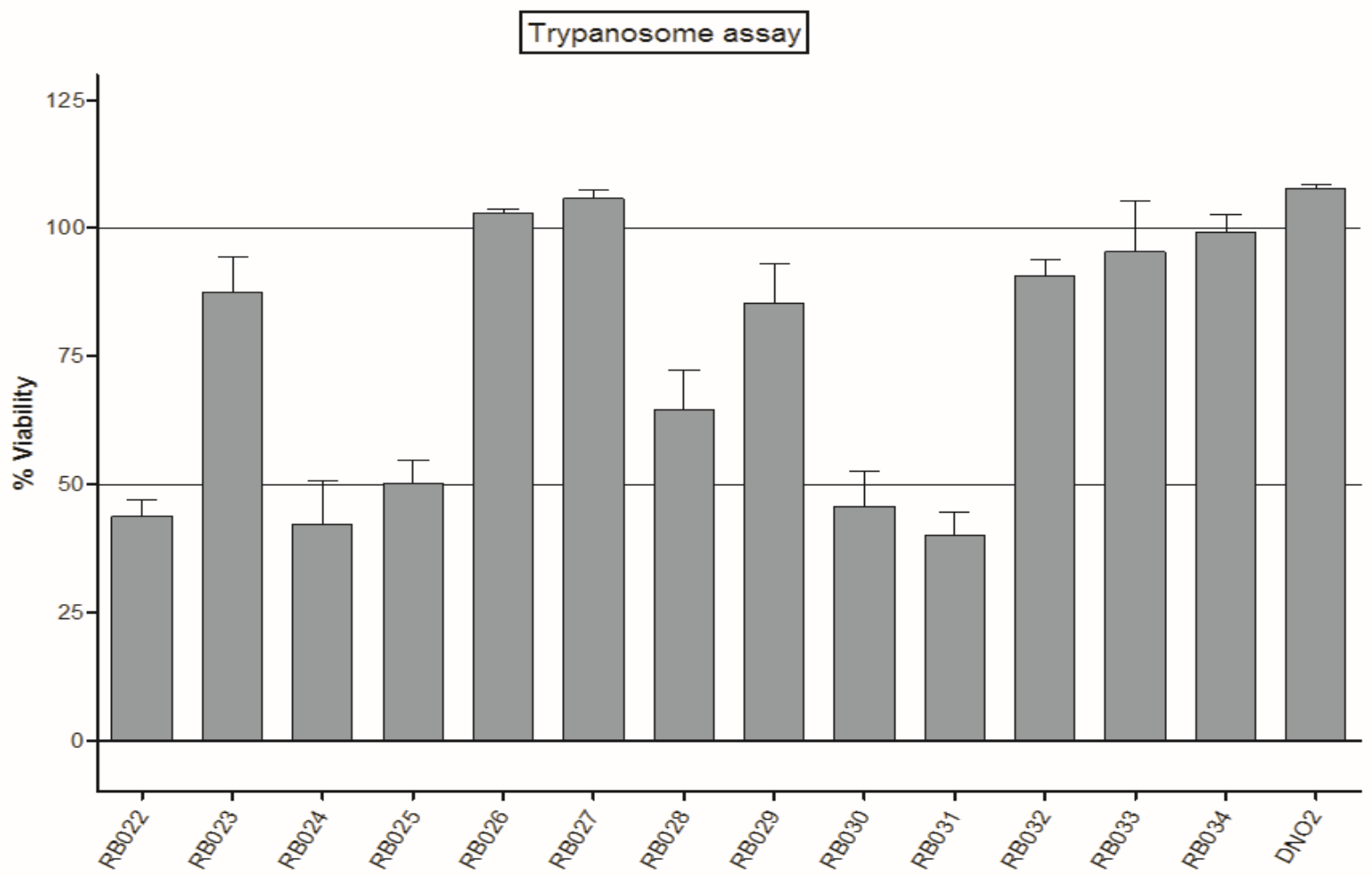

Duplicate samples at $20 \mathrm{uM}$

Figure S11b: Compounds inhibitory potential against T.b. brucei parasites at $20 \mu \mathrm{M}$.

Compounds were added to in vitro cultures of T.b. brucei in 96-well plates at a fixed concentration of $20 \mu \mathrm{M}$. After an incubation period of 48 hours, the numbers of parasites surviving drug exposure were determined by adding resazurin. Reduction of resazurin to resorufin by living cells was quantified in a multiwell fluorescence plate reader $\left(\mathrm{Exc}_{560} / \mathrm{Em}_{590}\right)$. The results are expressed as parasite \% viability relative to untreated controls. Compounds were tested in duplicate wells, and a standard deviation (SD) calculated. Only compounds exhibiting less than $20 \%$ parasite viability were considered for $\mathrm{IC}_{50}$ determination. 


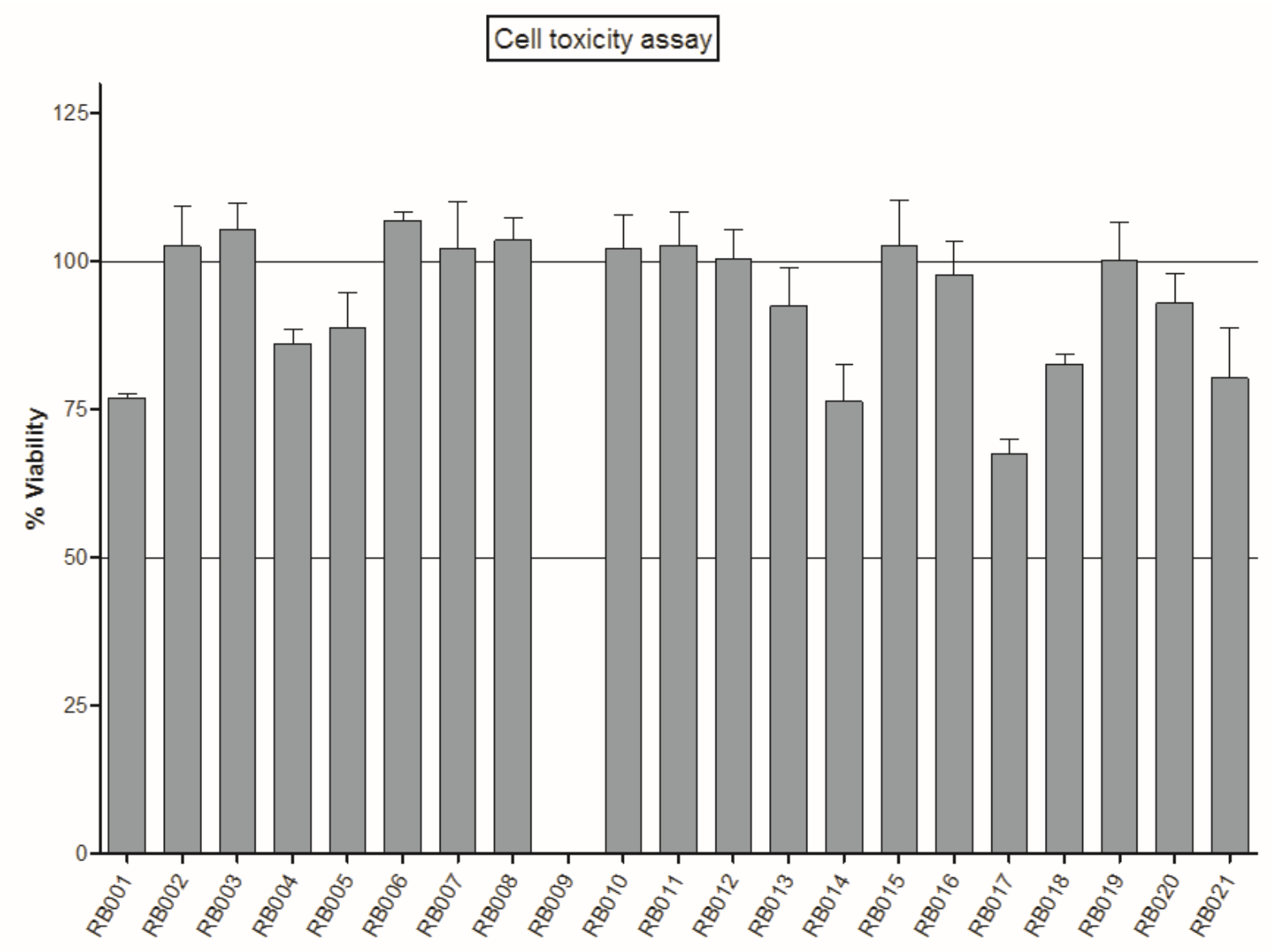

Duplic ate samples at $20 \mathrm{uM}$

Figure SI2a: Compound cytotoxicity against HeLa cells at $20 \mu \mathrm{M}$.

Compounds were added to in vitro cultures of HeLa (human cervix adenocarcinoma) cells in 96-well plates at a fixed concentration of $20 \mu \mathrm{M}$. After an incubation period of 48 hours, the numbers of cells surviving drug exposure are determined by adding resazurin, which was reduced to resorufin by living cells. Resorufin was quantified in a multiwell fluorescence plate reader $\left(\operatorname{Exc}_{560} / \mathrm{Em}_{590}\right)$. The results are express as cell \% viability. Compounds were tested in duplicate wells, and a standard deviation (SD) calculated. With the exception of compound RB009, this series shows no extensive cytotoxicity against HeLa cells. 


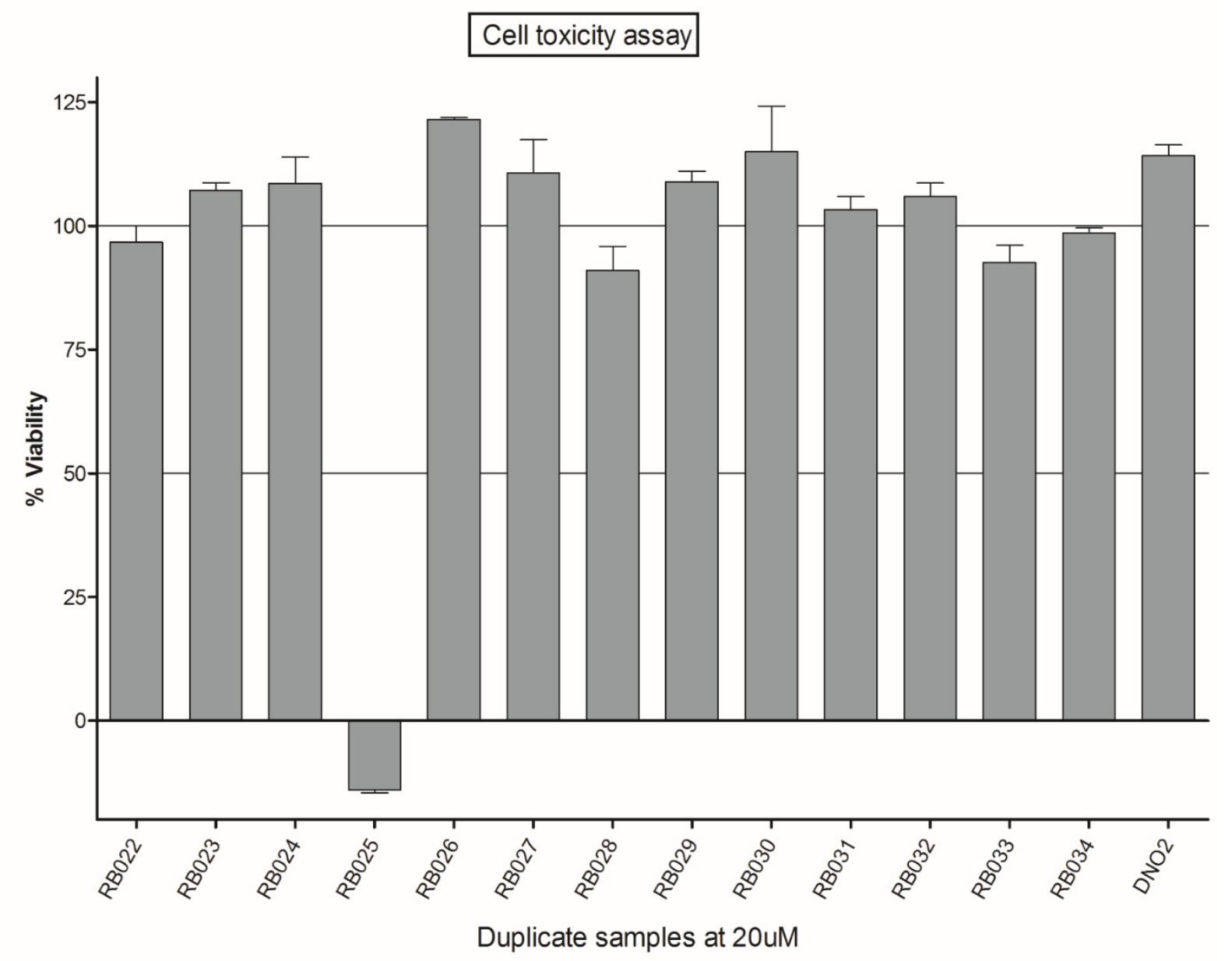

Figure SI2b: Compound cytotoxicity against HeLa cells at $20 \mu \mathrm{M}$.

Compounds were added to in vitro cultures of HeLa (human cervix adenocarcinoma) cells in 96-well plates at a fixed concentration of $20 \mu \mathrm{M}$. After an incubation period of 48 hours, the numbers of cells surviving drug exposure are determined by adding resazurin which was reduced to resorufin by living cells. Resorufin is was quantified in a multiwell fluorescence plate reader $\left(\operatorname{Exc}_{560} / \mathrm{Em}_{590}\right)$. The results are express as cell \% viability. Compounds were tested in duplicate wells, and a standard deviation (SD) calculated. With the exception of compound RB025, this series shows no cytotoxicity against HeLa cells. 